Portland State University

PDXScholar

Summer 9-30-2015

\title{
Effects of Aerial Exposure on Preservation of Low- Temperature Calothrix Biosignatures in Silica Sinter from Queen's Laundry, Yellowstone National Park, USA
}

Shana Kendall

Portland State University

Follow this and additional works at: https://pdxscholar.library.pdx.edu/open_access_etds

Part of the Geology Commons

Let us know how access to this document benefits you.

\section{Recommended Citation}

Kendall, Shana, "Effects of Aerial Exposure on Preservation of Low-Temperature Calothrix Biosignatures in Silica Sinter from Queen's Laundry, Yellowstone National Park, USA" (2015). Dissertations and Theses. Paper 2537.

https://doi.org/10.15760/etd.2534

This Thesis is brought to you for free and open access. It has been accepted for inclusion in Dissertations and Theses by an authorized administrator of PDXScholar. Please contact us if we can make this document more accessible: pdxscholar@pdx.edu. 
Effects of Arial Exposure on Preservation of

Low-Temperature Calothrix Biosignatures in

Silica Sinter from Queen's Laundry, Yellowstone

National Park, USA

by

Shana Lynn Kendall

A thesis submitted in partial fulfillment of the requirements of the degree of

\author{
Master of Science \\ in \\ Geology
}

Thesis Committee:

Scott F. Burns, Chair

Sherry Cady

Richard Hugo

James Jackson

Portland State University

2015 
@ 2015 Shana Lynn Kendall 


\begin{abstract}
Mineral-depositing hydrothermal ecosystems, such as the hot springs in Yellowstone National Park, provide an unparalleled opportunity to document how microbial biosignatures form and contribute to the body of evidence indicative of the microbial inhabitants of active hot springs. Mineralization of microbial communities in silicadepositing hot springs can result in the preservation of microbial biofacies in the geologic record. To determine the effects of prolonged aerial exposure on the preservation potential of mid-to-low temperature cyanobacteria dominated microbial communities that are typically permineralized in the siliceous sinter, modern biofacies samples of such communities were collected from the active and inactive parts of Queen's Laundry hot spring in Yellowstone National Park. The strategy of the research was to: (1) perform qualitative and quantitative characterization of structural and morphometric attributes of subaqueous and aerially exposed Calothrix biofacies samples collected from terraces; and (2) determine whether prolonged subaerial exposure affected the fidelity of morphological biosignatures (i.e., biofabrics and microbial cells) in the aerially exposed samples.

To ensure that the permanently subaqueous and aerially exposed samples were comparable, a protocol developed to describe structural and morphological attributes of stromatolites was utilized to characterize the hot spring samples. Morphometric analysis of both types of Calothrix biofacies samples (i.e., partly silicified subaqueous and aerially exposed samples) revealed the presence of: distinct microbially influenced structures; thicker lamina at or near the base of the terraces; the greatest density of microorganisms in microbial structures; and increased microbial structure flatness as height of the
\end{abstract}


microbial structures within the terrace proper increased. These characteristics were also used to provide a means to interpret the environmental conditions within which the terrace structures developed.

To determine whether prolonged subaerial exposure affected the morphological fidelity of the biosignatures in the aerially exposed samples, the microstructure of these samples was studied in detail petrographically. A silica layer defined the boundary between laminae and was referred to as the "capping" silica deposit because it was found to "cap" all of the laminae in the Calothrix biofacies samples. The top most capping silica deposit of the aerially exposed Calothrix biofacies samples was found to be distinctly different from the capping silica deposits in the interior of the same sample and in the partly mineralized subaqueous Calothrix biofacies samples. The aerially exposed capping silica deposit was milky and glassy in appearance and contained fine laminations. The fine laminations were not found in any laminae of the biofacies samples.

Another key finding of the project is a new evaluation of the preservation potential of the Calothrix terrace samples. Petrographic observations revealed that preservation of the morphological fidelity of the laminae and the microstructures within them was significantly higher within the microbial shrub and domical structures in both the partially silicified subaqueous and aerially exposed Calothrix biofacies samples than other microstructure types observed.

In summary, a detailed morphometric characterization protocol confirmed that it is possible to identify similar features in Calothrix biofacies found inside the active part of the hot spring as well as beyond the perimeter (i.e., aerially exposed for $\geq 3$ years) at multiple spatial scales; only the top-most capping silica deposit of the aerially exposed 
samples is altered by subaerial exposure; the preservation potential for Calothrix biofabrics is highest within shrub and domical structures; and morphometric analysis on a variety of Calothrix terraced structures could lend insight into the factor(s) responsible for terrace formation. This research lays the foundation for analyzing similar structures in geologically older rocks and for recognizing how microbial organisms can and likely have influenced terrace formation. The work also suggests that aerial processes can alter such samples and biosignatures within them. It is recommended that additional nondestructive and spatially correlated analytical methods be considered in the search for chemofossils in the sinter surrounding filaments past and present. 


\section{Acknowledgements}

As this chapter of my life comes to an end it is not without the help and assistance of many. My supportive parents who have hung in there with me, enjoyed the good times, and were there to offer words of encouragement when they were needed. Neither of you ever wavered in your knowledge of a successful outcome from this journey. Thank you, you are the best. Also, my two brothers and their lovely families who never tired of hearing my familiar response of "I am busy writing" when they would inquire about what I was doing or how school was going. My two nephews and niece, though very young during this time, provided much needed times of fun to let the hair down.

My advisor, Professor Emeritus Sherry Cady, who introduced me to the wonderful world of geobiology and my life has not been the same since. It all started with a summer field class to Yellowstone National Park. Since then she has assisted me in becoming a better scientist. My world has been opened to many opportunities and experiences that I would not have had otherwise, I thank you.

To my other committee co-chair Professor Scott Burns. You are a truly amazing individual. I thank you for all your words of advice and the investment of your time toward helping me to succeed.

Jim Jackson and Rick Hugo both willingly accepted my invitation to serve on my thesis committee. They both gave me great advice and I cannot thank you enough for your participation.

I need to thank to David Percy and Deborah Theisen for their assistance to create georeferenced maps. Dr. Andrea Goforth and Sheng-Kuei Chiu assistance in obtaining XRD data. However, there are so many friends and fellow geology students that were encouraging and provided countless hours of fun entertainment along the way.

Last, but not least, I thank NASA for providing funding for this research. 
TABLE OF CONTENTS

Page

Abstract

Acknowledgements

List of Tables $\quad v$

List of Figures vi

CHAPTER 1 INTRODUCTION

CHAPTER 2 BACKGROUND

2.1 Yellowstone National Park 4

2.2 Field Setting 6

2.3 Hot Spring Biofacies 8

$\begin{array}{ll}2.4 \text { Calothrix and Terraces } & 10\end{array}$

CHAPTER 3 METHODS and MORPHOMETRIC ANALYSIS

3.1 Field Collection

3.1.1 Perimeter Mapping $\quad 11$

3.1.2 Sample Collection $\quad 12$

3.1.3 Samples Used to Compare Partially

Silicified Subaqueous and Aerially Exposed

Calothrix Biofacies

3.2 Optical Light Microscopy

3.2.1 Sample Preparation for Thin Sections $\quad 15$

3.2.2 Stereomicroscopy of Petrographic

Thin Sections with Transmitted Light $\quad 16$

3.2.3 Petrographic Microscopy 21

3.3 Analytical Methods

3.3.1 Scanning Electron Microscope Sample Preparation 23

3.3.2 Sputter Coater 24

3.3.3 Scanning Electron Microscope Operating
Conditions

3.4 X-ray Diffraction Spectroscopy

3.4.1 Sample Preparation $\quad 24$

3.4.2 X-ray Diffraction Operating Conditions 25

CHAPTER 4 RESULTS

4.1 Field Setting of Queen's Laundry Hot Spring 27

4.2 Mineralogy 28

4.3 Field Context of the Partially Silicified Subaqueous and

Aerially Exposed Calothrix Biofacies Samples

4.3.1 Partially Silicified Calothrix Biofacies 
4.3.2 Aerially Exposed Calothrix Biofacies

4.4 Partially Silicified Subaqueous Calothrix Biofacies (sample 110921.6)

4.4.1 Sample Collection $\quad 32$

4.4.2 Optical Light Microscopy - Stereoscope $\quad 35$

4.4.2. Laminae Observations $\quad 35$

4.4.2.b Sub-laminae and Topography 39

4.4.2.c Attributes of Microbial Structure in 41

Calothrix Biofacies Laminae

4.4.3 Optical Light Microscopy - Petrographic

4.4.3.a Calothrix Filaments

43

4.4.3.b Microstructure $\quad 45$

4.4.3c Laminae Development

4.4.3.c.i Microbial colonization on Silica

Precipitates

47

4.4.3.c.ii Microbial Colonization on Detrital

Materials

4.4.3.c.iil Microbial Colonization on Biological Material

4.4.4 Scanning Electron Microscopy

4.5 Aerially Exposed Calothrix Biofacies (sample 110919.24B)

4.5.1 Sample Collection

4.5.2 Optical Light Microscopy - Stereoscope 53

4.5.2.a Laminae Observations 53

4.5.2.b Microbial Structure Attributes

Characterization

4.5.3 Optical Light Microscopy - Petrographic

4.5.3.a Microstructure

4.5.3.b Calothrix Filaments

4.5.3.c Laminae Development

4.5.3.ci Microbial colonization on Silica

Precipitates

4.5.3.c.ii Microbial Colonization on Detrital Material

4.5.3.d Aerially Exposed Capping Silica

Deposit

4.5.4 Scanning Electron Microscopy

4.6 Scanning Electron Microscopy Energy Dispersive Spectroscopy of Partially Silicified Subaqueous and Aerially Exposed Calothrix Biofacies Samples

\section{CHAPTER 5 DISCUSSION}

5.1 Partially Silicified Subaqueous and Aerially Exposed Calothrix Biofacies - Characterization sensu Hofmann (1969) 
5.2 Objective 1: Similarity of Partially Silicified Subaqueous and Aerially Exposed Calothrix Biofacies Samples

5.3 Objective 2: Effects of Aerial Exposure on the Fidelity of Biofabrics

5.4 Environment Created by Tenraces that Develop In Hot Spring Drainage Aprons

5.5 Preservation Potential of Calothrix Biofacies

CHAPTER 6 CONCLUSIONS

References

Appendix 1

Georeferenced and characterized transects of the broad drainage apron of Queen's Laundry hot spring

Appendix 2 Images of samples collected in the field and sample preparation and resultant thin sections

Appendix 3

Characterization spreadsheets of terraces

91

Appendix 4

$\mathrm{XRD}$ pattern from subaqueous and subaerial samples

98 
Table

Page

1. Spacing of microbial structures $\quad 19$

2. Structural attributes characterization of biofacies sample $\quad 42$

3. Morphometrics of biofacies structures 43

4. Structural attributes characterization of lithofacies sample 57

5. Morphometrics of lithofacies structures 58

6. 2008 Transect 2 measurement and characterization 83

7. 2008 Transect 3 measurement and characterization 83

8. 2008 Transect 4 measurement and characterization 84

9. 2009 Transect 2 measurement and characterization 85

10. 2009 Transect 3 measurement and characterization 86

11. 2009 Transect 4 measurement and characterization $\quad 87$

12. 2011 Transect 2 measurement and characterization 88

13. 2011 Transect 3 measurement and characterization 89

14. 2011 Transect 4 measurement and characterization 90

15. Morphometrics of structures in partially silicified sample $110921.6 \quad 96$

16. Attributes of structures in partially silicified sample $110921.6 \quad 97$

17. Morphometrics of structures in aerially exposed sample 110919.24B 99

18. Attributes of structures in aerially exposed sample 110919.24B 100 
LIST OF FIGURES

$\begin{array}{ll}\text { Figure } & \text { Page }\end{array}$

1. Anatomy of hydrothermal features 5

2. Panoramic strip of Queen's Laundry Hot Spring 6

3. Location map for Queen's Laundry in Yellowstone National Park 7

4. Facies model for siliceous sinter biofacies 9

5. Field photos of Calothrix biofacies 13

6. Samples used to compare partially silicified and aerially exposed Calothrix biofacies 15

$\begin{array}{ll}\text { 7. Description of laminae growth profiles } & 17\end{array}$

8. Attributes of microbial structures 18

9. Geometric attributes of microbial structures 20

10. Microscale characteristics $\quad 22$

11. Aerial image of Queen's Laundry hot spring 28

12. XRD of biofacies and lithofacies samples 29

13. Field image of partially silicified Calothrix biofacies 30

14. Field image of aerially exposed Calothrix biofacies 32

15. Field setting to thin section, partially silicified Calothrix biofacies 34

16. Annotated partially silicified biofacies thin section photo mosaic 37

17. Partially silicified biofacies features: an annottaed image 40

18. Optical light microscopy of partially silicified Calothrix biofacies bulk
sample and thin section

19. Partially silicified biofacies microstructures 46

$\begin{array}{ll}\text { 20. Microbial colonization on silica precipitates } & 47\end{array}$

21. Filamentous growth from detrital materials 48

22. Microbial colonization on biological materials 49

23. SEM images of partially silicified Calothrix biofacies 50

24. Field setting to thin section, aerially exposed Calothrix biofacies 52

25. Annotated aerially exposed sample thin section 54

26. Microstructure of aerially exposed Calothrix biofacies 60

27. Optical light microscopy of aerially exposed Calothrix biofacies 58

28. Subaerial effects on silica capping deposit 63

29. SEM images of aerially exposed Calothrix biofacies 64

30. SEM image of Calothrix filaments with false color EDS data 65

31. SEM images of Calothrix filaments and moulds with false color EDS dats 66

32. Field to lab images of partially silicified biofacies sample $110921.6 \quad 91$

33. Field to lab images of partially silicified biofacies sample $110921.5 \quad 92$

34. Field to lab images of partially silicified biofacies sample $110921.3 \quad 92$

35. Field to lab images of partially silicified biofacies sample 110921.4

36. Field to lab images of aerially exposed biofacies sample $111001.10 \quad 93$ 
37. Scanned images of partially silicified and aerially exposed biofacies samples thin sections

38. Annotated partially silicified sample thin section photo mosaic 95

39. Annotated aerially exposed sample thin section 98

40. XRD pattem of sample $110921.4 \quad 101$

41. XRD pattem of sample $110921.6 \quad 102$

42. XRD pattem of sample $110921.35 \quad 102$

43. XRD pattem of sample 111001.3

44. XRD pattem of sample $111001.10 \quad 103$

45. XRD pattems of hand ground versus mechanical milling of aerially exposed sample 111001.3 
Chapter 1

Introduction

In the past few decades, microbial biosignature preservation research has focused on silica-depositing hydrothermal environments because of their relevance to understanding some of the earliest inhabitants on Earth (Konhauser et al., 2003) and for their use as paleobiological analog deposits in astrobiology search strategies (Walter and Des Marais, 1993; Farmer and Des Marais, 1999). The recent discovery of silica rich deposits on Mars, which have been interpreted as evidence of inactive hot springs (Skok et al., 2010), continues to support the hypothesis that such deposits would be important astrobiology targets on the red planet (Grotzinger et al., 2011). Mineral-depositing hydrothermal ecosystems, such as the hot springs in Yellowstone National Park, provide an unparalleled opportunity to document how microbial biosignatures form and contribute to the body of evidence indicative of the microbial inhabitants of active hot springs. The benthic microbial communities that occupy particular thermal regimes in hot springs create distinctive biofacies that, when mineralized, produce a corresponding distinctive lithofacies. Mineralization in silica-depositing hot springs occurs when microbial communities become entombed in opaline silica, which precipitates when subsurface hydrothermal fluids charged with dissolved silica and cool and evaporate while flowing from the proximal to distal ends of hot spring outflow systems. The entombment process can result in the lithification and preservation of microbial biofacies in the 
geologic record (Hinman and Walter, 2005). Thus hot spring lithofacies can be correlated morphologically with their corresponding biofacies.

In this project, the microscale and microstructural characteristics of Calothrix biofacies samples collected from the low-temperature end of an active silica-depositing hydrothermal systems - known as Queen's Laundry hot spring - were studied in detail and compared to Calothrix lithofacies samples that were collected from an inactive ( $>$ three years) part of the same hot spring. The Calothrix biofacies (sensu Walter, 1976) is well developed at the distal ends of alkaline hot springs where fluid flow shallows, cools to $<40^{\circ} \mathrm{C}$. The Calothrix biofacies is a visually distinct microbial community dominated by populations of a Calothrix spp., a sheathed filamentous cyanobacterium. Calothrix spp. are the main components of the microbial mats that colonize shallow pools dammed by terraces, and they typically colonize the terraces as well (Cady and Farmer, 1996). At the macroscale, the terrace morphology is visually distinctive, an aspect important for sample collection from within and beyond the perimeter of the actively flowing drainage apron. The similar morphology of extant and extinct sinter biofabrics and terrace structures enabled comparative analysis of actively forming Calothrix biofacies and air-dried Calothrix lithofacies.

The goal of this project was to determine whether initial prolonged (beyond an annual cycle) aerial exposure affected the fidelity of morphological biosignatures indicative of Calothrix dominated microbial mats, referred to hereafter as the Calothrix biofacies. Samples of actively 
accreting Calothrix biofacies from subaqueous regimes were collected along with fragments of sinter, referred to hereafter as the Calothrix lithofacies, which were known to have been aerially exposed for at least three years. The objectives of the study were twofold. First, determine whether the biofacies and the lithofacies sinter samples used in the comparative study formed under similar conditions. Second, determine whether prolonged exposure to the air or other processes affected the fidelity of the biosignatures (i.e., biofabric and microbial cells) in the lithified samples. 
Chapter 2

Background

\subsection{Yellowstone National Park}

Yellowstone National Park, established in 1872, is the nation's first national park (U.S. Statutes, 1873). The preservation of the thermal features led to the park's creation, as it truly is a national treasure. For example, within 2.59 square kilometers of Old Faithful nearly one-fifth of all the world's geysers reside; more than one hundred geysers. There are more than ten thousand thermal features, including geysers, hot springs, fumaroles, and mud pots.

The major geological forces responsible for sculpting the Yellowstone region into its modern form are: glaciation, tectonic activity, and volcanic eruptions. The park's recent geologic history begins with the first caldera forming eruption, 2.1 million years ago and is associated with the arrival of the Yellowstone "hot spot" into the region. There have been three major caldera-forming eruptions at: 2.1 million, 1.3 million and 639,000 years ago. Each of these major eruptions was accompanied by lava flows. Volcanism continued to about 70,000 years ago, including a small caldera event 180 , 000 years ago that is occupied by the present day West Thumb of Yellowstone Lake (Christiansen and Blank, 1972). The lava flows that have been left behind are rhyolitic and basaltic in composition.

Yellowstone's ongoing thermal and geologic activity is attributed to young volcanism associated with a magma chamber 8 to 11 kilometers below the surface (Fritz and Thomas, 2011). Buried, young volcanic 
products conduct heat to the surrounding rock during the time it takes for the erupted material to cool (Fritz and Thomas, 2011). The underlying magma chamber is also continuously heating the overlying rock. A portion of the meteoric precipitation at the surface makes its way below the surface via fissures within the local rock. The cold water descends to depth where the heated rock heats the water; it then rises to the surface due to lower density and increased buoyancy (Figure 1).

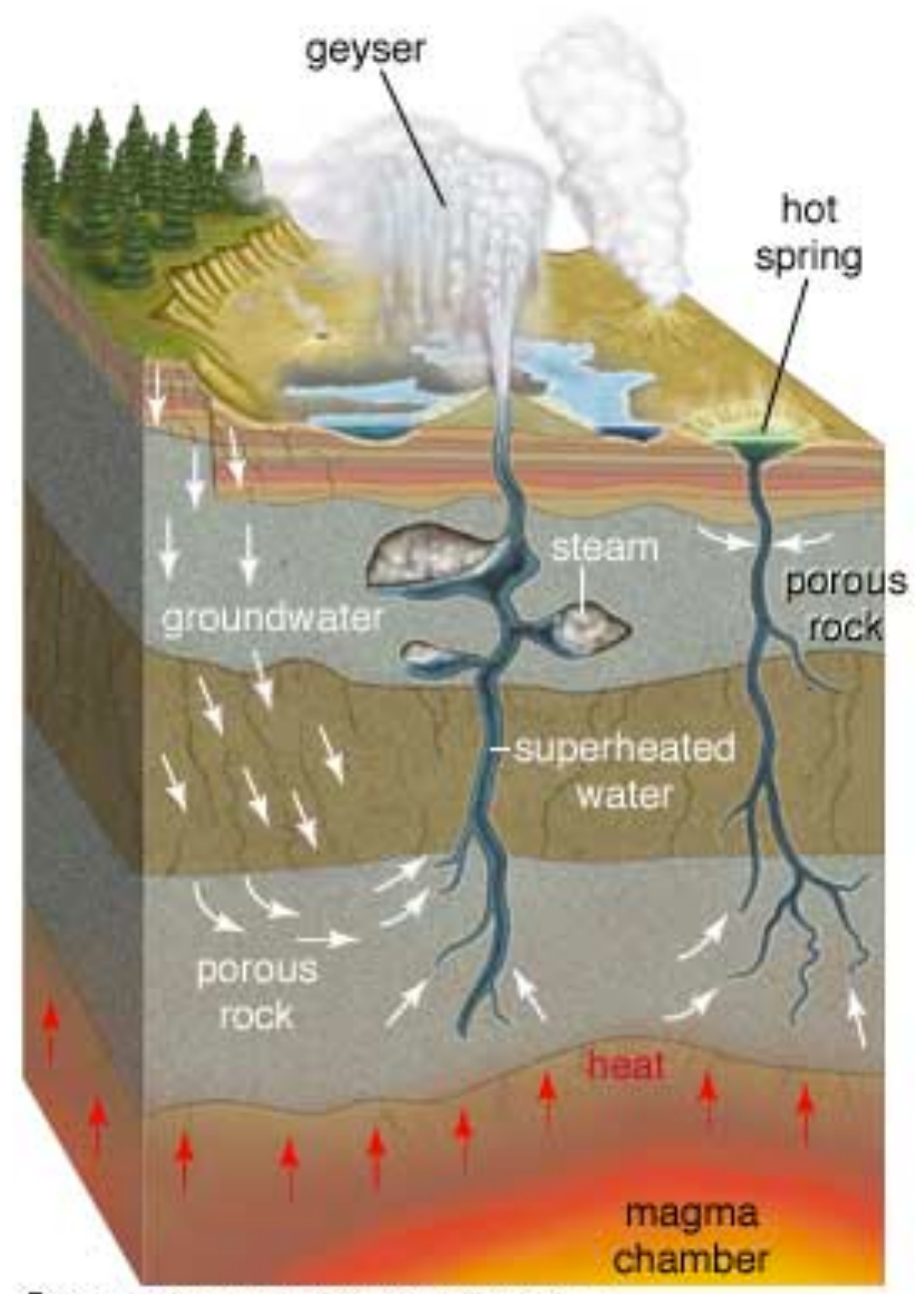

Fig. 1. An essential ingredient for thermal activity is heat. During cooling, tremendous quantities of heat are transmitted by conduction into the solid rocks surrounding the magma chamber. Local precipitation seeps to depth via fissures and cracks and heats to extremely high temperatures that enable the dissolution of minerals from surrounding rock. The heated water rises to the surface due to decreased density and increased buoyancy (illustration from Encyclopedia Britannica, 2014). 
At depth and under pressure, the heated water approaches $300^{\circ} \mathrm{C}$,

partially dissolves the local rock and transports the dissolved elements and minerals toward the surface (Fournier and Truesdell, 1970). A hot spring is the intersection of a hydrothermal fluid conduit and the surface of the earth. The silica dissolved in the hydrothermal fluid precipitates out onto available surfaces within the discharge area of the hot spring.

\subsection{Field Setting}

Queen's Laundry (Fig. 2), located at the west end of Sentinel Meadows in Yellowstone National Park (Figure 3), is a silica-depositing, slightly alkaline hot spring. It is characterized as a gently boiling/surging hot spring based on the activity of the silica-rich fluids it discharges at the main pool (classification sensu Lowe and Braunstein, 2003).

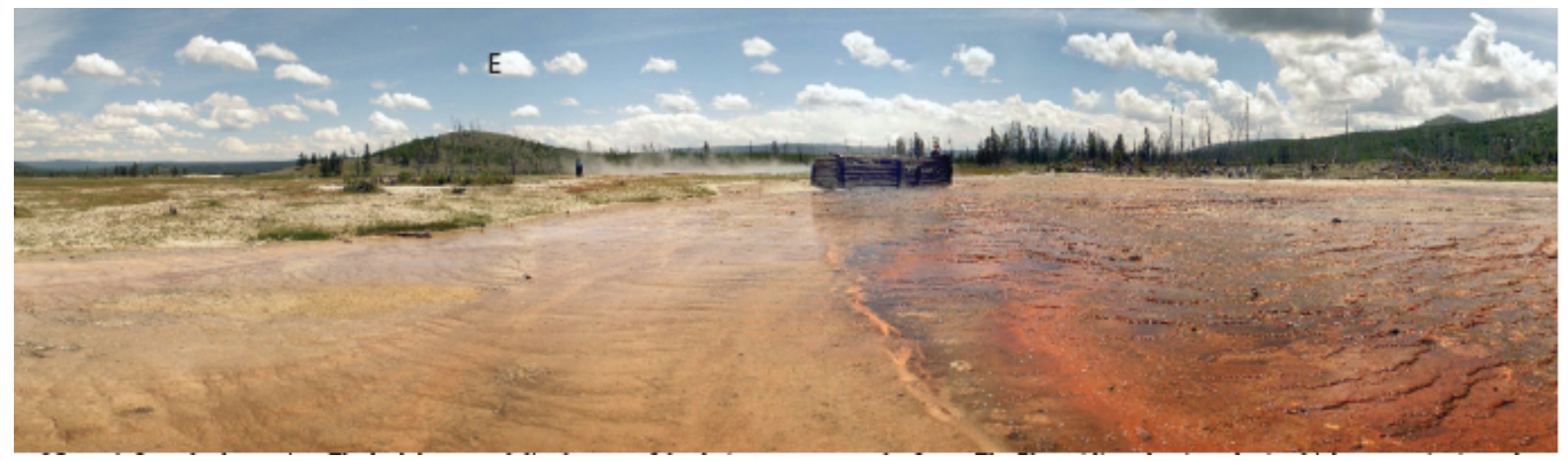

Fig. 2. Panoramic image of Queen's Laundry hot spring. The bathhouse and distal zones of the drainage apron are the focus. The Phormidium dominated microbial community is on the right with the orange and darker pigmentation. On the left, characterized by light tan and brown pigmentation, is the Calothrix dominated microbial community - the focus of this research. The brown curvi-linear features in the Calothrix biofacies area are terraces, a characteristic sedimentary structure associated with Calothrix. E is a directional indicator for east. Image courtesy of Frank Granshaw, 2009. 


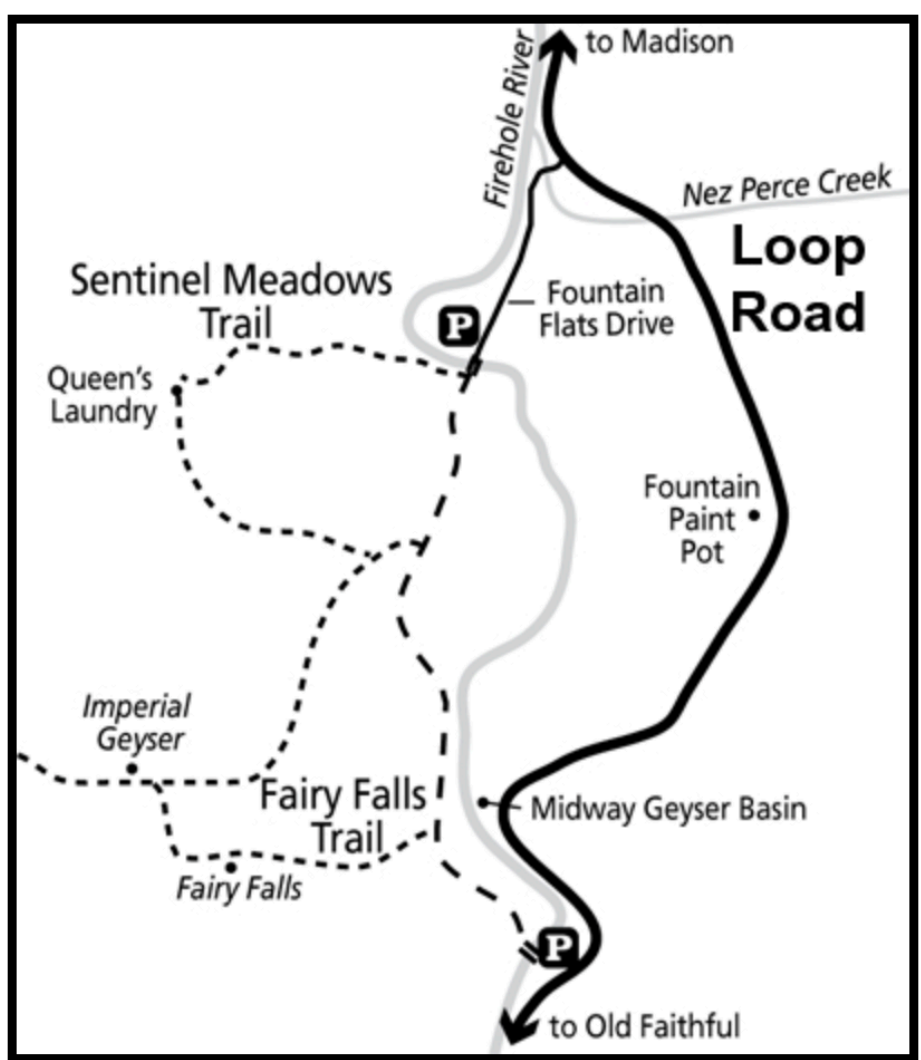

Fig. 3. Location map of Queen's Laundry hot spring located in Yellowstone National Park. The hot spring is in the west end of Sentinel Meadows in the Lower Geyser Basin (Yellowstone National Park Hiking Guide).

\subsection{Biofacies and biosignatures}

The term biosignature is used in astrobiology and paleobiology to describe phenomena produced by microbial life as a result of its presence, behavior, metabolism, and interactions with other life and its surroundings. In modern settings, the biogenicity (i.e., biogenic origin) of a possible biosignature is relatively easy to detect. In contrast, demonstrating the biogenicity of ancient rocks that might have formed in the presence of microbial life is much more challenging and not always possible (Oehler and Cady, 2014). Microbial signatures have been classified in a variety of ways and a generalized classification scheme includes (1) microbial body fossils and 
extracellular remains, (2) organosedimentary structures and sedimentary fabrics that display evidence that indicates they were influenced by microbial activity, and (3) chemical fossils, such as biominerals, isotopic signatures, and bacterial lipids (Cady et al., 2003). Biosignature characterization and interpretation is essential for evaluating the presence and influence microbial life may have had on a sedimentary structure.

\subsection{Biofacies and Lithofacies}

A biofacies is defined as a body of sedimentary rock characterized by specific and distinctive biological characteristics, and a lithofacies is defined as a body of sedimentary rock characterized by specific and distinctive physical and chemical characteristics (Kearey, 2001). Chemical and thermal gradients within hot springs delineate ecological niches occupied by visually distinctive microbial communities (Fig. 4) that can be recognized by the pigmentation of the dominant microorganisms (Walter and Des Marais, 1993). These communities are associated with distinct biofacies (Hinman and Walter, 2005) and evidence of these microbial communities can be preserved as biosignatures in siliceous sinter lithofacies.

Walter (1976) provided the first detailed description of the full suite of biofacies that occur in a hot spring ecosystem. A later study by Cady and Farmer (1996) provided the first detailed scanning electron microscope (SEM) images of partly silicified biofacies and revealed details about how the various microbial communities contribute to the biosedimentological 
characteristics of siliceous sinters. In that study, taphofacies - which

correspond to the dominant fossilization mechanisms for any one hot spring biofacies or sinter lithofacies — were proposed for silica sinters (Cady and

Farmer, 1996) (Fig. 4). The study by Cady and Farmer (1996) also

demonstrated how, at the submicroscopic scale, microbial mats and biofilms

influence the fabrics of sinters that form along the entire thermal gradient of

silica-depositing hot springs, even those that formed in the presence of

hyperthermophilic biofilms, (i.e. hyperthermophiles live at temperature $\geq$

$\left.80^{\circ} \mathrm{C}\right)$

FACIES MODEL for SILICEOUS SINTER

BIOFACIES

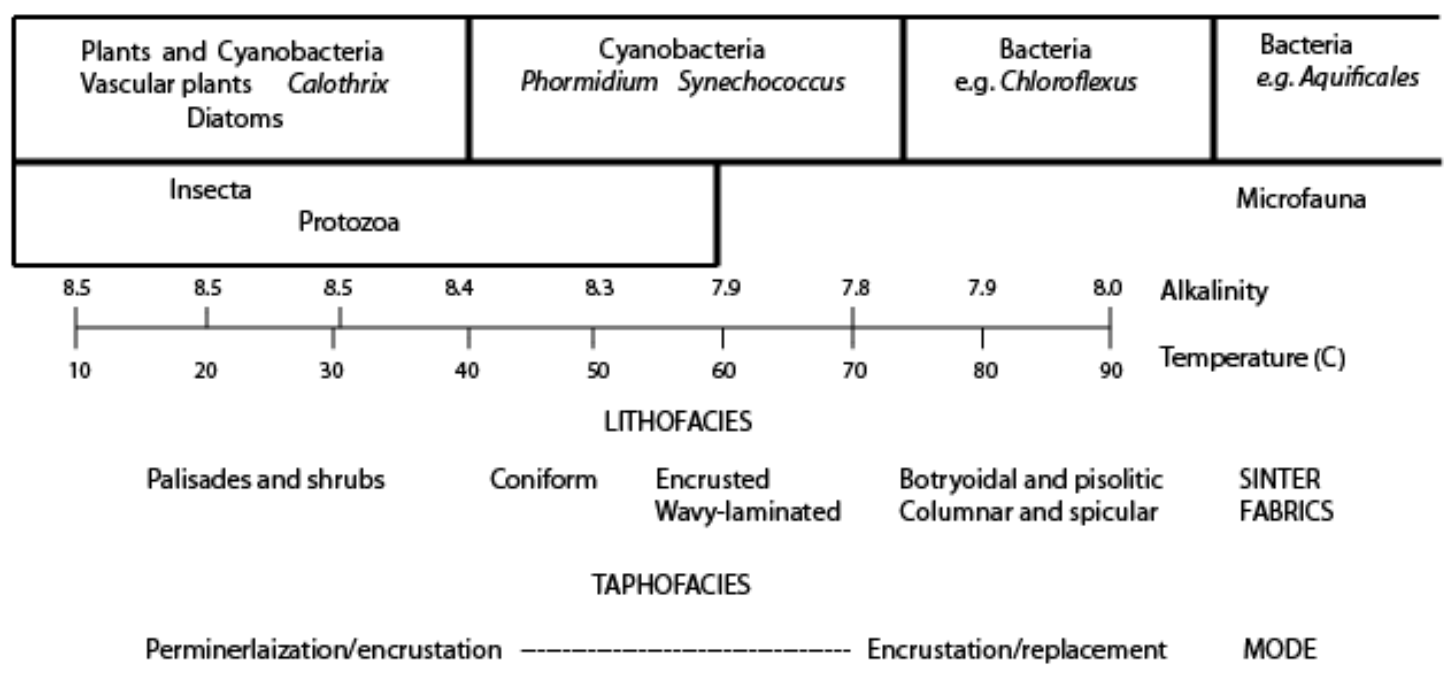

Fig. 4. Siliceous sinter biofacies and lithofacies model "developed by Walter (1976) based on his studies of silica-depositing thermal springs in Yellowstone National Park." Cady and Farmer (1996) added their observed taphonomies (post-mortem history) of microorganisms (Cady and Farmer, 1996).

Since that time, numerous studies have focused on characterizing the various microbial biosignatures in more detail with the use of higher 
resolution imaging, chemical and structural analytical approaches (e.g., Benning et al., 2004; Preston et al., 2008). Recent studies have also demonstrated that microbial signatures of thermophilic and hyperthermophilic microbial communities can persist in the rock record in spite of the deleterious effects of diagenesis (e.g., Hinman and Walter, 2005; Walter and Des Marais, 1993).

\subsection{Calothrix and Terraces}

Calothrix is the dominant microorganism found at the distal end of drainage aprons of silica-depositing hot springs and it grows optimally in alkaline waters with a temperature of $<40^{\circ} \mathrm{C}$ (Jones et al., 1998). Calothrix is a sheathed, filamentous cyanobacterium characterized by tapered ends and filament lengths that can exceed $500 \mu \mathrm{m}$. Typical Calothrix filament diameters are on the order of $10-12 \mu \mathrm{m}$ (Jones et al., 2003). Even when the cells are destroyed, silicified empty sheaths can provide morphological evidence of cells in life position.

Within the drainage apron, the Calothrix biofacies is associated with pools dammed by terraces (Cady and Farmer, 1996). When laterally continuous, centimeter-high terraces are oriented perpendicular to the main direction of flow and they can dam the outflow channels and create small ponds. 


\section{Chapter 3}

Methods and Morphometric Analysis

\subsection{Field Collection}

Siliceous sinters associated with subaqueous and aerially exposed

Calothrix biofacies that displayed similar terrace macro-morphologies were collected for this study in 2011 from inside and outside, respectively, of the main drainage apron of Queen's Laundry hot spring. The terrace morphology was visually distinctive in the field and, as noted above, is a common feature associated with the distal end of silica-depositing hot spring outflow channels. Terraces are often continuously bathed in a thin film of fluid characterized as "sheet" flow. Multiple visits over three field seasons to the field site during the summer months confirmed that the lateral extent of the drainage apron margin did not expand beyond the collection sites of the recent terrace sinters for at least three years.

\subsubsection{Perimeter Mapping}

To date, three perimeter maps have been made at the Queen's laundry hot spring. The first one was obtained by a student (Steve Walsh) as part of a field course taught by Dr. Cady during the summer of 2008. A second one was made by another student (the author) during the summer of 2009. And a third perimeter map was made as part of this thesis project in the summer of 2011. David Percy, from Portland State University, collaborated to establish the following protocol for mapping the active/inactive boundary of the hot 
spring system. Active is defined as visible hydrothermal fluid at the surface. The perimeter map was acquired with the GPS by walking at 1 meter from the moist to dry interface, or at an appropriate safe distance from that interface, at a pace of one step per second. The perimeter was georeferenced with a Trimble Juno that georectified in real time to decimeter accuracy.

\subsubsection{Sample Collection}

Samples were collected from a hot spring within Yellowstone under the National Park Service Research Study \# YELL-01994. Prior to sample collection, all of the sinter samples were photo-documented (as shown in Appendix 2) in their natural hot spring setting. Calothrix-dominated mats and their associated terraces were collected in a sterile manner for optical and electron microscopy. Samples of cohesive and partly silicified mats and their underlying sinters were cut into rectangles prior to collection, and they were removed with alcohol-sterilized knives. The samples were gently placed into $50 \mathrm{~mL}$ Falcon ${ }^{\circledR}$ tubes (ethanol rinsed/dried) where they were immersed in a $4 \%$ gluteraldehyde (electron microscopy grade) solution prepared with diluted, filtered (sterile $0.2 \mu \mathrm{m}$ Nalgene syringe filter) hot spring fluid to cease bacterial activity (Parafilm ${ }^{\circledR}$ was used to prevent leakage of fluid from the Falcon tubes during transport and storage). The Parafilm sealed Falcon tubes were placed on ice in a cooler for transport to the Geomicrobiology and Electron Microscopy Laboratory at Portland State University, where they were stored in a refrigerator at $6^{\circ} \mathrm{C}$. 


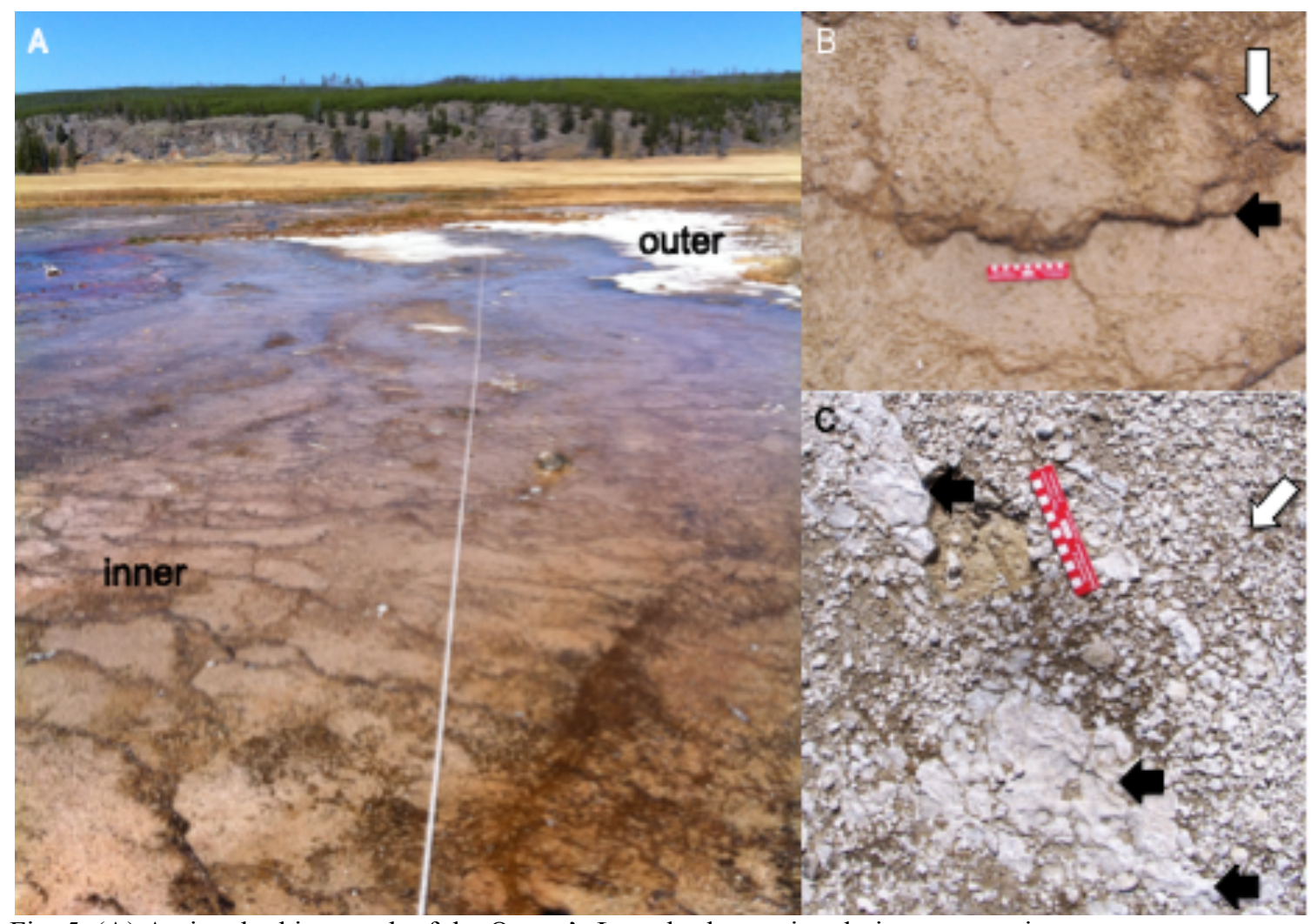

Fig. 5. (A) A view looking north of the Queen's Laundry hot spring drainage apron in Yellowstone National Park. The margin of the drainage apron is visible because permanently submerged sinters are colonized by Calothrix mats and have a characteristic brown color, whereas the lithified samples appear white, as they are dry. The inner, pigmented, wetted, and active margin and the outer, white, and non-wetted outer margin are labeled accordingly. (B) Terraces are the darker brown curvi-linear features associated with Calothrix biofacies within the inner margin of the drainage apron. (C) Collection site of siliceous sinters that displayed the terrace morphology at the macroscopic scale. This macro-morphology, combined with the microbial pigment, are key indicators of possible Calothrix biofacies. Black arrows indicate the curvi-linear features of the terrace within the large, intact silica deposits. Scale bar used in both images is $15 \mathrm{~cm}$ and the white arrows indicate the direction of present or interpreted past hydrothermal fluid flow.

Aerially exposed lithified samples were collected beyond the furthest edge of the drainage apron margin on the basis of their macro-morphological features, which were consistent with those of the Calothrix biofacies. After the aerially exposed lithified samples were collected they were wrapped in new aluminum foil for transport back to the laboratory. Upon their return, these samples were unwrapped and a "tent" of new aluminum foil was used 
to loosely cover the samples so that they could dry at ambient temperature,

in the absence of most air-borne contamination. Once visibly dry, they were

then loosely rewrapped for storage in new aluminum foil.

\subsubsection{Samples Used to Compare Partially Silicified and Aerially Exposed}

\section{Calothrix Biofacies}

A comparison of the samples collected from the partly silicified and aerially exposed Calothrix biofacies that were investigated at different spatial scales are shown in Figure 6.

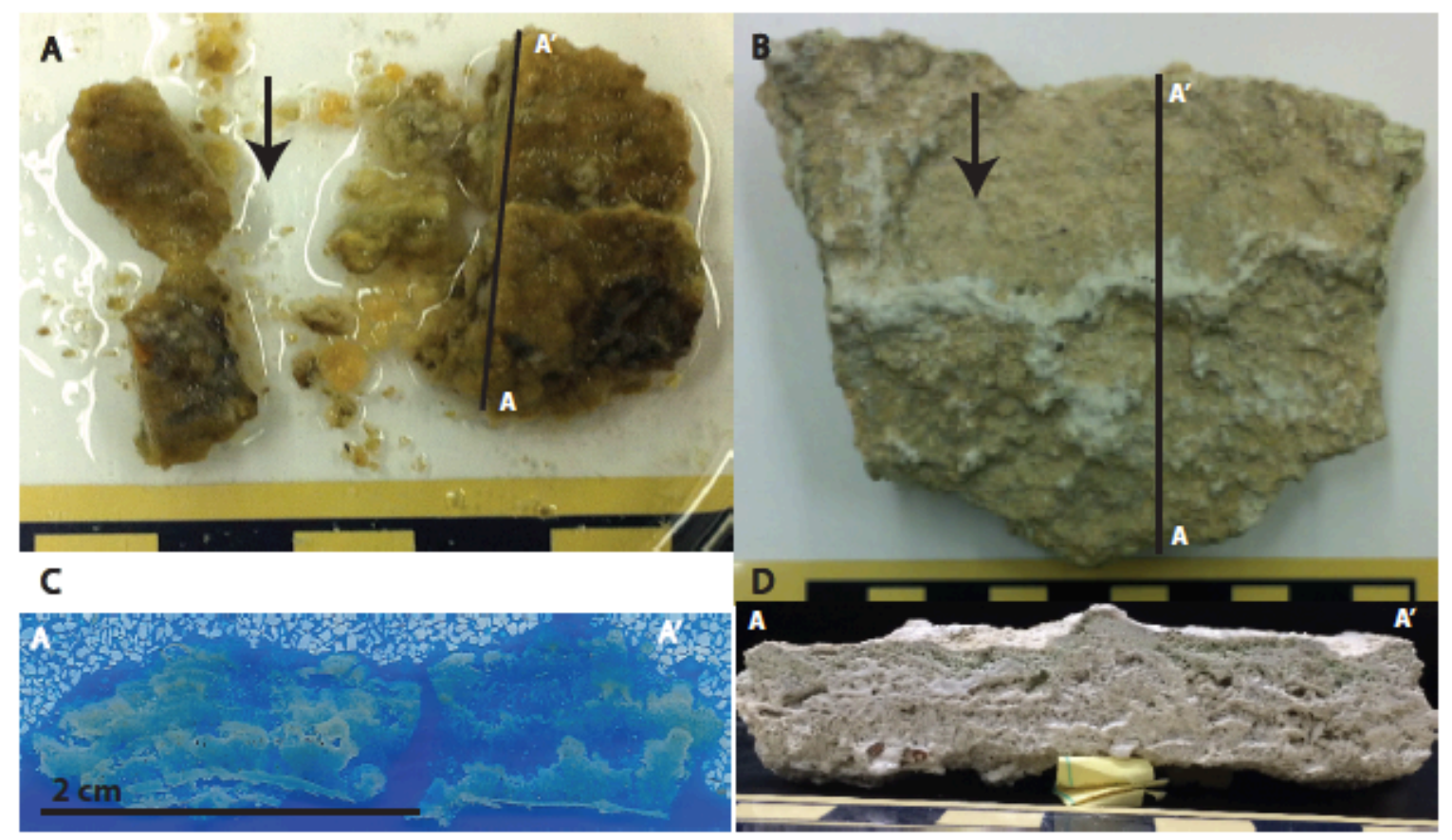

Fig. 6. Photographs of the samples used to study the biofabric of partially silicified and aerially exposed Calothrix biofacies terraces. The partially silicified Calothrix biofacies (A, C) and aerially exposed Calothrix biofacies (B, D) samples are shown in top-down view (A, B) and in cross-section (C, D). Note that the black arrows shown in (A) and (B) indicate the general direction of hydrothermal fluid flow across the sample (i.e., fluid flow was observed in A and is presumed in B based on field context). (A) Partially silicified sample (\#110921.6) in a petri dish shown after being cut to prepare a thin section along the A to A' transect. (B) Aerially exposed sample (\#110919.24) consists of a solid piece of sinter with a prominent curvi-linear terrace $(\mathrm{T})$. The transect $\mathrm{A}$ to $\mathrm{A}^{\prime}$ indicates where the sample was cut. (C) Petrographic thin section illustrates the laminated character of the Calothrix terraces. 
(D) The sawn section of the aerially exposed Calothrix biofacies sinter, which was cut in a direction that paralleled fluid flow to provide a cross-sectional view of the sinter fabric and internal structures. Scale bars are in centimeters for A, B, and D.

The orientation of each sample relative to the direction of fluid flow (black arrow) was documented photographically in the field and maintained while the samples were processed at the laboratory (Fig. 6).

\subsection{Optical Light Microscopy}

\subsubsection{Sample Preparation for Thin Sections}

The preparation of petrographic thin sections from the field samples was different for the two sample types. The partially silicified biofacies samples contained living microorganisms while the aerially exposed biofacies were dry sinters. The partially silicified biofacies samples were rinsed twice, ten minutes each, with $0.1 \mathrm{M}$ cacodylate buffer to rinse the $4 \%$ gluteraldehyde from the samples. The rinsing of the partially silicified biofacies samples may have introduced additional porosity, though no obvious visual evidence of mineral residue was observed in the waste solution. The partially silicified and aerially exposed Calothrix biofacies samples were then cut parallel to the direction of hydrothermal fluid flow, which revealed the profile of the sample and the terrace accretionary history. Petrographic thin sections were prepared from these cross-sectional surfaces. The thin section preparation included embedding the samples in a resin with blue dye. The resin was used to enhance the structural integrity of the samples for 
processing and the blue dye was added to reveal porosity and enhance the contrast of the sample in thin section.

\subsubsection{Stereomicroscopy of Petrographic Thin Sections with Transmitted} Light

Stereomicroscopy was used to characterize qualitatively and quantitatively the partially silicified and aerially exposed Calothrix biofacies samples and the structures and features within them in thin sections. However, rather than using stereomicroscopy in the traditional sense because to look at geological or biological samples in reflected light, the stereoscope was used to characterize the samples as they appeared in petrographic thin section in transmitted light. This approach was taken because microbial structures could be viewed with higher resolution than could be obtained with the naked eye.

The morphological description of the upper lamination surface, which in the samples studied was defined by a silica capping layer, were described on the basis of their morphological similarity in cross section to those of sedimentary bedform structures as viewed in cross-section (Fig. 7). This nomenclature does not imply process of formation. Rather, the descriptions of the laminations using this convention ensured that the lamina profile was described in a consistent manner. 


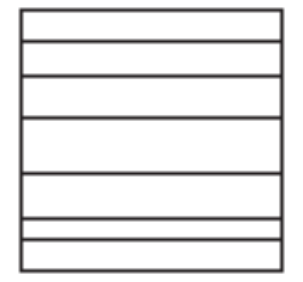

sharp planar

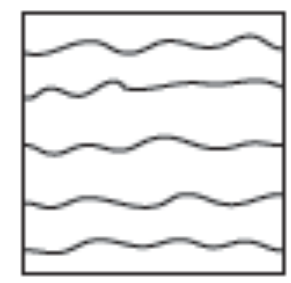

wavy

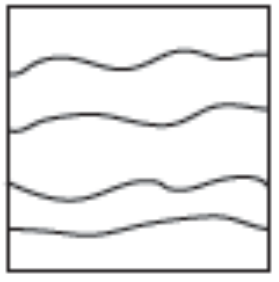

sharp irregular

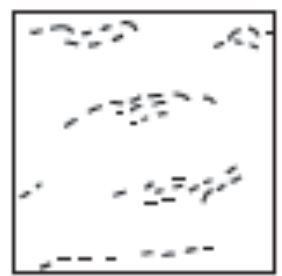

wispy

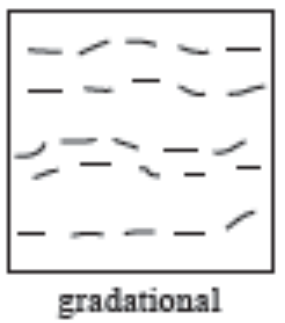

irregular

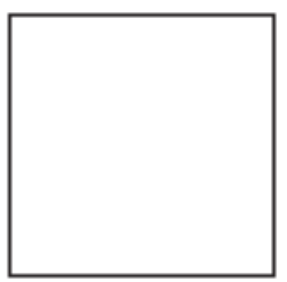

massive

Fig. 7. Terms for the description of laminae growth profiles recorded by silica capping layers. (modified from Coe et al., 2010).

Attributes of microbial structures were characterized following the procedures described by Hofmann (1969), which included: qualitative characterizations of structure profile and inheritance, and quantitative measurements for linkage and spacing.

"Structure profile" refers to the perimeter curvature of distinct structures typically microbial structures in cross-section whether observed on cut or sawn block faces or in petrographic thin sections. If successive overlying laminae in a sample reflected a similar structure profile, the resultant inheritance was noted.

"Linkage" refers to whether the structures are continuous across the intermound space of two defined structures. 


Structure Profiles Contiguous

Fig. 8. Illustration of microbial structure attributes. Calothrix biofacies and lithofacies samples included: structure profile, linkage, spacing, and inheritance (modified from Allwood et al., 2007, and Hofmann, 1968).

"Spacing" refers to the distance between adjacent structures relative to the diameter of one of the structures (see Table 1, modified after Hofmann, 1969). For example, if the distance between the structures is greater than the diameter between the structures, then the spacing between them is referred to as "open."

Table 1. Spacing of microbial structures is determined by dividing the distance between two adjacent structures by the widest diameter of a structure. The resultant value is then used to classify the spacing between the two structures.

\begin{tabular}{|l|c|l|}
\hline Operation & Value & Spacing \\
\hline Distance / Diameter & 0 & Contiguous \\
\hline Distance / Diameter & $\leq .5$ & Very close \\
\hline Distance / Diameter & $\leq 1$ & Close \\
\hline Distance / Diameter & $>1$ & Open \\
\hline
\end{tabular}


"Inheritance" describes the degree to which the topography of an underlying lamina is reflected by the overlying successive laminae. How successively stacked structures are related from one lamina to another is described by the degree of inheritance, which was classified as low, intermediate, and high.

Low - stacking of various shaped lamina Intermediate - stacking where vertical and lateral development continues

High - stacking of identical shaped lamina

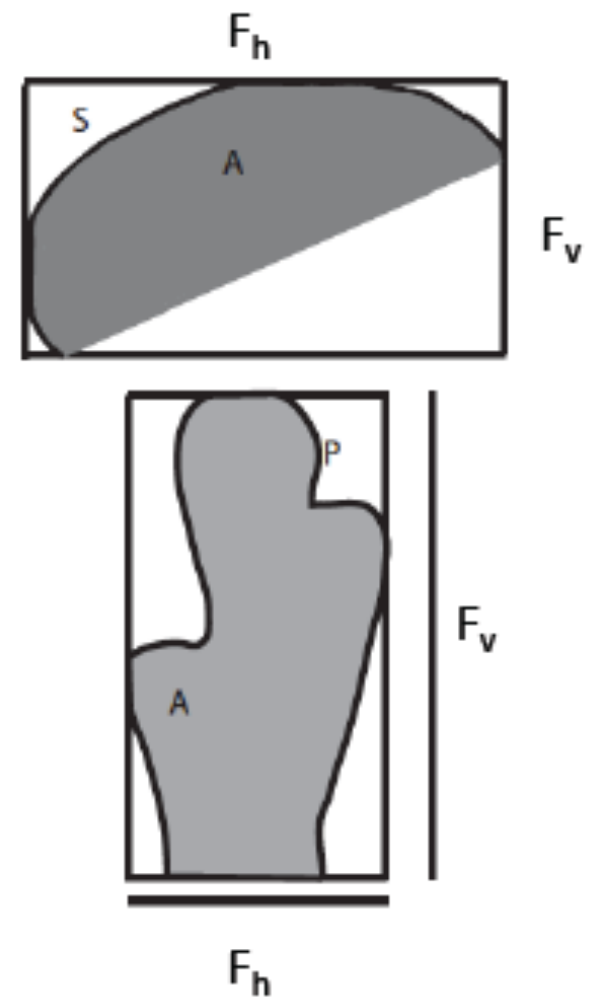

Fig. 9. Top figure - Geometric attributes that were measured on individual structures within lamina: perimeter $(\mathrm{S})$, area $(\mathrm{A})$, width $\left(\mathrm{F}_{\mathrm{h}}\right)$, and height $\left(\mathrm{F}_{\mathrm{v}}\right)$. Bottom figure - Geometric attributes that were measured on structures exhibiting inheritance, where $S$ is the entire perimeter of the structure, $A$ is entire area of the structure, $F_{h}$ is the full width of the structure, and $F_{v}$ is the full height of the structure (modified from Hofmann, 1994). 
Quantitative characterization and morphometric analyses of the microbial structures followed nomenclature established by Hofmann (1994). The morphometric analysis was performed with the use of ImageJ (ImageJ, 2009), an open source software. Attributes measured on individual microbial structures were height $\left(\mathrm{F}_{\mathrm{v}}\right)$, width $\left(\mathrm{F}_{\mathrm{h}}\right)$, perimeter $(\mathrm{S})$ (not including the base), and area (A) (Fig. 9).

Microbial structures that displayed inheritance, that is microbial structures that developed successively atop each other in multiple laminae, were also measured. The attributes measured on the entire inherited structure were height $\left(F_{v}\right)$, width $\left(F_{h}\right)$, perimeter $(P)$ and area $(A)$ (Fig. 9).

\subsubsection{Petrographic Microscopy}

The microstructure of representative sections of partially silicified and aerially exposed Calothrix biofacies was characterized with the use of a Leica petrographic microscope. Plane and cross-polarized light microscopy was used for thin section analysis. The microstructure of the microbial structures in any one lamination and the areas between microbial structures within any one lamination were described using the terminology after Komar et al. (1965) shown in Figure 10 based on similarity to the patterns shown. For the representative samples of the partially silicified and aerially exposed Calothrix biofacies samples studied in detail, the microstructure of all of the laminations and the structures within them was identified.

The patterns describe the different spatial relationships of the silica precipitate and microorganisms vs. the porosity within the laminated 


\begin{tabular}{|ll}
\hline Type & Subtype \\
Ribboned & uniformly wavy-ribboned \\
Striated & non-uniformly ribboned \\
\hline & inearly striated
\end{tabular}

Fig. 10. A classification system of patterns used by Komar et al. (1965) to describe stromatolite microstructures. In this study, these patterns were used to characterize the microstructures of partially silicified and aerially exposed Calothrix biofacies samples, with the dark areas of the patterns above representing microorganisms and opaline silica and the white areas of the samples representing porosity.

samples of the partially silicified and aerially exposed Calothrix biofacies.

The dark areas of the patterns shown in Figure 10 corresponded in this study

to the presence of microorganisms and minerals whereas the white areas of 
the patterns were assigned to pore space (i.e., areas that lacked any visible matter in that particular plane of thin section of the sample).

\subsection{Analytical Methods}

A variety of analytical methods were used to characterize microbial biosignatures in the partially silicified and aerially exposed Calothrix biofacies sinters. When applied to the partially silicified biofacies samples, these methods characterized the primary biosignatures that formed in the presence of the living microbial communities. The same methods were used to characterize similar features in the aerially exposed sinter specimens in order to determine whether and how aerial exposure altered the primary biosignatures. Instruments used in this study included a scanning electron microscope (SEM) and an X-ray diffractometer (XRD). Adjacent samples were prepared for SEM and for XRD analysis.

\subsubsection{Scanning Electron Microscope Sample Preparation}

Biofacies samples that were collected and stored at $6^{\circ} \mathrm{C}$ in a $4 \%$ gluteraldehyde solution prepared with cold filtered $(0.2 \mu \mathrm{m})$ hot spring fluid were prepared for scanning electron microscopy analysis by fixation with $0.1 \mathrm{M}$ osmium tetroxide in 0.1 cacodylate buffer for sixty minutes. They were rinsed twice by immersion in $0.1 \mathrm{M}$ cacodylate buffer for ten minutes each, and dehydrated with a graded ethanol series: $30 \%, 50 \%, 70 \%, 95 \%$, and $100 \%$ for fifteen minutes each and twice with $95 \%$ and $100 \%$ 
concentrations of ethanol (Dykstra and Reuss, 2003). All of the samples for scanning electron microscopy were critical point dried with a Pelco CPD2.

\subsubsection{Sputter Coater}

A Gatan Model 682 Precision Etching and Coating System was used to deposit a conductive coating onto the bulk samples to reduce surface charging during scanning electron microscopy. The bulk samples were coated with $10 \mathrm{~nm}$ of gold palladium. The thin sections were coated with 2 $\mathrm{nm}$ of gold with the use of a Cressington 180 Auto Sputter Coater.

\subsubsection{Scanning Electron Microscope Operating Conditions}

The specimens prepared for SEM analysis were investigated with an FEI Sirion XL 30 field emission gun SEM. An accelerating voltage of $15 \mathrm{keV}$ was used for EDS analysis (Goldstein et al., 2007) and various accelerating voltages were used for imaging. The TruMap feature of the SEM Oxford Aztec software was used to process the spectral data, which performed a least squares fit of the spectral data to remove the background noise for elemental peak identification.

\subsection{X-ray Diffraction Spectroscopy}

\subsubsection{Sample Preparation}

Sample splits for XRD analysis were prepared from the partially silicified Calothrix biofacies deposit, aerially exposed Calothrix sinter, and a thick capping silica layer from an aerially exposed Calothrix biofacies sample. The aerially exposed sample was prepared to assess whether the structural 
order of the opaline silica of sinter samples would be altered due to mechanical grinding with the micronizing mill. XRD analysis of partially silicified Calothrix biofacies samples were performed on a split of each sample that was obtained during the SEM sample preparation process after the gluteraldehyde had been removed.

The sample splits for XRD were air-dried in a desiccator jar with fresh desiccant and percussively reduced in size with a stainless steel mortar and pestle until they passed unaided through a $.495 \mathrm{~mm}$ sieve. The resultant powder was placed into a clean PVC grinding jar with agate grinding elements that was a part of the McCrone micronizing mill and ground automatically on the micronizing mill for one minute to reduce grain size to $\sim 20 \mu \mathrm{m}$ or less (Bish and Reynolds, 1989).

\subsubsection{X-ray Diffraction Operating Conditions}

The powdered samples were analyzed in the Department of Chemistry with the use of a Rigaku Ultima IV X-ray diffractometer. The X-ray diffractometer was operated with a copper K-alpha radiation source at $40 \mathrm{kV}$ and $40 \mathrm{~mA}$, with a step size of $0.03^{\circ}$, a scan rate of $1^{\circ} 2 \theta$, and measurements were made over the $2 \theta$ range of $3^{\circ}-110^{\circ}$. The powdered XRD samples were randomly packed between two glass well slides, one of which was removed to expose the sample to the X-ray beam during analysis. The instrument was calibrated with a different sample used for routine 
calibration in Dr. Goforth's laboratory just prior to analysis of the samples used in this study. 


\section{Chapter Four}

Results

\subsection{Field Setting of Queen's Laundry Hot Spring}

The aerial satellite view of the Queen's Laundry hot spring illustrates the positions of the georeferenced perimeter line, the sample collection sites, and the main features of the hot spring system (Figure 11). The perimeter line shown in Figure 11 designates most, but not all, of the active perimeter of the system during September 2011. It was not possible to complete the perimeter at the active end of the system because walking across and/or through active parts of a hot spring system was prohibited under the rules of the collection permit. The partial perimeter lines acquired during July and August 2008, and August 2009, plot at the same location as the perimeter line acquired in 2011, hence they are not shown in Figure11. Though a number of Calothrix-dominated samples have been collected from this hot spring over the years, only the collection sites of the 2 samples described in detail in this thesis, marked "CSB" and "CSL," are shown in Figure 11.

The main features of the hot spring system are created when hydrothermal fluid discharges via the main outflow channel ( $\leq 1 \mathrm{~m}$ wide) and cools and evaporates while it moves across the gently sloping broad discharge apron (several 10's of meters wide) (labeled in Figure 11). At the distal end of the system, the hydrothermal fluid flows into a diatomaceous marsh that then drains into a creek that runs through the middle of Sentinel Meadows. The areas of dried sinter adjacent to and on the NE and SW sides of the active 
hot spring system appear to have been created by lateral shifting of the hot spring drainage apron over several tens to hundreds or more years.

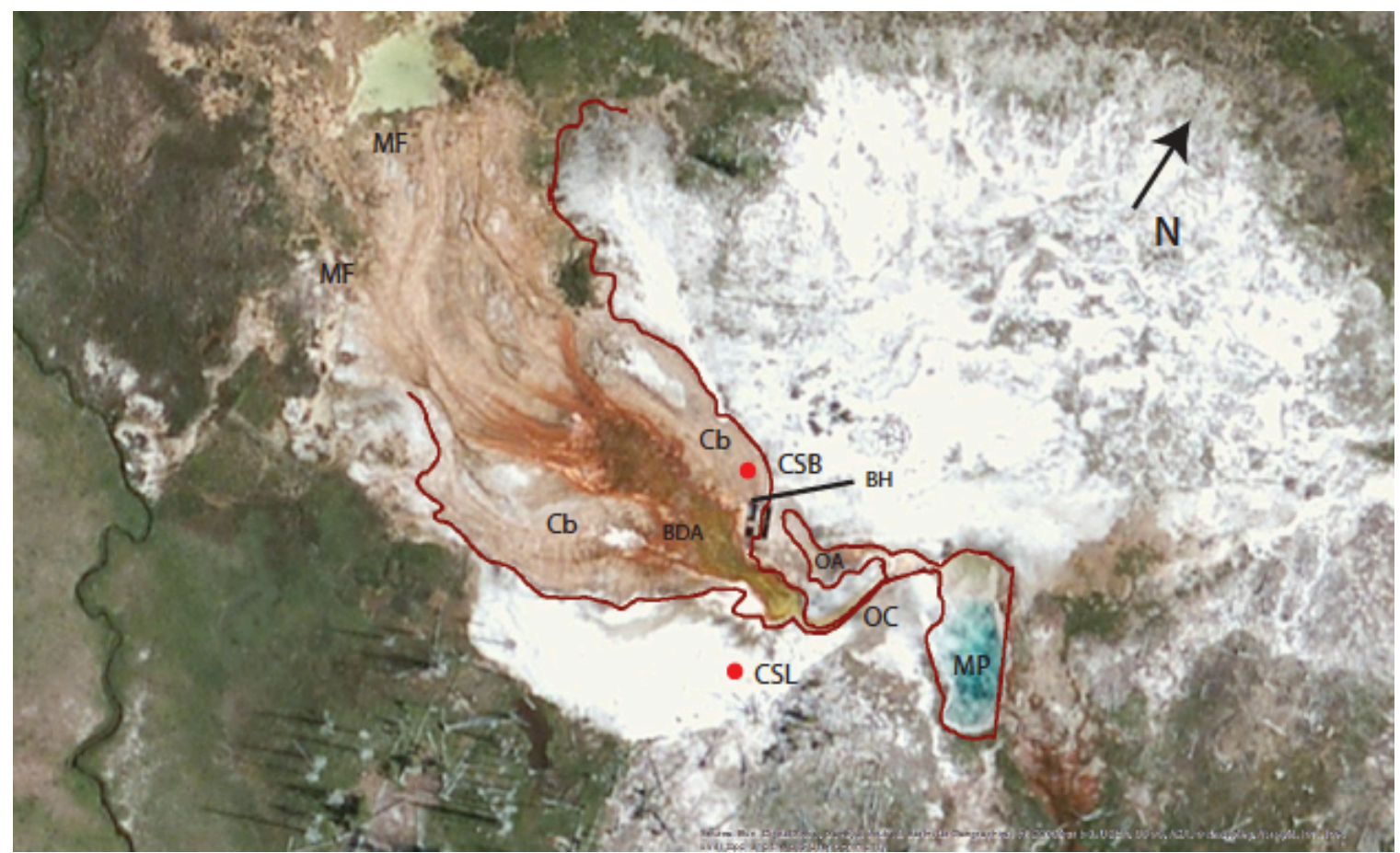

Fig. 11. Aerial image of Queen's Laundry hot spring (image from ArcGIS). Note that the Calothrix, partially silicified and microbial mat, biofacies $(\mathrm{Cb})$ is distinguished by its color, which in this satellite image appears to be pink. In a true-color image $\mathrm{Cb}$ would appear brown (see Fig 12). The partial perimeter line, shown in red, is georeferenced and was generated by walking with a GPS along the perimeter of the active rim of the system during the fall of 2011. The collection sites of the samples described in detail in this study are marked with red dots. Also shown are the main components of the hot spring system: main pool (MP), narrow outflow channel (OC), overflow area (OA), marsh facies (MF), the bathhouse $(\mathrm{BH})$, and broad drainage apron (BDA). Surrounding the active hot spring system is dried sinter, visible as white ground cover. The bathhouse for scale is $\sim 8$ ' $\mathrm{x} 19^{\prime}$.

\subsection{MINERALOGY}

\subsection{X-ray Diffraction}

XRD patterns of powdered aerially exposed Calothrix biofacies sinters

and the partly silicified Calothrix biofacies samples indicated that all of the samples consisted exclusively of non-crystalline opal (also referred to as 
opal-A, the "A" designating "X-ray amorphous"). The XRD pattern of opal-A is characterized by a broad silica hump at $\sim 22^{\circ} 2 \theta$ (Fig. 12).

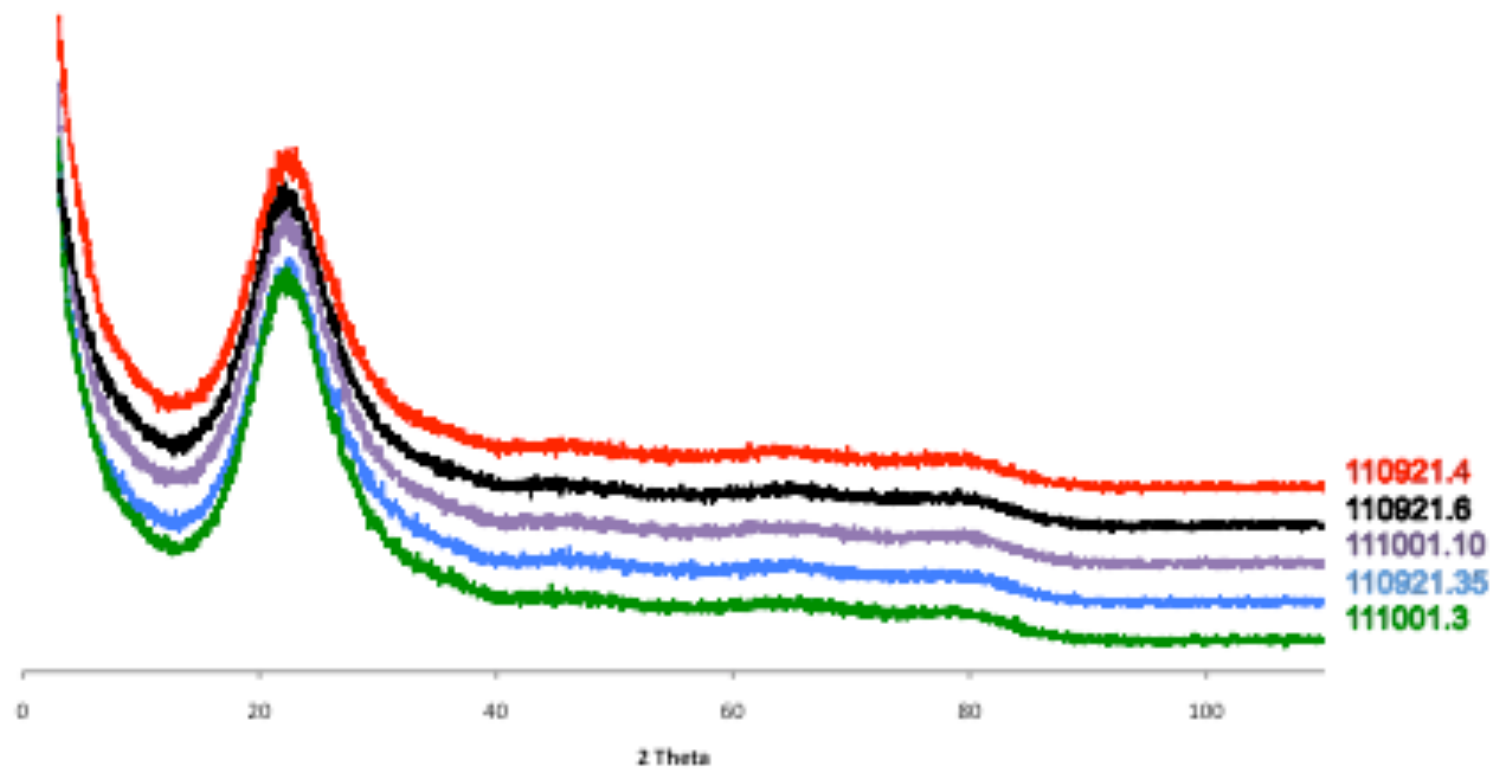

Fig. 12. A comparison of the XRD patterns of powdered Calothrix lithofacies (samples 111001.3, 110921.35, and 111001.10) sinters and Calothrix biofacies mats (samples 110921.4 and 110921.6).

\subsection{Field Context of the Partially Silicified and Aerially Exposed Calothrix}

Biofacies Samples

\subsubsection{Partially Silicified Calothrix Biofacies}

As shown in an aerial photograph (Fig 11), the partially silicified

Calothrix biofacies at Queen's Laundry hot spring is distributed across a broad drainage apron. The field photograph shown in Figure 13, which was taken along the perimeter looking west toward the inner part of the drainage apron, shows how the partially silicified Calothrix biofacies appeared during 
July, 2008. The terraces were identifiable because of their darker brown, curvi-linear features. In general, terraces extend laterally in a direction oriented perpendicular to the flow. The terraces at top and center of Figure 13 were easily distinguished because they were separated from each other just far enough to make them recognizable as distinct parallel-to-semiparallel curvi-linear features. In the foreground of Figure 13, the terraces were fewer in number and less distinct.

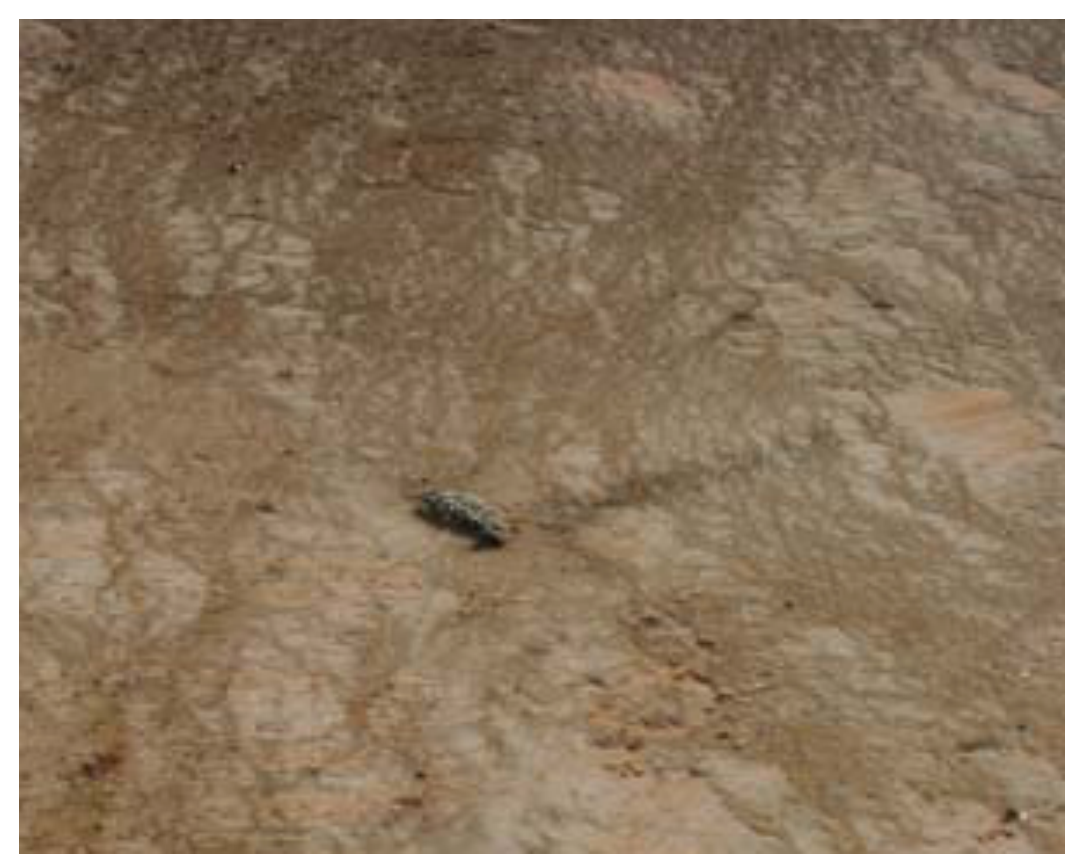

Fig. 13. Field photograph of a typical area in the broad drainage apron at Queen's Laundry hot spring that illustrates the curvi-linear terraces and shallow pools that develops between the terraces. The patches of salmon-colored mats associated with the partially silicified Calothrix biofacies in this photograph represent the recent growth of Phormidiumdominated microbial mat-forming communities. The blackish "blob" near the center of the image is bison feces.

\subsubsection{Aerially Exposed Calothrix Biofacies}

The aerially exposed Calothrix biofacies lies beyond the perimeter of the active part of the Queen's Laundry hot spring (e.g., as seen in the background of field photograph shown in Fig. 14). This is because as the 
hydrothermal fluid cools to ambient temperature and evaporates along the edge of the relatively cooler part of the outflow channel, it creates an ideal environment for Calothrix growth. The transition from the partially silicified brown-colored Calothrix-dominated microbial mats within the active hot spring system to the white opaline, aerially exposed, silica sinter biofacies beyond the perimeter is visually abrupt due to the color difference and presence or absence of hydrothermal fluid. It was possible in the field to identify the aerially exposed "Calothrix" biofacies based on the presence of terraces and the characteristic palisade fabric in the sinter.

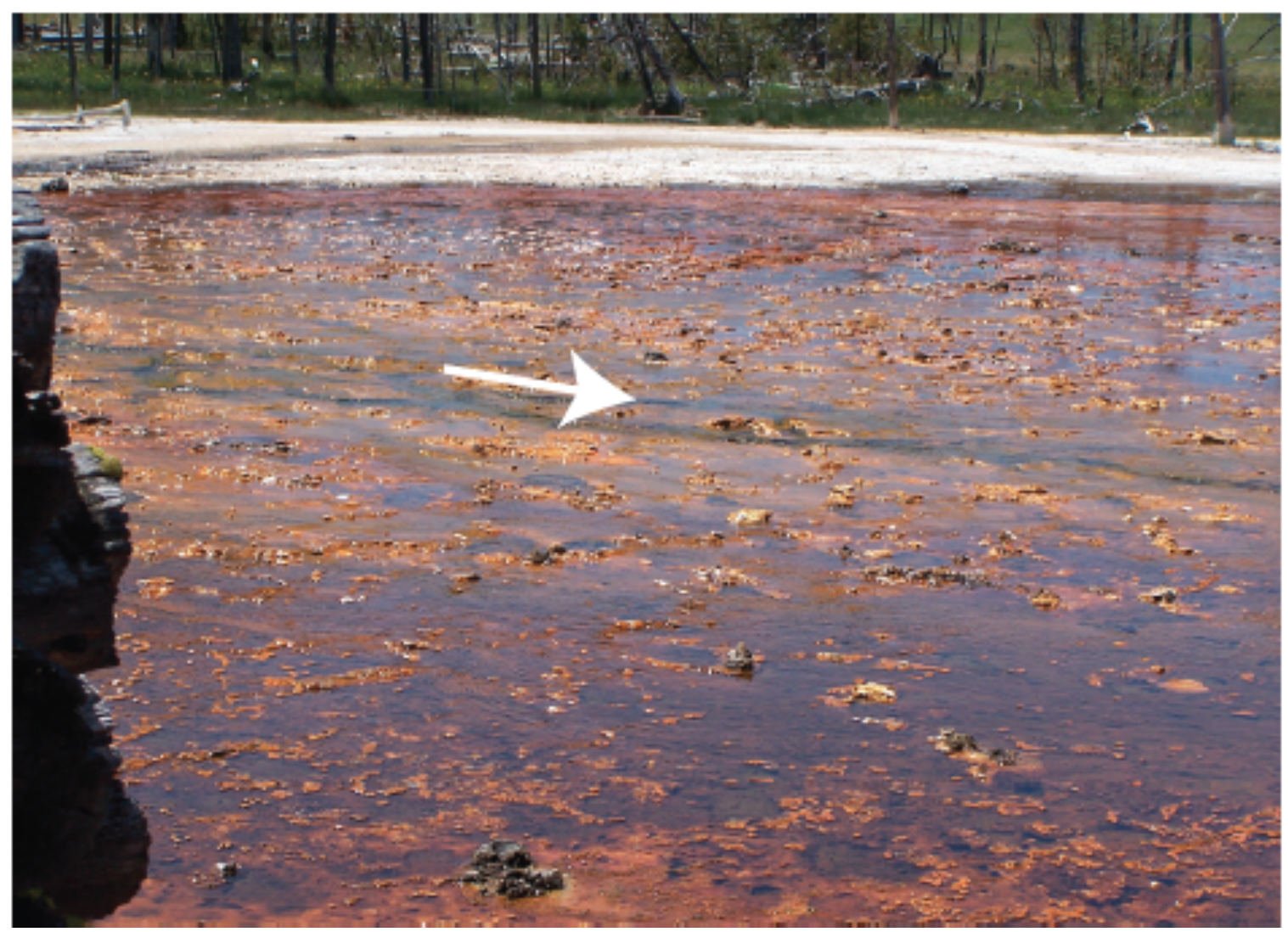

Fig. 14. This field photograph, taken just beyond the northwest corner of the bathhouse (visible on the left-hand side of the image) looking to the SW, illustrates the abrupt boundary between partially silicified Calothrix-dominated microbial mats in the active part of the system and the aerially exposed Calothrix biofacies in the adjacent dried sinter. Note the distinctive pigments of the dominant cyanobacteria in the different microbial mats (e.g., 
green in the hotter central channels and orange on the discharge apron). White arrow indicates general hydrothermal fluid flow direction.

A large area $\left(\sim 1 \mathrm{~m}^{2}\right)$ of solid aerially exposed Calothrix biofacies was located among the brecciated sinter located just beyond the active part of the hot spring system. The aerially exposed sample was collected from this solid block because it had not previously been disrupted (e.g., by bison tracks). Careful consideration was taken when selecting the aerially exposed samples to not only sample what was interpreted to be Calothrix biofacies, but also to collect material from areas beyond the perimeter that had not been submerged for at least three years.

\subsection{Partially Silicified Calothrix Biofacies (sample 110921.6)}

\subsubsection{Sample Collection}

As illustrated in the photographs of the hot spring system, the terraces in the partially silicified Calothrix biofacies zone are centimeters-to-decimeters in width (measured from the rim of "dams" created by the terraces to the downflow rim of the terrace) and several meters in length (measured as the lateral extent of a terrace in a direction oriented perpendicular to the flow).

For this study, the macroscale features of the partially silicified Calothrix biofacies of interest included the terraces (shown in top-down view in Figs. $15 \mathrm{~A}, \mathrm{~B}, \mathrm{D}$ ), the mats that colonized the terraces (also shown in top-down view in Fig, 15C), the terrace profile (visible when the terrace is viewed in cross-section, as in Fig 15D), and the laminae within the terraces (Fig 15E). As shown in Figure 15, Sample \#010921.6 was removed from the leading 
edge of a terrace in the partially silicified Calothrix biofacies zone. In

general, photo-documentation of the samples prior to and after collection

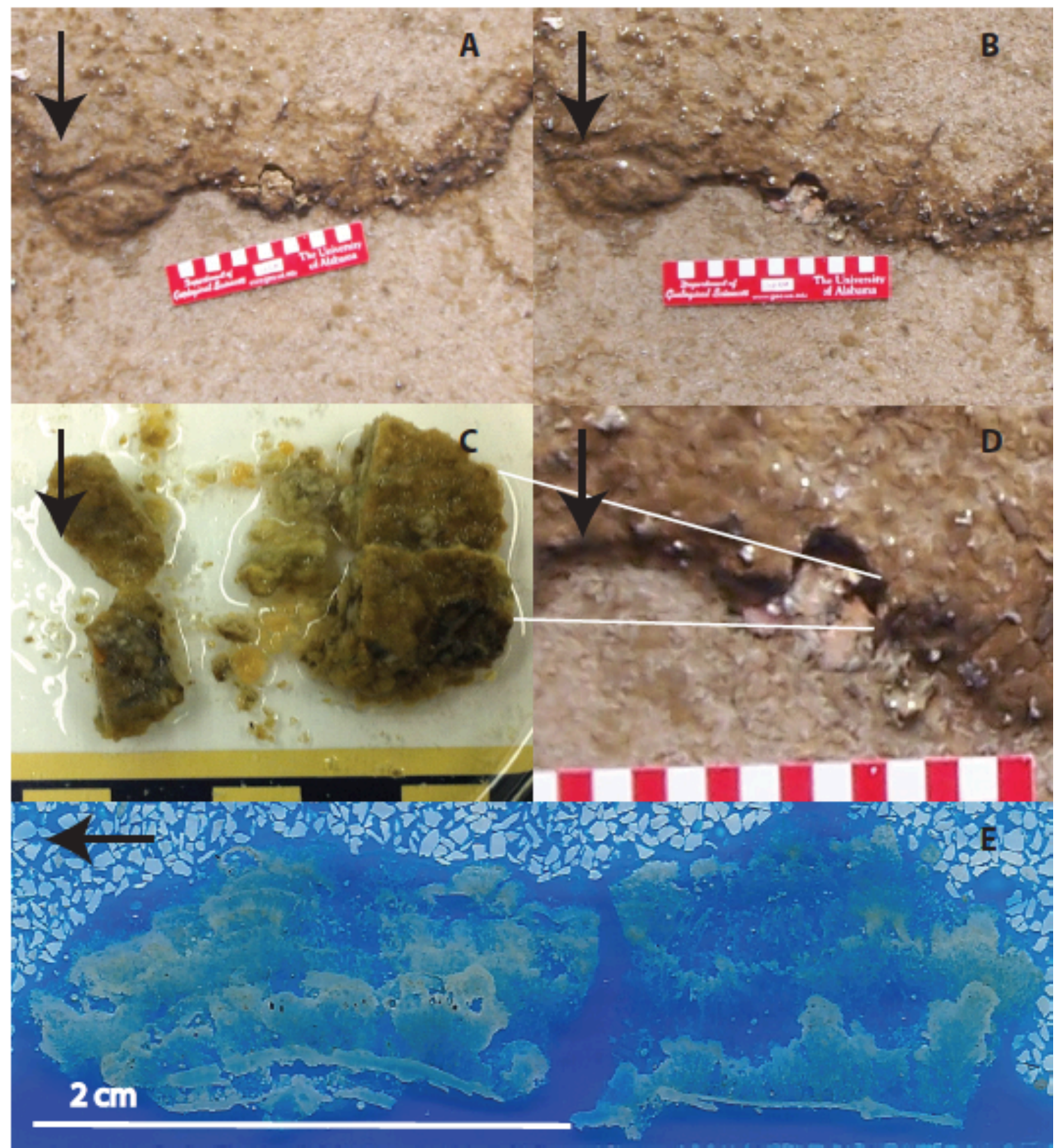

Fig. 15. Terrace sample (110921.6) collected from the east side of the Queen's Laundry hot spring in the partially silicified Calothrix biofacies zone. The sinter sample is smaller than the full terrace width, as evidenced by the darker color of the Calothrix mat and the presence of multiple curvi-linear features within the terrace. (A) and (B) Field photographs with centimeter scale showing sample collection site. (C) and (D) Photographs of the terrace sample collected from the field. The sample in the petri dish (C) illustrates how the silicified microbial mat was cut prior to preparation of the thin section shown in (E). (D) Image of sample extraction site, which made it possible to orient correctly the terrace sample post-extraction. (E) Resin embedded thin section of terrace. The sample was 
embedded in blue dyed resin with quart grains in the resin around the sample to ensure proper thickness of the thin section. Black arrows indicate hydrothermal fluid flow.

and prior to and after preparing them for destructive analyses in the laboratory made it possible to retain their orientation relative to the fluid flow (shown by the black arrows) for all spatial scales investigated.

While the field photographs and photographs of hand samples of the partially silicified Calothrix biofacies revealed their predominant morphological characteristics, petrographic thin sections were required to study the biofabrics in detail. For example, while it was possible to recognize that the biofabric of sample \#110921.6 is laminated and that it contains different types of structures within the laminae, the petrographic section was required to distinguish the different degrees of silicification, the structure profile, linkage, spacing, inheritance, and microstructure.

\subsubsection{Optical Light Microscopy - Stereoscope}

To identify and characterize the nature of the laminae and structures within the thin section of the biofacies, the biofacies samples were investigated with a stereoscope and a petrographic optical microscope. As described in Section 4.4.2a, laminae were identified on the basis of the location of a distinctive capping silica deposit, they were numbered, their microstructure profiles were identified and sub-numbered, the nature of the laminae contacts were described, and the lamina height was measured. In Section 4.4.2b, the Sub-Laminae Observations section, additional structural features that were associated with seasonal features are described. In Section 
4.4.2.c, the Structural Attributes Characterization section, the attributes characterized include profile, linkage, spacing, inheritance, and morphometric analyses (height and width).

\subsection{2.a Laminae Observations}

In the terrace sample from the partially silicified Calothrix biofacies, shown in Figure 16, six distinct laminae were identified. The laminae were numbered from the bottom to the top of the sample for ease of reference. The upper boundary of a lamina was a capping silica deposit. The capping silica areas are distinguished by a denser concentration of opaline silica that was almost always observed to occur in the upper section of each lamina. As a result, the capping silica deposit typically appears as a distinct white boundary between two laminae.

The bottom-most lamina (labeled "1") differs from the other five above it in terms of its topography and the amount of silica it contains. This lamina does not have a capping silica per se and the heavily silicified lamina is nearly completely mineralized. The upper surface of this lamina is laterally continuous and near planar (which puts it into the category of "sharp planar" sensu Coe et al., 2010, refer to nomenclature illustrated in Fig. 7). The thickness of the lamina (reported as height in Table 15 in Appendix 3) as observed in cross-section is fairly consistent along its length. Microbial cells or microbial structures were not observed within this lamina in either the silicified mat block or in the thin section. 
Lamina"2" has a pronounced laterally continuous capping silica deposit that consists of two parts: the basal part of the capping deposit at the top of the lamina is marked by an increase in the amount of opaline silica (relative to the bottom most section of the lamination). The top part of the capping deposit that defines the uppermost surface of the lamina is typically massive white opaline silica. Prominent microbial structures (e.g., shrubs, domical structures, etc.) have a thicker capping silica deposit than areas of the

A
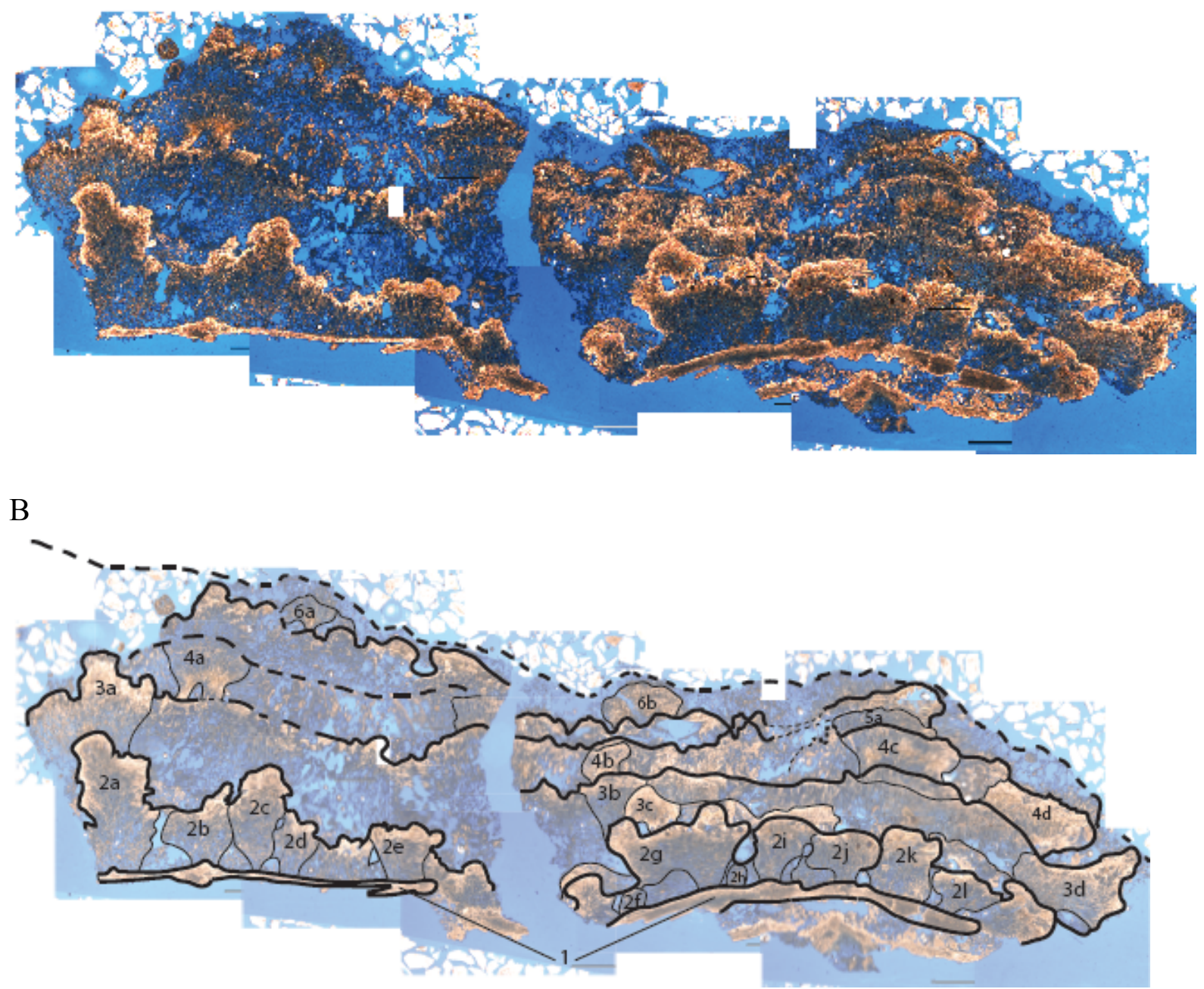

Fig. 16. Mosaic of stereoscope photomicrographs of the thin section (\#110921.6) of a terrace collected within the partially silicified Calothrix biofacies zone of Queen's Laundry hot spring. The sample was cut parallel to the flow direction to illustrate the fabric of the 
terrace sample in cross section. The fabric is comprised of different types of laminations that have different types of microstructures, as described in Section 4.2.3 below. Note the sample orientation and fluid flow are reversed compared to that shown in Fig. 15. (A) Nonannotated photomosaic illustrates the heavily silicified tops of laminations and prominent structures that were analyzed in this study. The transparency of the annotated photomosaic was decreased by $50 \%$ with the use of Adobe Illustrator CS4.

partially silicified biofacies without recognizable microbial structures. The upper surface of lamina two is sharp irregular (sensu nomenclature in Fig.

7). Abundant microbial structures are observed to comprise nearly the full width of the terrace sample. The thickness of the lamina (referred to hereafter as "lamina height") varied across the sample width. The greatest height differences occur toward the upstream end of the sample (i.e., the left side of the sample shown in Figure 16). Of note is the high number of distinctive microbial structures in this lamination.

Lamina " 3 " has a fairly uniform and recognizable capping silica deposit. Toward the upstream end of the sample the upper surface of the lamina is discontinuous in places. In general, the upper surface of this lamina is characterized as wavy and it contains four morphologically distinct microbial structures. The biofabric of the remaining lamina microstructure is not as developed as that within the microbial structures. The lamina height varies primarily because of the irregular topographic relief of the bottom of the lamina. This lamina thins near the terrace face.

Lamina "4" has a discontinuous capping silica deposit. Most of the capping silica deposit is observed on the right side of the thin section. However, on the left side it is discontinuous. The upper boundary of the lamina is characterized as wavy. There are four morphologically distinct 
microbial structures; the lamina height is much narrower than previous laminae; and the downstream margin of this lamina does not appear to advance beyond the position of the large structure observed in lamina " 3 ". Lamina " 5 " has a capping silica deposit that has variable thickness and is laterally discontinuous. The lamina terminates just beyond the apex (highest point) of the terrace sample toward the downstream end and terminates near the upstream end of the terrace. The nature of the upper lamina boundary varies laterally: on the left-hand side of the sample the boundary appears gradational wavy, in the center it is sharp irregular, and on the right it transitions to sharp wavy (sensu nomenclature in Fig. 7). The biofabric on the left side of the sample is not as organized and dense as it is within the structures on the right of the sample.

The uppermost lamination, lamina " 6 ", differs from the previously described lamina in that it lacks a capping silica deposit or any heavy silicification. The existing upper limit to the biofabric appears to be distorted and truncated. It is likely that these distortions occurred during the process of making the petrographic thin section of the sample. As such, the absence of a well-defined upper boundary for this lamina eliminated the possibility to measure the lamina height. In spite of such limitations, two small microbial structures were identified within this lamina.

The laminae observations are summarized as follows: most of the microbial structures occurred in lamina 2; the capping silica deposit was present in each of the lamina except on the modern accretionary surface 
(lamina 6); the lamina height decreased as the biofacies developed; the irregularity of the upper boundary of the lamina dampened as the microbial mat developed; and at this scale there is no morphological evidence that the topography of successive laminae are inherited.

\subsection{2.b Sub-Laminae and Topography}

Structures in the middle and upper laminae of the terrace profile have layers of minor silica deposition that are referred to here as sub-laminae (LL in Fig. 17). The sub-laminae appear similar to the silica capping deposits, but are a highly localized feature limited to the stratigraphic column of the terrace located under the downstream apex (topographic high) of the sample. The sub-lamina silica deposit has a gradational to wispy character: the silica deposit across the entire sample is not continuous and some lamina are not distinct (shown in Fig. 16 with a dashed rather than solid line).

There is a minor topographic low in the sub-lamina labeled " $t$ l" that occurs just upstream from the local topographic high (indicated by the red line in Fig. 17). Beneath this topographic low region, laminae 4 through 6 do not have continuous capping silica deposits and the biofabric appears less dense and less organized. The label " $\mathrm{m}$ " on the left side of this less dense region refers to the mottled microstructure (Fig. 17). 


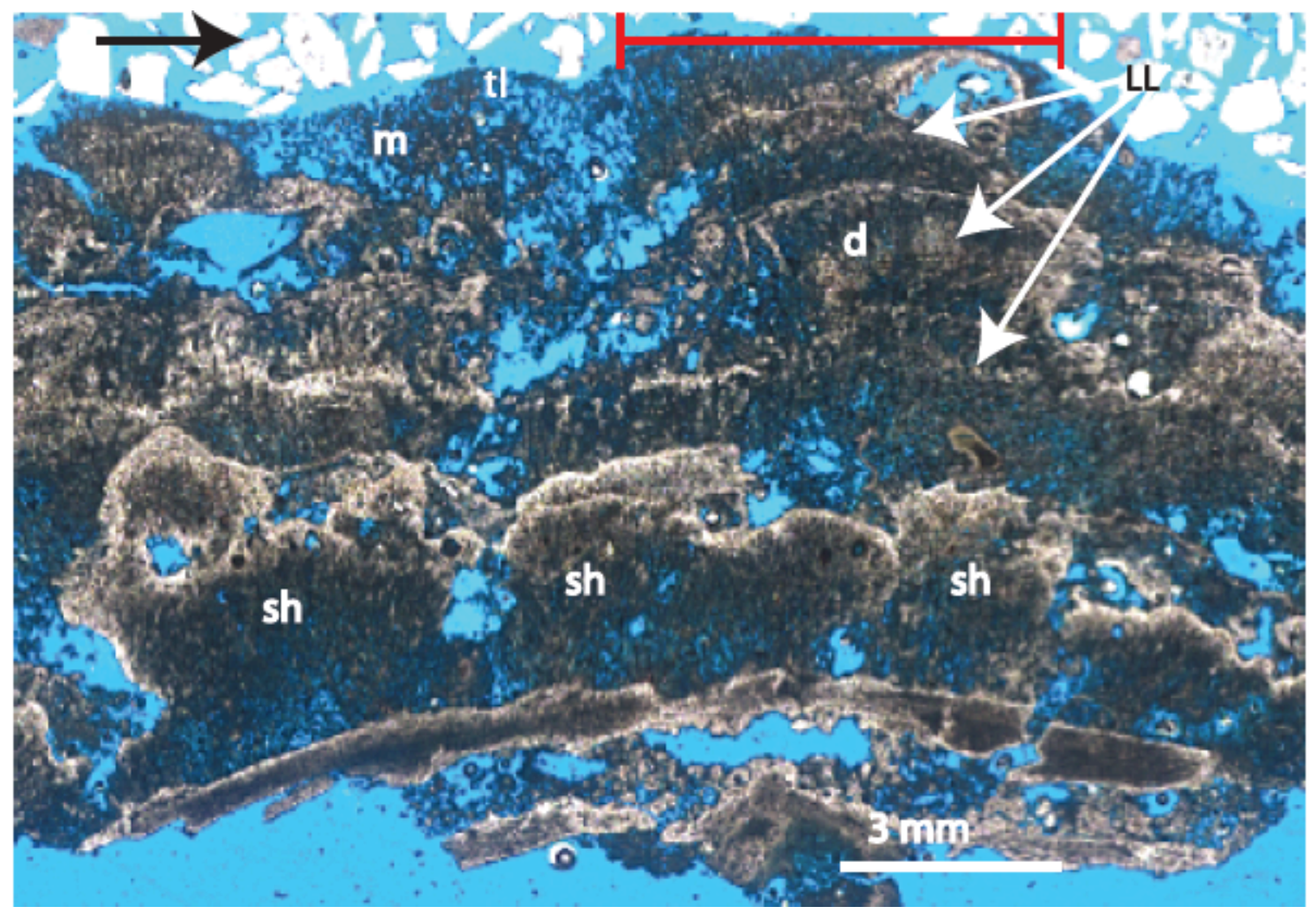

Fig. 17. The partially silicified Calothrix biofacies terrace sample 110921.6. Structures of note within the sample are: $\mathrm{sh}$ - shrub microbial structure, $\mathrm{d}$ - domical structure, $\mathrm{m}$ - mottle biofabric under the minor topographic low, $\mathrm{tl}$ - topographic low region, and LL - sublaminae. The localized silicified sub-lamina underneath the relatively high area of the sample is noted because both microbial cells and the sinter fabric are better preserved in this area. The black arrow indicates the direction of the hydrothermal fluid flow and the white arrows point to the sub-lamina (see Section 4.2.2b). The red line indicates the growth profile of the topographic high).

\subsection{2.c Microbial Structural Attributes}

The microbial structures observed within the partially silicified biofacies sample consisted of shrub (marked "sh", Fig. 17) and domical (marked "d", Fig. 17) structures. The shrub structures occurred in the lower lamina, while the domical structures occurred in the middle and upper laminae of the sample. The structures appear visually denser and less porous than the remaining areas of the biofabric within the sample, which appear to have a mottled appearance (marked "m", Fig. 17) as the fabric is more porous. 
Microbial structure attributes of the partially silicified biofacies sample, summarized in Table 2, included profile, linkage, spacing, and inheritance (as defined in Section 3.2.2 of the Methods Section). Two structures in the lowest lamina were partially linked whereas all other structures were unlinked, including those in successive laminae. Additionally the two structures in lamina 2 were nearly contiguous whereas all of the other structures were characterized as "open." Lamina and structural inheritance from the previous growth period overall was low for the entire sample.

Table 2. Summary of the characterized structural attributes associated with the partially silicified Calothrix biofacies terrace. Attributes include structure profile, whether the structures are linked, the spacing of the structures, and whether the structures reflected inheritance in their overall profile from the prior lamina.

\begin{tabular}{|c|c|c|c|c|c|}
\hline Sample & Struct. ID & Profile & Linkage & $\begin{array}{c}\text { Diameter }(\mathrm{mm}) \\
\text { and Spacing }\end{array}$ & Inheritance \\
\hline \multicolumn{6}{|l|}{110921.6} \\
\hline & $2 a$ & shrub & unlinked & 2.66 very close & low \\
\hline & $2 b$ & shrub & partly linked & 2.22 contiguous & low \\
\hline & $2 c$ & shrub & linked & 1.74 contiguous & low \\
\hline & $2 d$ & shrub & partly linked & 1.42 contiguous & low \\
\hline & $2 \mathrm{e}$ & shrub & unlinked & 2.32 close & low \\
\hline & $2 f$ & domical & par & 0.88 open & low \\
\hline & $2 g$ & shrub & partly linked & 4.31 very close & low \\
\hline & $2 \mathrm{~h}$ & domical & partly linked & 0.55 close & low \\
\hline & $2 i$ & shrub & partly linked & 2.01 very close & low \\
\hline & $2 j$ & shrub & partly linked & 2.29 very close & low \\
\hline & $2 \mathrm{k}$ & shrub & partly linked & 1.77 close & low \\
\hline & 21 & shrub & unlinked & 1.74 & low \\
\hline & $3 a$ & shrub & unlinked & 4.03 open & high \\
\hline & $3 b$ & shrub & unlinked & 1.61 contiguous & low \\
\hline & $3 c$ & dom-shrub & unlinked & 1.77 open & low \\
\hline & $3 d$ & shrub & unlinked & 4.21 open & low \\
\hline & $4 a$ & $\begin{array}{l}\text { domical } \\
\text { shrub }\end{array}$ & unlinked & 2.34 open & low \\
\hline & $4 b$ & domical & linked & 1.38 open & low \\
\hline & $4 c$ & domical & partly linked & 3.79 very close & intermediate \\
\hline & $4 d$ & domical & unlinked & open & low \\
\hline & $5 a$ & domical & unlinked & 3.57 open & intermediate \\
\hline & $6 a$ & $\begin{array}{l}\text { domical } \\
\text { shrub }\end{array}$ & unlinked & 1.74 open & intermediate \\
\hline & $6 b$ & domical & unlinked & 2.48 open & low \\
\hline
\end{tabular}


Morphometric analysis was performed on structures within the laminae of the terraces. The height and the width were measured with Image $($ after calibrating the measurement distances with a glass slide inscribed with a metric scale. The width of any one structure was then divided by its height to determine the flatness of the structure. Structures with a flatness value

Table 3. The heights of the partially silicified Calothrix dominated structures decreased and their profile became flatter with the upward development of the terrace. The table summarizes the results of the morphometric analysis of microbial structures within the partially silicified Calothrix biofacies terrace profile. The measurements were made with the use of ImageJ software.

\begin{tabular}{|c|c|c|c|c|}
\hline Sample & $\begin{array}{c}\text { Structure } \\
\text { identifier }\end{array}$ & $\begin{array}{l}\text { height (Fv) } \\
(\mathrm{mm})\end{array}$ & $\begin{array}{c}\text { width (Fh) } \\
(\mathrm{mm})\end{array}$ & $\begin{array}{l}\text { flatness } \\
(\mathrm{Fh} / \mathrm{Fv})\end{array}$ \\
\hline \multirow[t]{22}{*}{110921.6} & $2 a$ & 4.46 & 2.66 & 0.60 \\
\hline & $2 b$ & 2.61 & 2.22 & 0.85 \\
\hline & $2 c$ & 3.46 & 1.74 & 0.50 \\
\hline & $2 d$ & 2.04 & 1.42 & 0.70 \\
\hline & $2 e$ & 1.88 & 2.32 & 1.23 \\
\hline & $2 f$ & 0.71 & 0.57 & 0.81 \\
\hline & $2 \mathrm{~g}$ & 2.72 & 4.57 & 1.68 \\
\hline & $2 \mathrm{~h}$ & 0.72 & 0.68 & 0.94 \\
\hline & $2 i$ & 2.04 & 1.96 & 0.96 \\
\hline & $2 j$ & 1.76 & 2.40 & 1.37 \\
\hline & $2 k$ & 2.13 & 1.74 & 0.82 \\
\hline & 21 & 1.38 & 2.14 & 1.55 \\
\hline & $3 a$ & 2.55 & 4.03 & 1.58 \\
\hline & $3 b$ & 1.79 & 2.34 & 1.31 \\
\hline & $3 c$ & 1.50 & 1.84 & 1.23 \\
\hline & $4 a$ & 1.70 & 2.34 & 1.38 \\
\hline & $4 b$ & 1.06 & 1.38 & 1.31 \\
\hline & $4 c$ & 1.52 & 3.79 & 2.49 \\
\hline & $4 d$ & 1.64 & 2.86 & 1.74 \\
\hline & $5 a$ & 1.12 & 3.57 & 3.19 \\
\hline & $6 a$ & 1.04 & 1.74 & 1.67 \\
\hline & $6 b$ & 1.05 & 2.48 & 2.35 \\
\hline
\end{tabular}

greater than one are wider than they are tall (e.g., domical structures) and structures with a flatness value less than one are taller than they are wide (e.g., shrub structures). A geometric analysis was performed on all of the 
microbial structures within the biofacies sample. In general, the structures became increasing flat within successively higher laminae (Table 3).

\subsubsection{Optical Light Microscopy - Petrographic}

\subsection{3.a Calothrix filaments}

Calothrix is a sheathed, filamentous, cyanobacteria characterized by tapered ends and filament lengths that can exceed $500 \mu \mathrm{m}$. Typical Calothrix filament diameters are on the order of $10-12 \mu \mathrm{m}$ and the diameters of the sheath are typically $<22 \mu \mathrm{m}$ (Jones et al., 2003). Optical light microscopy observations revealed that Calothrix consisted of long, brown-sheathed filaments with tapered ends (Fig. 18).

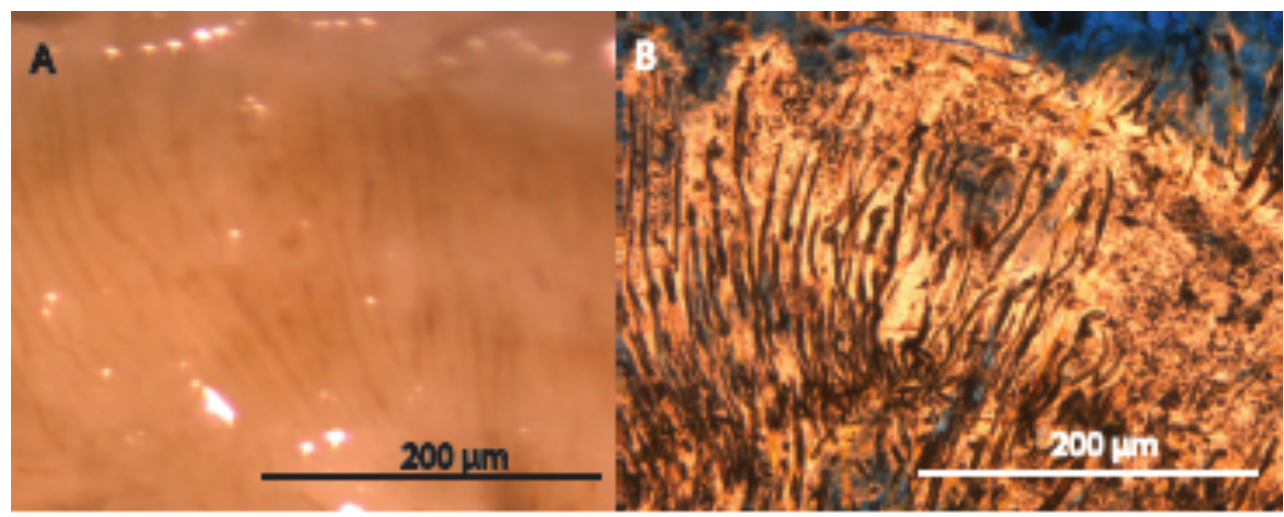

Fig. 18. Optical light microscopy images of a partially silicified Calothrix biofacies sample collected from a hot spring microbial mat. (A) Clean-cut edge of the bulk sample prior to thin section preparation. The brown filaments in near vertical orientation are morphologically consistent with Calothrix. (B) A petrographic thin section image of nearvertical brown filaments of Calothrix.

The length of the filaments could not always be determined as they were not always visible in their entirety. The overall morphological observations within the biofacies are consistent with a Calothrix dominated microbial community. Calothrix filaments were observed to be in near perpendicular 
orientations with respect to the growth surface. Only in a small, localized area at the base of the sample at the leading edge of the terrace face in lamina 3 were the filaments found to be in a near-horizontal orientation with respect to the growth surface.

\subsection{3.b Microstructure}

The microstructures of the partially silicified Calothrix terrace biofacies were identified in petrographic thin sections. Three different microstructures were identified in this study, shown schematically and in petrographic photomicrographs in Figure 19, based on their similarity to visually similar microstructures as defined by Komar et al. (1965). As shown in the schematic drawings of these microstructures, they include non uniformly wavy-ribboned, fragmentary lumpy, and irregularly lumpy.

- Non uniformly wavy-ribboned microstructures in the sample have a noticeably higher microbial density than the surrounding biofabric. The microorganisms are near parallel and when they are associated with silica deposition they produce a dense microstructure.

- Fragmentary ribboned microstructures display a lower density of microbial filaments in the field of view, silica deposition associated with the filaments, and an increase in porosity.

- Irregularly lumpy microstructures characterized the edges of isolated microbial structures, areas between structures (intermound space), and the biofabric upstream from the terrace (laminae 4-6). These 
biofabrics were comprised of fewer microorganisms and, as a result, lesser amounts of silica. Depending upon the visual assessment of microbial population, the amount of unoccupied blue resin and

\section{Sample 110921.6 Biofacies}

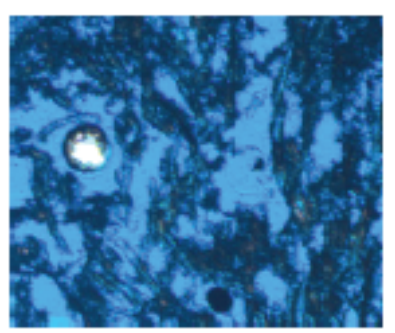

irregularly lumpy

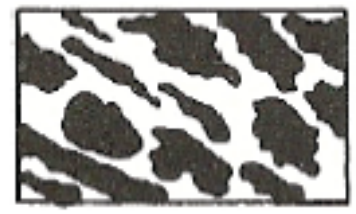

fragmentary ribboned
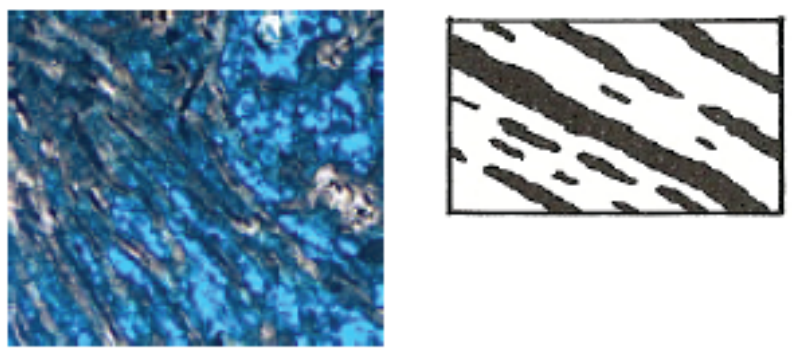

non uniformly wavy-ribboned
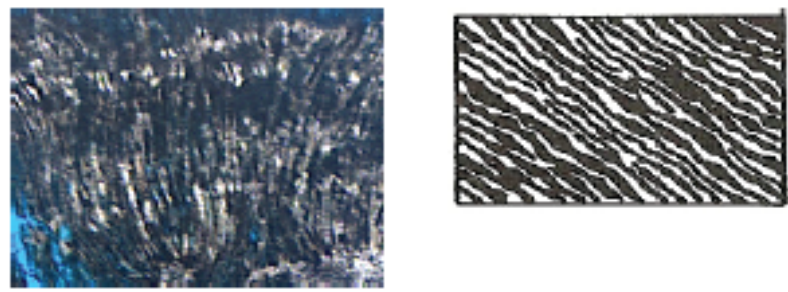

Fig. 19. Three microstructures were observed within the partially silicified Calothrix biofacies sample: irregularly lumpy, fragmentary ribboned, and non uniformly wavyribboned (shown in left column of figure). The microstructure patterns of the partially silicified biofabrics infer microbial abundance and porosity of the local biofabric. The porosity is higher and microbial density much less in the irregular lumpy microstructure when compared against the two observed shrub microstructures. In the right column are corresponding illustrations by Komar et al. (1965) where the dark represents microorganisms and silica present in the thin section and the white is the blue dyed resin.

comparison to published microstructure types, these microstructures were referred to as either fragmentary lumpy or irregularly lumpy. 


\subsection{3.c Laminae development}

Calothrix filaments were found to have colonized different types of surfaces in the biofacies terrace samples. These surfaces included silica precipitates (e.g., former accretionary surface), detrital materials (e.g., grains of country rock, brecciated sinter, and dislodged partly silicified biofacies), and biological materials (e.g., microbial cells, biofilms, mats, and their degraded remains).

\subsection{3.c.i Microbial colonization on silica precipitates}

An example of microbial colonization on silica precipitates is shown in Figure 20, which illustrates colonization of Calothrix on the basal lamina. Note the narrower filaments, interpreted to be the cyanobacterium Phormidium, entombed within the lamina (Fig. 20A). The observed colonization of accretionary surfaces ranged from a few, isolated, near vertical, microorganisms attached at or very near the substratum surface to a few microbes, small bushy clusters, and groups of a few microbes in near proximity to one another. 


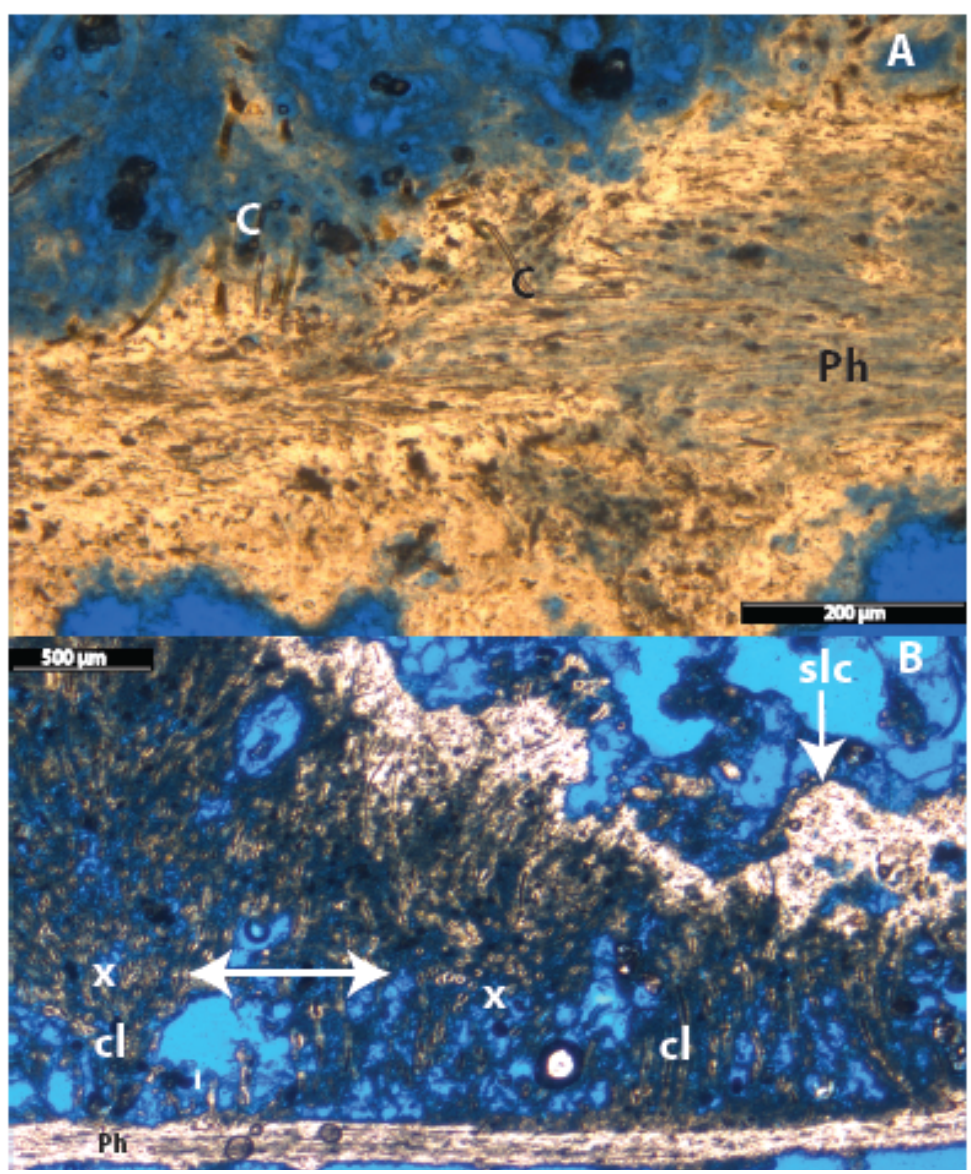

Fig. 20. Laminae development from a substratum surface does not appear to be heavily colonized by microorganisms when compared to the microbial abundance higher up in the lamina. (A) The relatively flat substratum, interpreted to be Phormidium (Ph), surface is not heavily colonized and the biofabric is markedly different from that of the lamina above. (A) Individual microorganisms and small clusters (cl) of Calothrix, labeled $\mathrm{C}$, colonize the flat substratum surface. A potential second colonization occurred higher up in the lamina as many microorganisms are viewed in cross section (x) as microbial abundance increases and are in viewed here in cross section. The silica "capping" layer (slc) denoting the boundary between lamina is easily viewed.

\subsection{3.c.ii Microbial Colonization on Detrital Materials}

\section{Microorganisms were observed to have colonized small detrital grains of}

brecciated sinter and bits of dislodged biofacies (Fig. 21). Detritus can be

introduced into the hydrothermal system through wind, rain events, and

animal activity. Once introduced into or dislodged in the hydrothermal 


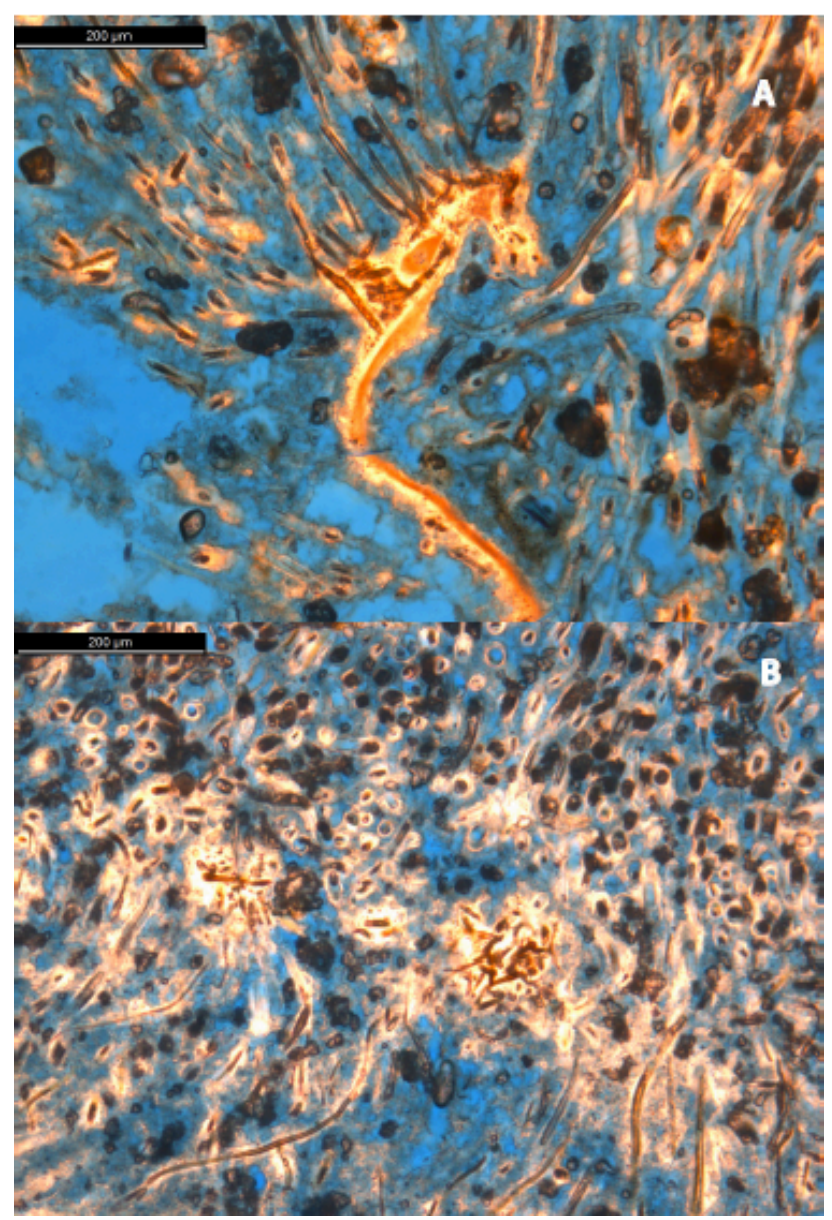

Fig. 21. Optical light microscopy images of the petrographic thin section of the Calothrix biofacies sample show of microbial colonization on: (A) an apparent piece of dislodged biofacies, and (B) on detrital input with the hot spring system.

system, detrital material may be relocated via hydrothermal fluid flow and other perturbation events. Detrital material observed in Figure 21, the upper surface of a detrital grain was colonized with filaments in near vertical to irregular orientation, though no microorganisms appeared to have colonized the underside of the detritus.

\subsection{3.c.iii Microbial Colonization on Biological Materials}

Microbial densities tended to increase as the structures within the laminae continued to grow (Fig. 22). The increased density could be attributed to 


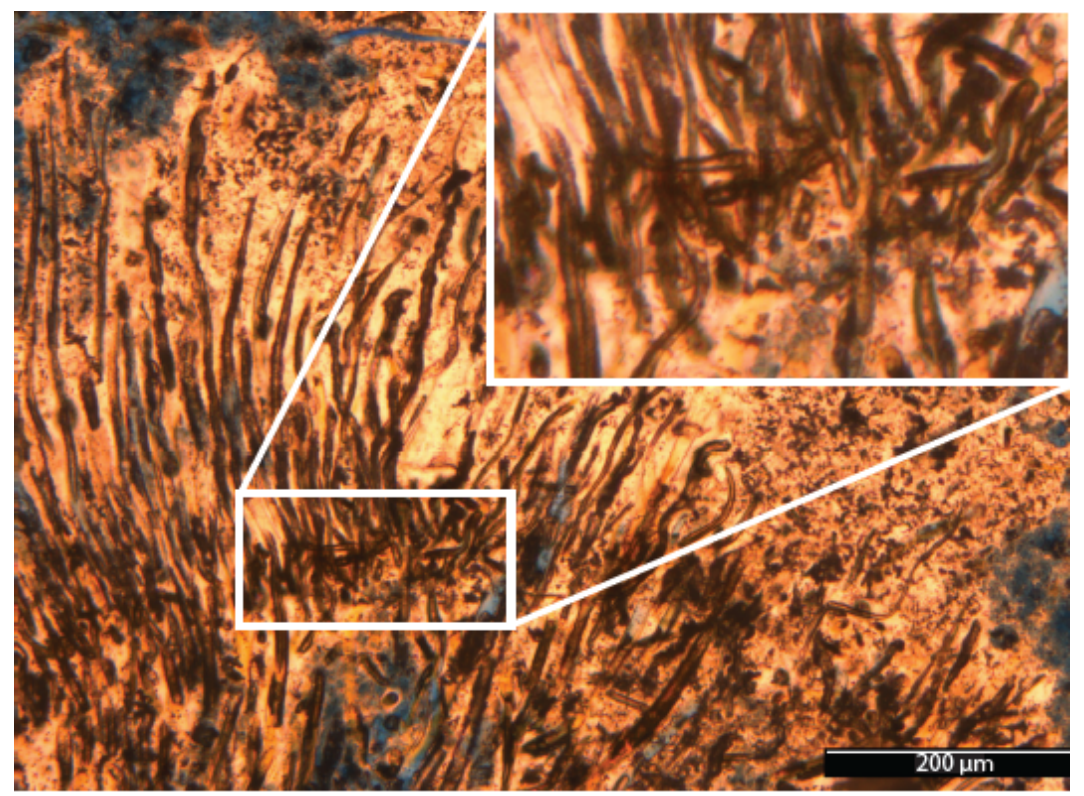

Fig. 22. Microorganisms were observed to be entombed, in near vertical orientation, within the full height of the capping silica layer. Also, though not shown in this image, many microbes were observed to escape entombment as the filaments protruded from the capping silica layer and into the next successive lamina. Inset: A small percentage of microorganisms were observed to be in near horizontal orientation within the capping silica layer.

colonization by additional or new growth of Calothrix filaments. Some filaments were observed in cross and oblique section near a level where new colonization was observed. Repeated colonization of shrub or domical structures by filaments tended to define their three dimensional nature.

\subsubsection{Scanning Electron Microscopy}

The scanning electron microscope (SEM) analysis provided additional morphological information about the partially silicified Calothrix biofacies sample (Fig. 23). Additional details included more precise observations of filament and sheath diameters, which were consistent with those reported for Calothrix in the literature. The characteristic palisade fabric texture was 
observed. Thus, the overall morphological observations of the biofabric was consistent with Calothrix dominated microbial communities and biofabrics.

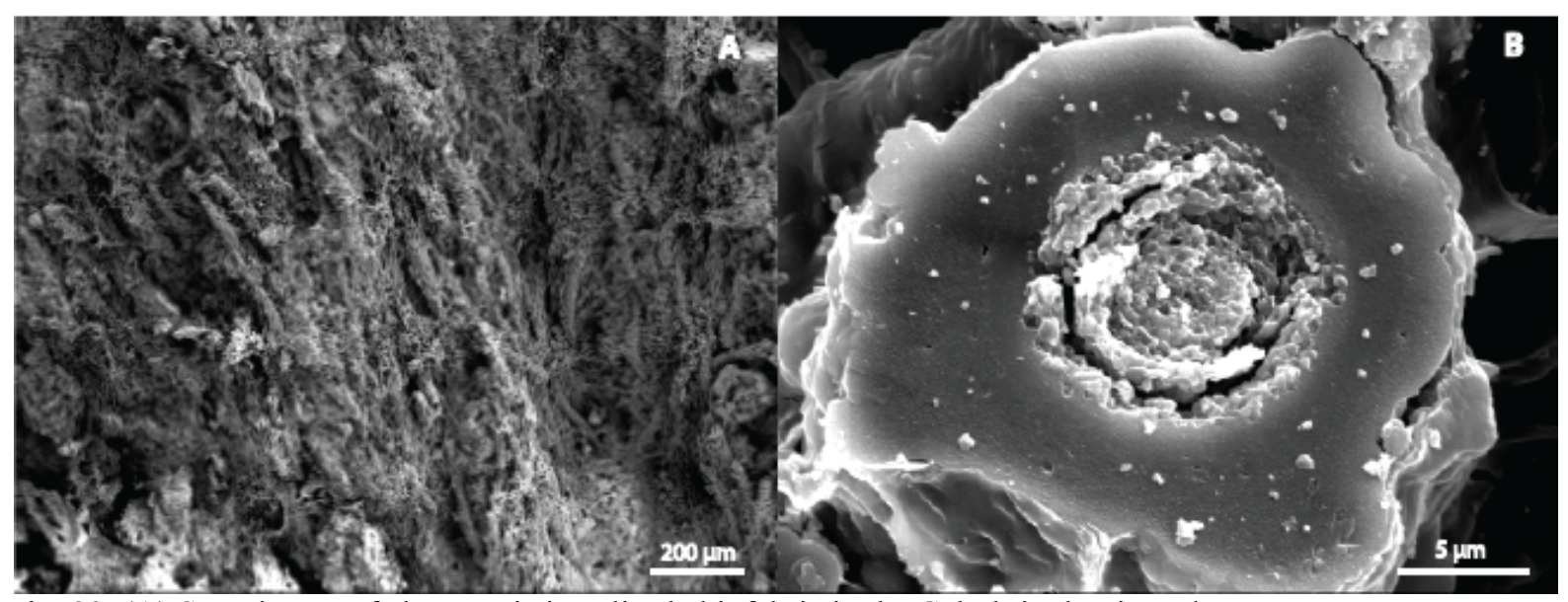

Fig. 23. (A) SEM image of characteristic palisade biofabric in the Calothrix dominated niche of alkaline, silica depositing hydrothermal systems. (B) SEM image of the crosssection of a fractured silicified Calothrix filament.

4.5 Aerially Exposed Calothrix Biofacies (sample 110919.24B)

\subsubsection{Sample Collection}

The aerially exposed biofacies sample collection site located beyond the perimeter of the active drainage apron. A large, intact section of what appeared to be aerially exposed Calothrix biofacies deposit was available for sampling. Morphologically, the lithified sinter consisted of curvi-linear terrace features with a spatial occurrence similar to the terraces observed in the partially silicified Calothrix biofacies of the active drainage apron (Fig. 24). Initial inspection in the field revealed that the Calothrix-like lithified sinters were internally laminated and characterized by a silicified palisade biofabric, a characteristic feature of the Calothrix biofacies-lithofaciestaphofacies model of Cady and Farmer (sensu Walter, 1976; Fig. 4). 


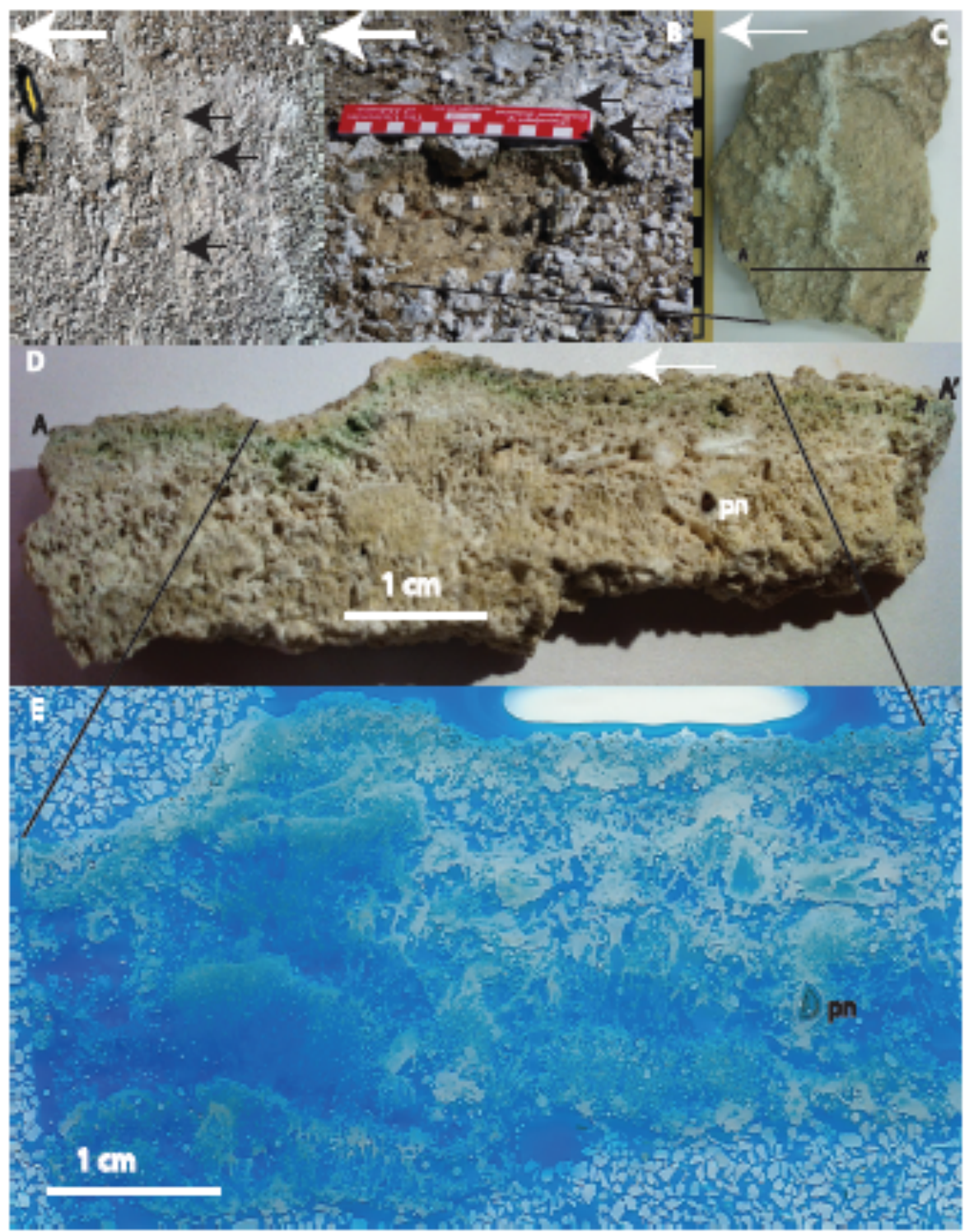

Fig. 24. Multiscale view (field to thin section) of the aerially exposed Calothrix biofacies sample described in detail in this study (sample \#110919.24B). (A) Top-down field photograph of the intact Calothrix-like sinter deposit located just beyond the perimeter of the modern drainage apron. (B) Oblique photo of sample collection site. (C) Top-down photograph of the bulk sample. (D) Sawn surface of the bulk sample from which the thin section was made. (E) Petrographic thin section of the lithified sinter sample. Knife in image (A) is $10 \mathrm{~cm}$, scale bars in (B) and (C) are centimeter increments. The white arrows in images $(\mathrm{A}-\mathrm{D})$ indicate past hydrothermal fluid flow direction and black arrows point to curvi-linear terraces. The pn label is for a pine needle entombed in the sample and presented in cross-section.

\subsubsection{Optical Light Microscopy - Stereoscope}


The stereoscope was used to characterize the nature of the lamina and structures within the aerially exposed biofacies thin section (\#110919.24B). As described in the Laminae Observations section below, features characterized included formal identification and numbering of individual lamina, an assessment of the degree of uniformity of the capping silica and its distinctiveness, the nature of the laminae contacts, and the lamina height. The attributes characterized include profile, linkage, spacing, inheritance, and morphometric analyses (height and width) performed with ImageJ.

\subsection{2.a Laminae Observations}

The aerially exposed silicified biofacies sample has six distinct laminae (Fig. 25). The laminae were numbered from the bottom to top lamination for ease of reference. As with the partially silicified biofacies laminae, the upper boundary of a lamina was a capping silica layer. Below is a description of features identified in each of the six lamina that are illustrated in Figure 25 (a transmitted light stereoscope image).

The basal lamina ("1") is has a discontinuous capping silica deposit and the upper surface of this lamina is sharp irregular. Note the limited width of the lamina in the sample, though the lamina height (based upon the upper surface profile) varies.

Lamina " 2 " has a fairly distinct and continuous capping silica deposit that varies in thickness. The upper surface of the lamina is characterized as wavy. There is one small morphologically distinct microbial structure located near the highest part of the growth surface. 


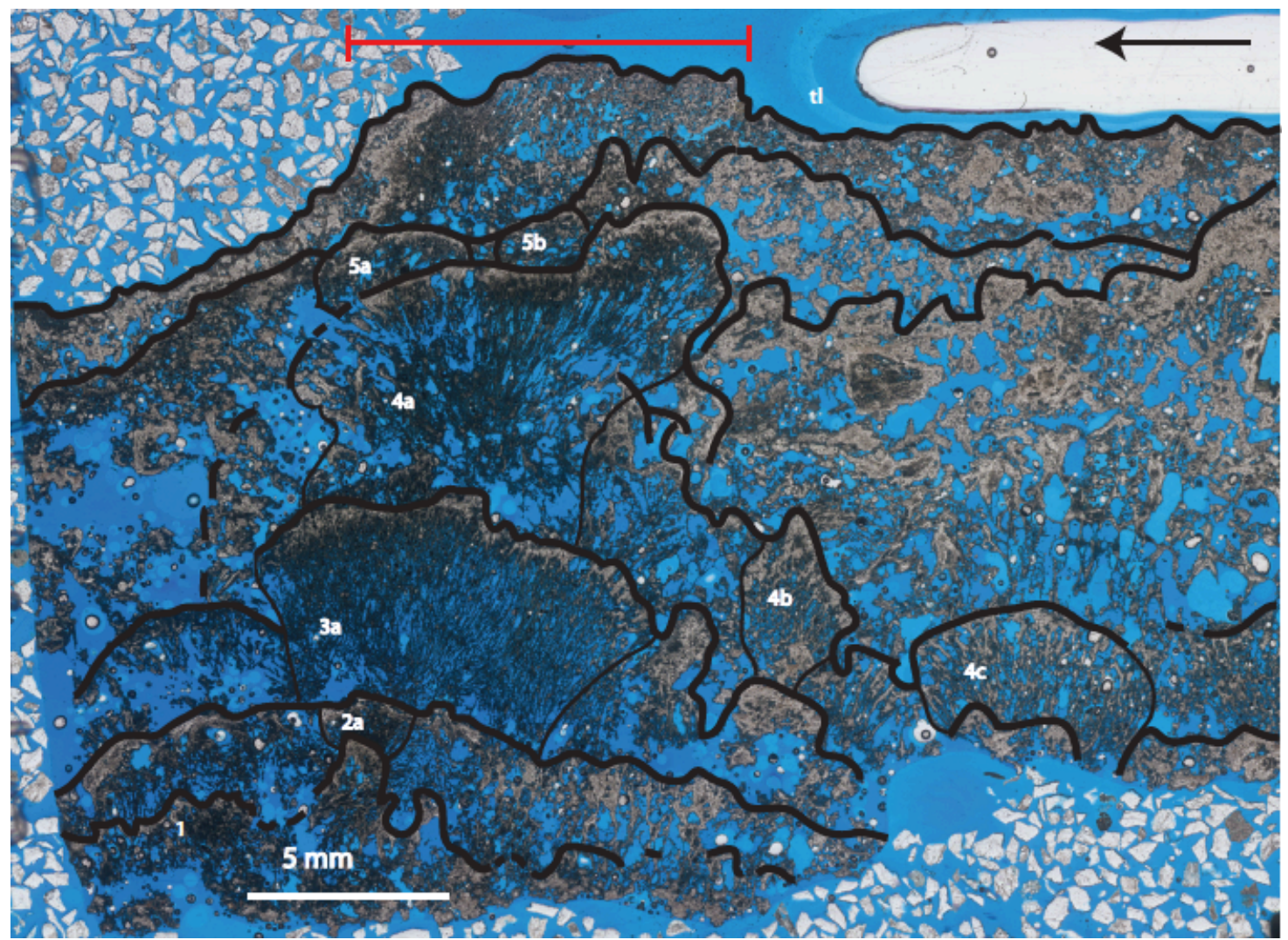

Fig. 25. Aerially exposed Calothrix biofacies sample - a petrographic thin section scanned using transmitted light — contains preserved intact structures and laminations. The silicified biofabric behind the terrace high (column under the red line) does not appear to have retained its original structure and appears to be in a topographic low region (labeled tl). Distinct microbial structures are numbered and the black arrow indicates the direction of hydrothermal fluid flow based on the orientation of the curvi-linear apex of the terrace.

Lamina 3 thickens upstream from the terrace and nearly disappears

downstream from it. The upper surface of the lamina is gradational irregular.

The lamina height varies across the sample width. This lamina, too, has a

limited width, but contains one well preserved microbial structure that

extends over the full height of the lamina.

Lamina " 4 " has a discontinuous capping silica deposit downstream of the terrace and a prominent capping silica deposit that defines the upper growth 
limit of the microbial structure. The upper surface of the lamina is gradational irregular (sensu nomenclature in Fig. 7). There is a prominent hybrid microbial structure that appears to be a combination of a shrub and a domical structure. Two additional microbial structures include a domical and a shrub structure. The lamina height varies wildly, due in part to the irregular topographic relief of the bottom and top of the lamina.

Lamina " 5 " has a continuous capping silica deposit from the downstream edge to the terrace stratigraphic column. Upstream from the terrace stratigraphic column the position of the capping silica layer was less obvious. Two small microbial structures were identified on the basis of the capping silica deposit profile and the associated silicified biofabric. The lamina height at the terrace stratigraphic column narrows significantly when compared to the previous two laminae. The lamina height downstream from the terrace stratigraphic column cannot be interpreted due to the lack of continuous capping silica from the previous lamina.

Lamina "6" has a thick and distinct capping silica deposit from just beyond the terrace apex and it continues downstream. The upstream capping silica layer apparently broke loose when a slab of the sample was cut from the bulk sample for a thin section. There were not any distinct microbial structures within this lamina. The lamina height narrows downstream from the terrace and its not clear upstream from the terrace. A minor topographic low occurs upstream from the terrace within the sample (labeled tl in Figure 25). The topographic low was observed on the 
bulk sample and well as recorded in images prior to cutting the bulk sample.

Laminae 3 and 4 behind the terrace have capping silica layer sections that can be connected to reveal an upper surface for each lamina. The capping silica broke off of lamina 6 , but reflects a surface that is very near the upper limit of the growth profile for this lamina.

In summary, the microbial structures in the Calothrix lithofacies were observed in laminae 2 through 5 (labeled in Figure 25), while microbial structures were absent in lamina 1 and lamina 6 . The microbial structures visually appeared denser and less porous than the biofabric upstream and downstream from the terrace apex. Lithified biofabrics that were not part of any microbial structure did not appear to have remained intact. The appearance of the prominent microbial structures within laminae 3 and 4 remain distinct and many filamentous microorganisms are present.

\subsection{2.b Microbial Structure Attributes Characterization}

Microbial structural attributes include profile, linkage, spacing, and inheritance (Table 4). The profile of microbial structures included shrub and domical. The microbial structures in laminae 4 and 5 were closely linked. Inheritance from the previous growth period overall was low.

Table 4. Summary of the structural attributes characterized with the use of a petrographic thin section in the aerially exposed Calothrix biofacies . Attributes included structure profile, the linkage and spacing of the structures, and the degree of inheritance. 


\begin{tabular}{|c|c|c|c|c|c|}
\hline Sample & Struct ID & Profile & Linkage & $\begin{array}{c}\text { Diameter }(\mathrm{mm}) \\
\text { and Spacing }\end{array}$ & Inheritance \\
\hline \multicolumn{6}{|c|}{$110921.24 \mathrm{~B}$} \\
\hline & $2 a$ & domical & unlinked & 1.93 isolated & low \\
\hline & $3 a$ & domical & unlinked & 7.80 isolated & low \\
\hline & $4 a$ & shrub & unlinked & 8.51 very close & intermediate \\
\hline & $4 b$ & shrub & unlinked & 2.64 very close & low \\
\hline & $4 c$ & domical & unlinked & 4.4 very close & low \\
\hline & $5 a$ & domical & unlinked & 2.8 very close & low \\
\hline & $5 b$ & domical & & 1.62 very close & low \\
\hline
\end{tabular}

Morphometric analysis was performed on the microbial structures within the terrace profile. The height and the width were measured with the use of ImageJ. The width was then divided by the height to determine the flatness of the structures within the terrace profile. Microbial structures with a flatness value greater than one are wider than they are tall and structures with a flatness value less than one are taller than they are wide. Shrub structures tended to have values less than one, while domical structures tended to have values greater than one (Table 5). Geometric analysis of the microbial structures revealed an overall trend of flatter microbial structures later in the growth history of the terrace.

Table 5. The heights of the Calothrix dominated structures decreased and their profile became flatter with the upward development of the terrace. The table summarizes the morphometric analysis (height and width) of microbial structures in the petrographic thin section of the aerially exposed Calothrix biofacies sample. The measurements were made with the use of ImageJ software.

\begin{tabular}{rcccc} 
Sample & $\begin{array}{c}\text { Structure } \\
\text { identifier }\end{array}$ & $\begin{array}{c}\text { height (Fv) } \\
(\mathrm{mm})\end{array}$ & $\begin{array}{c}\text { width (Fh) } \\
(\mathrm{mm})\end{array}$ & $\begin{array}{c}\text { flatness } \\
\text { (Fh/Fv) }\end{array}$ \\
\hline $110921.24 \mathrm{~B}$ & $2 \mathrm{a}$ & 1.113 & 2.072 & 1.862 \\
& $3 a$ & 5.85 & 9.552 & 1.632 \\
$4 \mathrm{a}$ & 9.003 & 10.588 & 1.176 \\
& $4 \mathrm{~b}$ & 3.051 & 3.031 & 0.767 \\
& $4 \mathrm{c}$ & 3.529 & 5.857 & 1.659 \\
& $5 \mathrm{a}$ & 2.356 & 4.532 & 1.924 \\
& $5 \mathrm{~b}$ & 1.759 & 3.042 & 1.729
\end{tabular}




\subsubsection{Optical Light Microscopy - Petrographic}

The petrographic microscope was used to identify and characterize the microstructures of the aerially exposed Calothrix terrace biofacies in thin sections. To characterize the microstructures in the aerially exposed sample, observations related to silica deposition and microbial abundance were performed. Lastly, morphological observations of the filamentous microorganisms were made to provide laboratory confirmation that the predominant filamentous microorganisms were consistent with Calothrix.

\subsection{3.a Microstructure}

Four different microstructures characterized as a function of the growth history of the local topographic high are: non uniformly wavy-ribboned, fragmentary ribboned, fragmentary lumpy, and irregularly lumpy (Fig. 26). Some of the upstream edges of microbial structures were fragmentary lumpy or fragmentary ribboned. The microbial structures were observed to have non uniformly wavy-ribboned microstructure. Upstream from the growth history of the local topographic high lays a topographic low with irregularly lumpy microstructure.

- Non uniformly wavy ribboned microstructures in the sample have a noticeably higher microbial density that the surrounding biofabric. The microorganisms appear to align near parallel within the microstructure and when the associated silica deposition is taken into 
account the resultant pattern closely resembles the non uniformly

wavy ribboned stromatolite microstructure pattern reported by

Komar et al. (1965).

- Fragmentary ribboned microstructures in the sample are similar to

the non uniformly wavy-ribboned. The differences are less microbial

density with deposited silica and an increase in porosity.

\section{Sample 110921.24B Lithofacies}

fragmentary lumpy

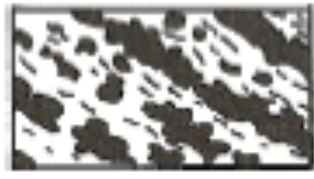

irregularly lumpy
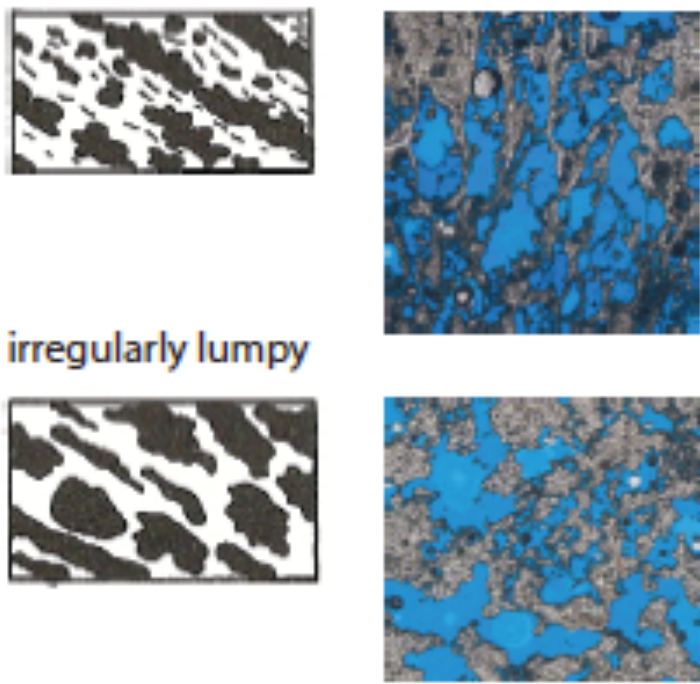

fragmentary ribboned
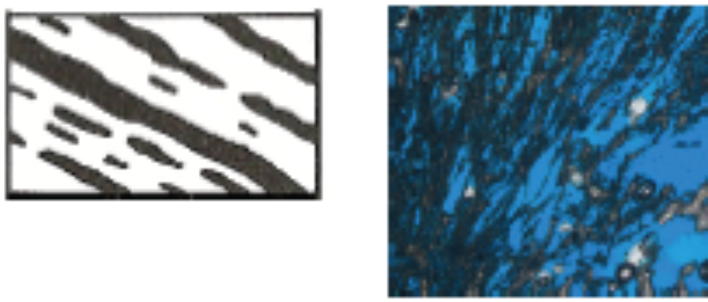

non uniformly wavy-ribboned
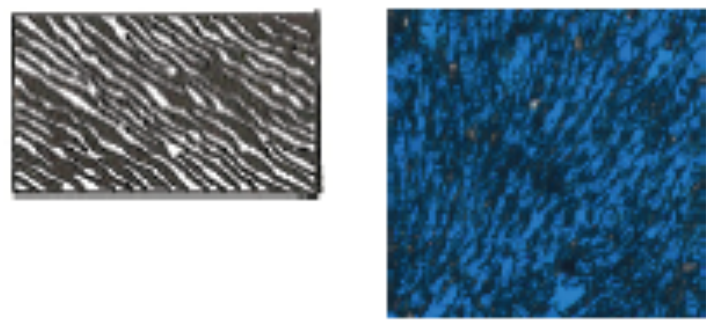
Fig. 26. The four microstructures observed within the aerially exposed Calothrix biofacies sample: fragmentary lumpy, irregularly lumpy, fragmentary ribboned and non uniformly wavy-ribboned (shown in left column of figure). Fragmentary lumpy, fragmentary ribboned and non uniformly wavy-ribboned were observed within microbial shrubs. The microstructure patterns of the biofabrics infer microbial abundance and porosity of the local biofabric. The porosity is higher and microbial density much less in the irregular lumpy microstructure when compared against the two observed shrub microstructures. In the left column are corresponding illustrations by Hofmann $(1968,1969)$ where the dark represents microorganisms and silica present in the thin section and the white is the blue dyed resin.

- The edges of isolated structures, areas between structures

(intermound space), and the biofabric upstream and downstream

from the terrace (laminae 4-6) were comprised of fewer

microorganisms and, as a result, lesser amounts of silica. These

biofabrics were characterized as either fragmentary lumpy or

irregularly lumpy depending upon visual assessment of the microbial

population, the amount of unoccupied blue resin, and comparison to

published microstructure types.

\subsection{3.b Calothrix Filaments}

Microbial observations of filamentous Calothrix in the aerially exposed

sample via optical light microscopy revealed that they consisted primarily of

long slender brown filamentous microorganisms that were, for the most part,

near perpendicular to the growth surface (Fig. 27). The length could not be 


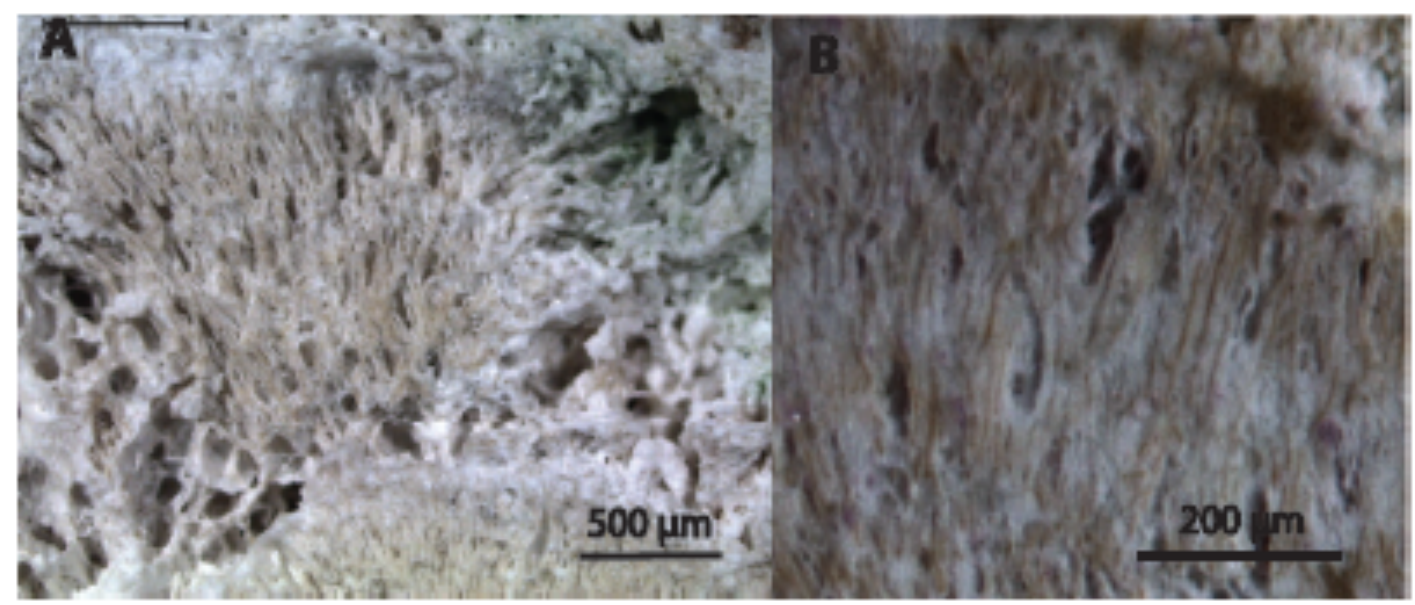

Fig. 27. Stereomicroscopy images of Calothrix dominated microbial structures in the lithofacies. The preserved tan filaments microorganisms observable, especially in Figure B, are consistent with Calothrix. (A) Image of a domical shrub and the tan Calothrix filaments. The domical microbial structure is denser than the surrounding microstructure. (B) Tan Calothrix filamentous microorganisms entombed within silica.

determined as the full lengths of the microorganisms were not visible. The filamentous microorganisms were not as abundant as what was observed in the biofacies, but they were quite prevalent within microbial structures. The overall microstructure and observable filamentous microorganisms within the lithofacies are consistent with a Calothrix dominated microbial community.

\subsection{3.c.i Microbial colonization on silica precipitates}

Microbial filaments in the aerially exposed Calothrix biofacies samples were observed to colonize the same types of surfaces they did in the partially silicified Calothrix biofacies samples. In general, the laminae were colonized by a few microbes, small bushy clusters of microbes, and groups of a few microbes in near proximity to one another. The microbial presence and influence on the growth of the shrubs was observed to increase with the 
height of the shrub. Microbial colonization contributed to the morphology of the growth profile.

\subsection{3.c.ii Non-laminae surface growth}

A few non-laminae surfaces appear to have been colonized by microorganisms. Some small sub-angular to sub-rounded whitish-grey grains in the sample appear to be brecciated sinter. The grains were consistent with silica deposited in the sample and they provided another surface for microorganisms to establish themselves. The small, brecciated sinters appear to have been colonized on the upper surface with filaments in near vertical orientation and near perpendicular to the growth surface orientation.

\subsection{3.d Aerially exposed capping silica deposit}

The capping silica deposit exposed at the top of aerially exposed samples (110919.24B and 111001.10) appeared different than other capping silica deposit within the sample (Fig. 28). The top-most subaerially exposed 


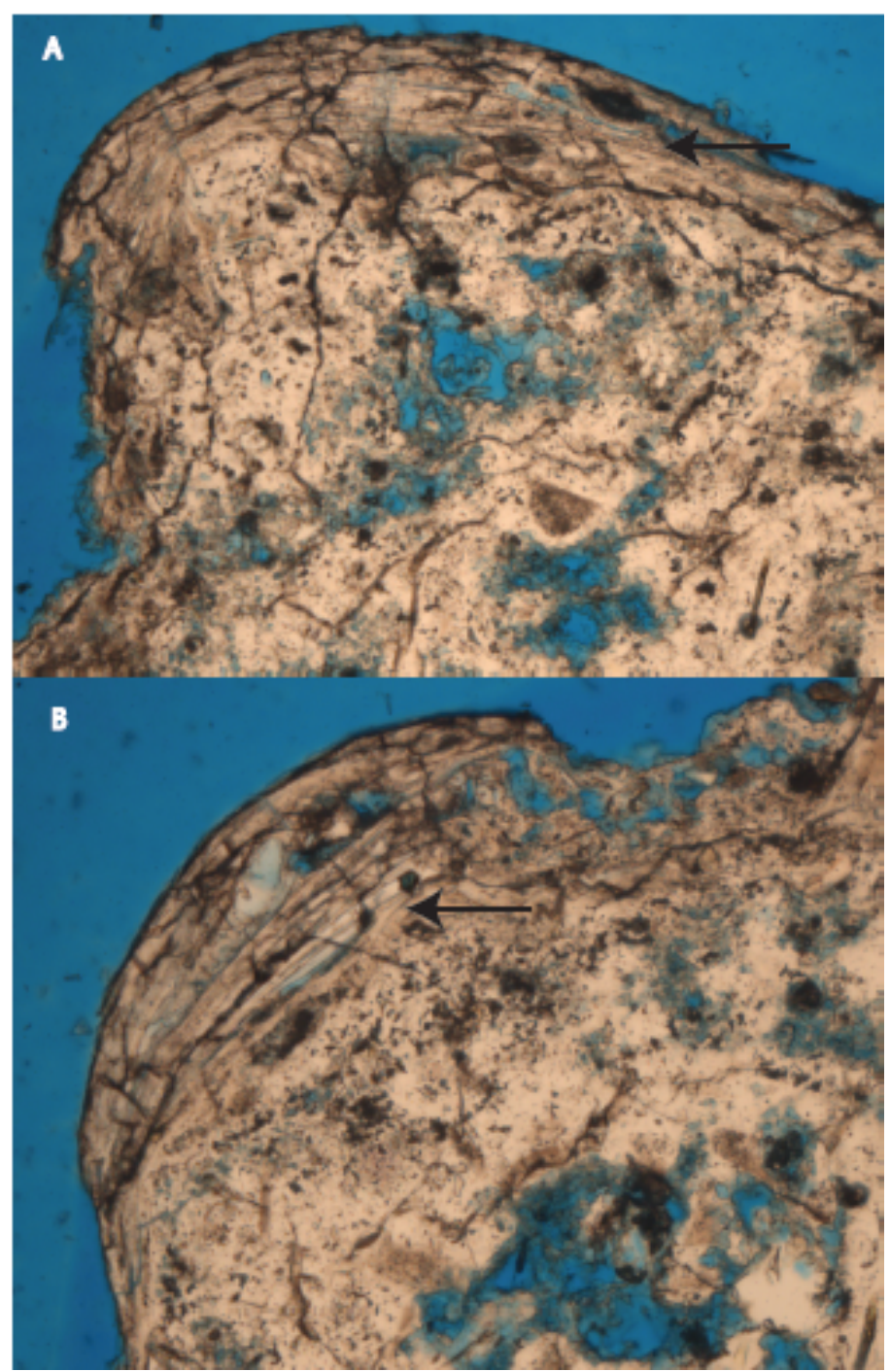

Fig. 28 The upper most, aerially exposed capping silica deposit of two different aerially exposed Calothrix biofacies samples have very fine laminations within them. (A) Sample 110919.24B (B) Sample 111001.10. Black arrows point toward the fine laminations.

capping silica deposit, when viewed in cross section, had a milky glass-like appearance that was different from all of the other capping silica deposits within the interior of either the partially silicified and aerially exposed samples. The capping silica deposit, when viewed in thin sections petrographically, appeared to be comprised of many fine laminations. Also, 
no microorganisms were observed in the fine laminations at the top of the uppermost capping silica deposit.

\subsubsection{Scanning Electron Microscopy}

The scanning electron microscope (SEM) analysis provided additional

morphological details of the aerially exposed Calothrix biofacies sample

(Fig. 29). The additional details primarily include more higher magnification

observations of filament and sheath diameters, which were consistent with

those in the literature. The characteristic palisade fabric was observed.

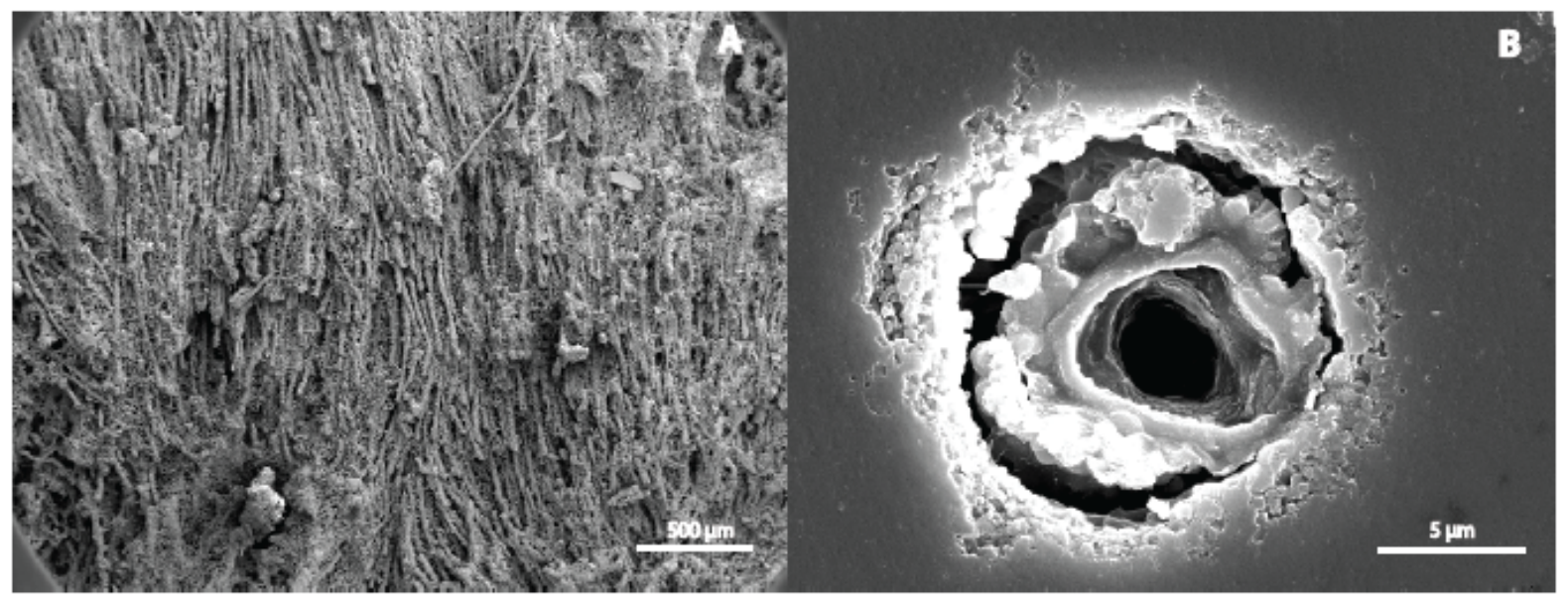

Fig. 29. (A) SEM image of characteristic silicified palisade biofabric that is found in the Calothrix dominated niche of alkaline, silica depositing hydrothermal systems. (B) SEM image of a silicified filamentous microorganism consistent with that of Calothrix. The mould of a filament was created by large and structureless silica deposition.

Thus, the overall morphological observations of the biofabric was consistent

with Calothrix dominated microbial communities and biofabrics.

\subsection{Scanning Electron Microscope Energy Dispersive Spectroscopy of}

Partially Silicified and Aerially Exposed Calothrix Biofacies Samples 
The scanning electron microscope (SEM) equipped with an energy

dispersive spectroscopy (EDS) detector was utilized to collect spatially

correlated elemental compositional data on both the partially silicified and

aerially exposed Calothrix biofacies samples. Elemental maps were acquired

on Calothrix filaments in cross-to-oblique section that were surrounded by

silica and on capping silica deposits with no observable microbial presence.

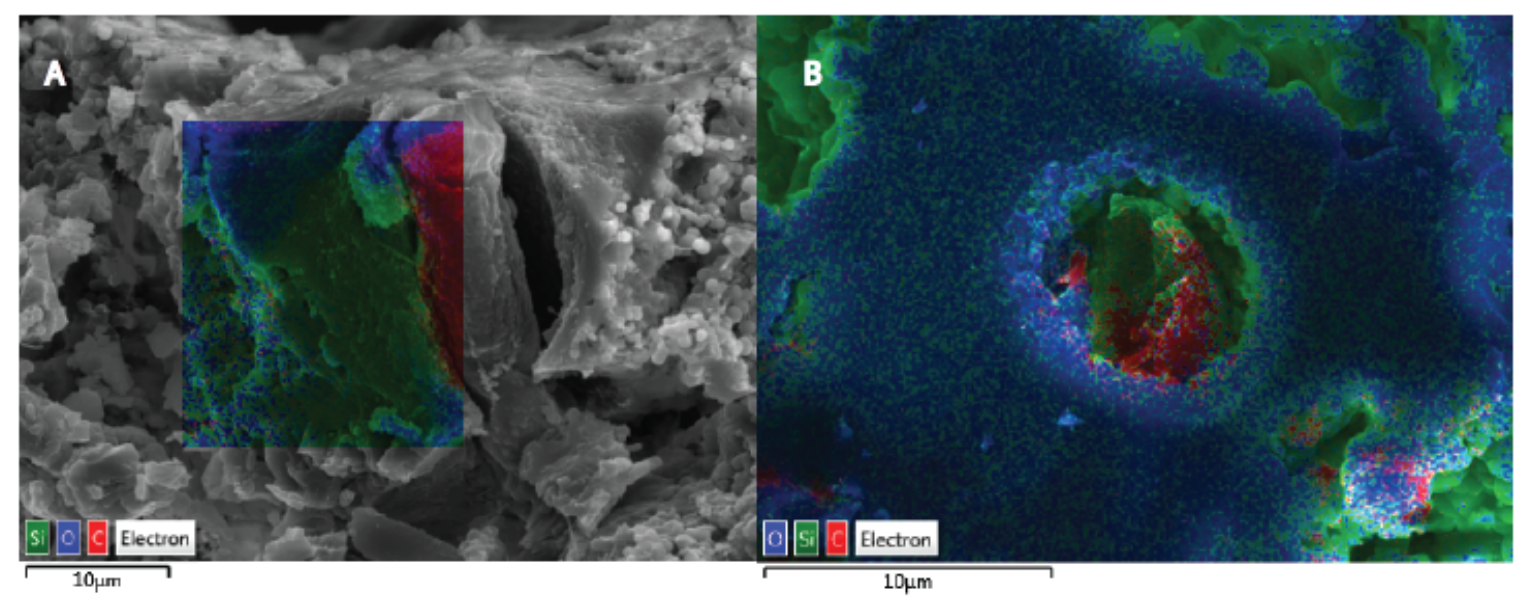

Fig. 30. SEM EDS false color images of a Calothrix filament and surrounding silica deposits from both the partially silicified and aerially exposed biofacies show similar distribution of the expected major elements. (A) Sample is a near vertical filament consistent with Calothrix and surrounded by silica deposits from the partially silicified 110921.6. (B) Aerially exposed sample 111001.3 with a filament consistent with Calothrix in cross section and surrounded by silica deposits. The detected element color indicators are as follows: red for carbon, blue for oxygen, and green for silica. False color images produced in Aztec software (2013).

The elements that were consistently detected in the areas analyzed on both the partially silicified and aerially exposed Calothrix biofacies are: carbon associated with the Calothrix filaments, silicon, and oxygen (Fig. 30).

Additional elements detected in the aerially exposed Calothrix sample 110921.24B are calcium and sodium. A higher concentration of sodium is 

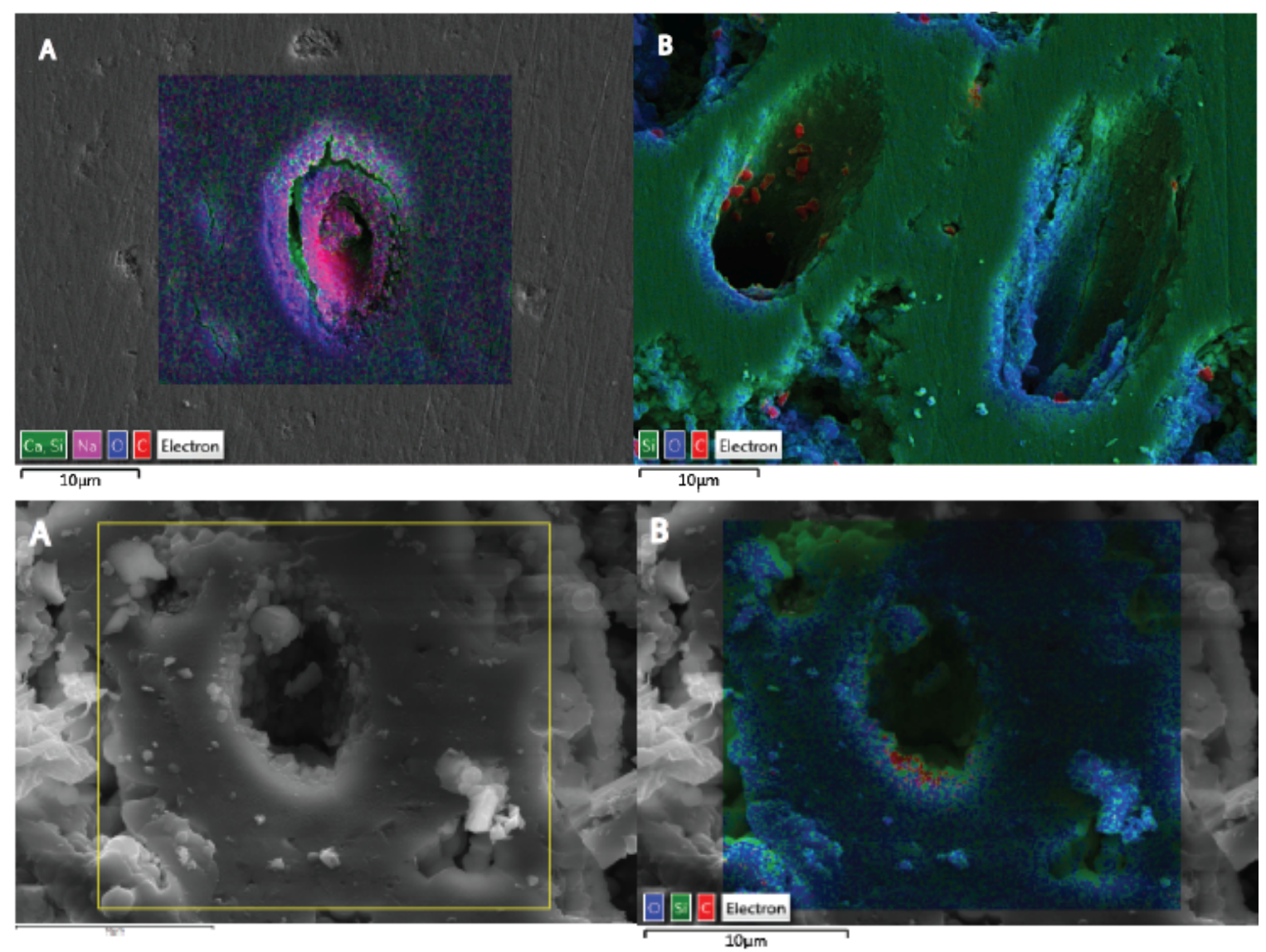

Fig. 31. SEM EDS false color images of carbon detected in the aerially exposed sample that is associated with Calothrix filaments and, potentially, Calothrix moulds, but not in the silica just beyond the Calothrix filament/sheath interface. (A) A filament consistent with Calothrix in cross section and surrounded by silica deposits. The red in the filament represents the carbon detected from the filament. There is also a strong sodium signal at the filament/sheath interface creating a partical rim. (B) Filament moulds consistent with Calothrix in oblique section show minor, but dectecable, amounts of carbon at the surface. (C) Aerially exposed Calothrix biofacies mould in cross section. The yellow box outlines the area of interest for the EDS map. (D) SEM EDS false coler image of the mould with detected carbon and surrounding silica. The color indicators for detected elements are as follows: red for carbon, blue for oxygen, and green for silicon. False color images produced in Aztec software (2013).

present in and around some of the aerially exposed Calothrix biofacies

filaments, but not consistently detected around all aerially exposed Calothrix

filaments (Fig. 31). Carbon was also detected in small quantities around the

periphery of some moulds (e.g. Fig. 31), but due to the surficial appearance

the results must be considered anomalous, as it could not be determined 
whether the carbon was residue from the sample preparation process versus carbonaceous material entrained within the sinter. The regions of interest within the thick capping silica deposits were carefully selected to avoid any observable microorganisms. EDS analysis revealed that the capping silica regions consisted of silicon and oxygen only.

\section{Chapter Five}

Discussion

Characterization sensu Hofmann (1969) 
The stromatologist Hans Hofmann developed and refined an objective qualitative and quantitative characterization protocol for various morphological attributes of marine stromatolites (1968, 1969, and 1994). Hofmann (1994) asserted that quantification of stromatolite attributes simplified communication and enhanced an understanding of the structures, and that the morphometric techniques could be applied to other types of geological features as well. Hofmann's approach was used here to characterize the attributes of partly silicified microbial mats dominated by the cyanobacteria Calothrix and their corresponding lithified sinters.

the detailed morphometrics characterization protocol was applied to two terrace samples that formed in the Calothrix biofacies zone - one that was still growing in the active biofacies region of the drainage apron of Queen's Laundry hot spring and the other that originated in the partially silicified Calothrix biofacies zone but was collected from beyond the hot spring system perimeter from an inactive aerially exposed zone. Multiple attributes within the samples were characterized, microbial structures within the terrace profile were described, and geometric measurements performed, as described in the results section. The significance of the results that advance the objectives of this study are presented below.

\subsection{Objective 1: Similarity of Partially Silicified and Aerially Exposed}

\section{Calothrix Biofacies Samples}

Hofmann's morphometrics approach was taken to achieve one of the objectives of this project: demonstrate that the biofabric and the structural characteristics of the partially 
silicified and aerially exposed terrace biofacies samples were the same. A variety of data were acquired to ensure that the partially silicified and aerially exposed Calothrix biofacies samples collected for this study could be compared. The perimeter line confirmed that partially silicified and aerially exposed Calothrix biofacies samples were collected from active and inactive parts of the hot spring system, respectively. The curvilinear features of the Calothrix terraces were abundant in both the partially silicified and aerially exposed biofacies regime. The aerially exposed sample collected displayed external and internal morphological features including lithified curvi-linear topographic highs, multiple laminations of palisade fabric, and microbial structures. These are similar to those described by Walter et al. (1996) who observed stratiform mats with palisade fabric and lithified terraces with pseudocolumnar stromatolites comprised of millimetric to centimetric laminar fabric..

\subsection{Objective 2: Effects of Aerial Exposure on the Fidelity of Biofabrics}

A second objective of the study was to determine whether prolonged exposure to the air or other processes affected the fidelity of the biosignatures studied including biofabrics and microbial cells) in the aerially exposed samples.

Diagenesis could have a deleterious effect on biosignature preservation. Diagenesis dissolve the primary silica phase and cause the precipitation of a structurally more ordered microcrystalline silica phases (e.g., Rodgers et al., 2004). The primary silica precipitate that deposits within near neutral, alkaline hot spring systems consists of X-ray amorphous opaline silica, a hydrated silica mineraloid (Fournier and Rowe, 1966). During diagenesis (e.g., driven by heat, time, fluid alteration), opaline silica dissolves and 
re-precipitates as progressively more ordered and thermodynamically more stable silica phases (i.e., re-ordering from least ordered opaline silica (opal-A), to opal-A/CT, to opalC, and then microcrystalline quartz) (Lynne et al., 2008). XRD analysis of all of the Calothrix biofacies and lithofacies samples studied here indicted they consisted of opalA, which confirmed that all the samples are recent deposits and that the mineralogy was not altered by diagenesis.

Petrographically, the microbial mats dominated by Calothrix were found to be characterized by a biofabric that consists of lamina that terminate with a capping silica deposit. Though the exact timing of the deposition of the capping silica deposit was not captured during the course of this study, it appears to develop sometime after the start of fall, based on the fact that there was no evidence (on the top surfaces of the samples or in petrographic thin section) that a capping deposit was beginning to develop on the surfaces of any of the 2011 field samples that were collected as a part of this study.

The top-most surface of the capping silica deposit of the aerially exposed Calothrix samples, however, was distinctly different from the capping silica deposits in the interior of the samples: the aerially exposed capping silica deposit was glassy in appearance and it contained fine laminations. Such fine laminations were not observed in any of the topmost laminae of the biofacies samples. A prolonged aerial hiatus without annual growth of the deposit via colonization by Calothrix (or other) microbes along with the deposition of silica could produce a massive opaline silica-capping deposit. This process is consistent with the type of processes that are likely to occur in the environmental setting where lithofacies are found, as they occur beyond the perimeter of the active hot spring. For example, re-direction of the fluid flow of the main drainage apron, or a change in the 
volumetric output of hydrothermal fluid at the source, could periodically or even permanently expose aerially those sinters that form along the edge of the drainage apron. Consequently, the growth of biofacies Calothrix-dominated microbial communities would cease. In this study, it was observed that microbial abundance in the top-most capping silica deposit of the aerially exposed sample was much lower than it was in all of the other capping silica deposits observed both within the interiors of the partially silicified and aerially exposed samples.

Whether the fine laminations that developed within the aerially exposed top-most capping silica deposit is an identifier of aerial exposure remains to be tested. Each lamination in the terrace samples from the Calothrix biofacies typically consists of a couplet of some type of microbial microstructure and a capping silica deposit at the top of the laminae. The dominant process(es) involved in the cyclic deposition of the capping silica deposit appears to vary depending on each hot spring locality (e.g., Jones and Peng, 2015; Konhauser et al., 2004). The capping silica deposits within the partially silicified and aerially exposed Calothrix dominated biofacies samples studied here have a significant microbial presence. Calothrix filaments were observed, for the most part, in near vertical orientation through out the height of the capping silica deposits. Further, use of the scanning electron microscope made it possible to observe unidentified cocci microbes and unsheathed filamentous microorganisms smaller in diameter than Calothrix in the capping silica deposits. In other studies where capping silica deposits within Calothrix dominated niches of hot springs have been reported, their orientation is parallel to the deposition of the capping silica (e.g., Konhauser et al., 2004).

It is interesting to note that sub-laminae were found only in some of the microbial 
structures of the partially silicified Calothrix biofacies laminae. Though sub-laminae appear similar to the capping silica deposits, they were only observed locally within microbial structures and sometimes several sub-laminae were identified within a single lamina couplet. While it appears likely that the capping silica deposit develops annually, while the sub-laminae appear to develop as a result of other factors that are yet to be verified.

\subsection{Environment Created by Terraces that Develop in Hot Spring Drainage Aprons}

The morphometric analyses used in this study revealed the presence of: distinct microbial structures; thicker lamina at or near the base of the terraces; the greatest density of microorganisms in microbial structures that form at the base of the terraces; increased microbial structure flatness as height of the microbial structures within the terrace proper increased; and higher preservation potential of Calothrix biofabrics in areas that were topographically relatively higher compared to the surrounding levels of the tops of same laminae in different parts of the samples. These characteristics provide a means to interpret the environmental conditions within which the terrace structures developed in the hot spring environment.

Terraces that develop within the Calothrix dominated microbial community create shallow pools for microbial mats to develop (Cady and Farmer, 1996). These terraces have also been preserved in the geologic record as far back as the Devonian in Australia. (Walter et al., 1996). Though Walter et al. (1996) described lithified sinters consistent with Calothrix; they did not specifically describe terraces as a structural feature of the deposit. 
In general, the growth of the terraces studied typically have prominent microbial structures at the lower part of the collected samples. The lamina height (thickness) decreases toward the top, and the accumulation of successive of microbial structures occurs in the upstream direction. Successive microbial structures that formed above the initial basal microbial structure became more domical and flatter with time. The vertical development of the terrace reflects the height of the hydrothermal fluid flowing over the terrace. A decreased hydrothermal fluid column would result in wider and shorter microbial structures in the successive laminae. It should be noted though that not all prominent shrubs lead to terraces.

To interpret the environmental conditions preserved within the Calothrix dominated terrace partially silicified and aerially exposed biofacies samples, one looks to the accretionary profiles as recorded in the laminae. The upper boundary condition for the formation of the structures and growth profile of each lamina was the height of the water column (Walter et al., 1972). For example, the basal Calothrix lamination within the partially silicified biofacies terrace had the greatest lamina heights and tallest microbial structures. This indicates a water column of sufficient depth for such microbial structures to have formed, and it was observed in the field setting that little ponds of water pooled behind terraces. As the terrace macrostructure aggraded via growth and silicification of successive laminae, the height of the water column flowing above the developing terrace decreased. The reduced height of the fluid column resulted in decreased height and increased flatness of the microbial structures. No overprinting by another microbial community was observed within the Calothrix accretionary profiles, which indicates a period of stable hydrothermal fluid conditions for Calothrix dominated microbial 
communities. Also, the vast majority of the Calothrix filaments were observed in near vertical orientation indicating that the flow rate of the hydrothermal fluid was relatively low and the potential was high for rapid silicification of the Calothrix sheaths. The terraces observed formed in the absence of topographic highs, which could have been from a prominent shrub, detrital input introduced into the hot spring, such as the pine needle in the lithofacies, and animal activity that disturbed the mats.

\subsection{Preservation Potential of Calothrix biofacies}

Opaline silica is precipitated abiotically due to cooling and evaporation of the hydrothermal fluids (Walter et al., 1972). Silica precipitated in hot springs may entomb, replace, and deposit on organic matter surfaces depending upon the nature of the organic matter. The microbial role in silicification remains unclear, however silicification occurs because the microorganisms cannot escape it or they benefit in some way (Phoenix et al., 2000).

The preservation potential of microorganisms is dependent upon a variety of factors, which include: silicification rate, the microbial anatomy (e.g., sheathed or not), and the nature of the organic matter to resist degradation (e.g., Cady and Farmer, 1996). Preservation of Calothrix filaments begins within the sheath (Hugo et al., 2011) and, due to rapid silicification; the filaments are preserved in or near life position (Cady and Farmer, 1996).

The preservation of Calothrix was observed to be significantly higher within the microbial structures that formed with those sections of laminae that developed beneath the high points of terrace structures (as opposed to topographical lows where other less 
consolidated biofabrics develop). The microbial structures (shrubs and domical) observed in the Calothrix terrace biofacies sample had a high density of microorganisms that was entombed by silica. By comparison the microbial preservation potential within the microbial structures of the lithified terrace sample were observed to be fairly good in both the partially silicified and aerially exposed biofacies. Although the aerially exposed had degraded, the microbial structural fabric still retained a significant amount of preservation, such as microbial presence and pigmentation.

Chapter Six

Conclusions

The objectives of the study were twofold. First, determine whether the partially silicified and aerially exposed biofacies sinter samples used in the comparative study formed under similar conditions. Second, determine whether prolonged exposure to the air or other processes affected the fidelity of the biosignatures studied (i.e., biofabric and 
microbial cells) in the lithified samples.

The terraces that form in the broad drainage apron of the Calothrix dominated microbial community of the hot spring ecosystem studied displayed both distinctive biological characteristics and physical characteristics. Morphological characteristics common to both the partially silicified and aerially exposed biofacies samples studied revealed that a considerable amount of primary biosedimentological features are preserved in the corresponding aerially exposed samples. The detailed characterization approach revealed the two samples developed in similar environments.

The presence of a finely laminated aerially exposed capping silica deposit suggests that initially, in the first few years of permanent aerial exposure, only the fidelity of morphological biosignatures in the uppermost surfaces of aerially exposed Calothrix biofacies will be altered.

The research presented here lays the foundation for a larger survey of the chemical nature of terraces and the Calothrix dominated niche within the modern hot spring environments. The foundation has also been laid for proceeding into deeper into geologic time to better understand how microbial organisms influenced terrace formation and surficial processes alter the structures and biosignatures through time. Additional nondestructive and spatially correlated analytical methods need to be considered in the search of chemofossils in the sinter surrounding filaments past and present. Instruments that may lend further insight are those proposed for the Mars 2020 mission, which include Raman and X-ray fluorescence (XRF) spectroscopy. 


\section{References}

Allwood, A.C., Walter, M.R., Burch, I.W., Kamber, B.S., 2007, 3.43 billion-year-old stromatolite reef from the Pilbara Craton of Western Australia: ecosystem-scale insights to early life on Earth: Precambrian Research, v. 158, p. 198-227.

Aztec 2.1, 2013: Oxford Instruments, United Kingdom.

Benning, L.G., Phoenix, V.R., Yee, N., and Tobin, M.J., 2004, Molecular characterization of cyanobacterial silicification using synchrotron infrared micro-spectroscopy: Geochemica et Cosmochimica Acta, v. 68, n. 4, p. 729-741.

Bish, D.L. and Reynolds, R.C., 1989, Sample preparation for X-ray diffraction: Reviews in Mineralogy and Geochemistry, v. 20, p. 73-99.

Cady, S.L., and Farmer, J.D., 1996, Fossilization processes in siliceous thermal springs: trends in preservation along thermal gradients: Evolution of hydrothermal ecosystems on Earth (and Mars?), Wiley, Chichester (Ciba Foundation Symposium 202), p. 150-173.

Cady, S.L, Farmer, J.D., Grotzinger, J.P., Schopf, J.W., and Steele, A., 2003, Morphological biosignatures and the search for life on Mars: Astrobiology, v. 3, n. 2, p. 351-368, doi: 10.1089/153110703769016442.

Christiansen, R.L. and Blank, H.R., 1972, Volcanic stratigraphy of the Quaternary rhyolite plateau in Yellowstone National Park: U.S. Geological Survey Professional Paper 729-B.

Coe, A. L., Argles, T.W., Rothery, D.A., and Spicery, R. A., 2010, Geological Techniques, $\left(1^{\text {st }}\right.$ ed $)$, Wiley-Blackwell, United Kingdom.

Dykstra, M.J. and Reuss, L.E., 2003, Biologicical Electron Microscopy: Theory, Techniques, and Troubleshooting $\left(2^{\text {nd }}\right.$ ed $)$, Springer-Verlag, Germany.

Encyclopedia Britannica, Hot Spring, 2014:

http://www.britannica.com/EBchecked/topic/272775/hot-spring (last accessed 2 July 2014).

Farmer, J.D. and Des Marais, D.J., 1999, Exploring for a record of ancient Martian life: Journal of Geophysical Research, v. 104, n. E11, p. 26,97726,995 . 
Fournier, R.O. and Rowe, J.J., 1966, Estimation of underground temperatures from the silica content of water from hot springs and steam wells: American Journal of Science, v. 264, p. 685-697.

Fournier, R.O. and Truesdell, A.H., 1970, Chemical indicators of subsurface temperature applied to hot spring waters of Yellowstone National Park, Wyoming, U.S.A.: Geothermics, v. 2, p. 529-535.

Fritz, W.J. and Thomas, R.C., 2011, Roadside Geology of Yellowstone Country ( $2^{\text {nd }}$ ed), Mountain Press, Montana.

Goldstein, J.I., Newbury, D.E., Lyman, C.E., Echlin, P., Lifshin, E., Sawyer, L. and Michael, J.R., 2007, Scanning Electron Microscopy and X-ray Microanalysis ( $3^{\text {rd }}$ ed), Springer, New York.

Grotzinger, J., Beatty, D., Dromart, G., Gupta, S., Harris, M., Hurowitz, J., Kocurek, G., McLennan, S., Milliken, R., Ori, G.G., and Sumner, D., 2011, Mars sedimentary geology: key concepts and outstanding questions:

Astrobiology, v. 11, n. 1, p. 77-87, doi: 10.1089/ast.2010.0571.

Hinman, N.W. and Walter, M.R., 2005, Textural preservation in siliceous hot spring deposits during early diagenesis: examples from Yellowstone National Park and Nevada, U.S.A: Journal of Sedimentary Research, v. 75, n. 2, p. 200-215, doi:10.2110/jsr.2005.016.

Hofmann, H.J., 1968, Stromatolites from the Proterozoic Animike and Sibley Groups, Ontario: Geological Survey of Canada, paper 68-69, p. 811.

Hofmann, H.J., 1969, Attributes of stromatolites: Geological Survey of Canada, paper 69-39, $58 \mathrm{p}$.

Hofmann, H.J., 1994, Quantitative Stromatolithology: Journal of Paleontology, v. 68, n. 4, p. 704-709.

Hugo, R.C., Cady, S.L., and Smythe, W., 2011, The role of extracellular polymeric substances in the silicification of Calothrix: evidence from microbial mat communities in hot springs at Yellowstone National Park, USA: Geomicrobiology Journal, v. 28, p. 667-675.

ImageJ, 2009: http://rsbweb.nih.gov/ij/download.html (last accessed 9 Dec 2009).

Jones, B. and Peng, X., 2015, Laminae development in opal-A precipitates associated with seasonal growth of the form-genus Calothrix (cyanobacteria), Rehai geothermal area, Tengchong, Yunnan Province, 
China: Sedimentary Geology, v. 319, p. 52-68.

Jones, B., Renaut, R.W., and Rosen, M.R., 1998, Microbial biofacies in hotspring sinters: a model based on Ohaaki Pool North Island, New Zealand: Journal of Sedimentary Research, v. 68, n. 3, p. 413-434.

Jones, B., Renaut, R.W., and Rosen, M.R., 2003, Silicified microbes in a geyser mound: the enigma of low-temperature cyanobacterial in a hightemperature setting: Palaios, v. 18, n. 2, p. 87-109.

Kearey, P., 2001, Dictionary of Geology ( $2^{\text {nd }}$ ed), Penguin Books, England.

Komar, V.A., Raaben, M.E., and Semikhatov, M.A., 1965, Conophytons of the Riphean of the USSR and their stratigraphic significance: Akad. nauk SSSR, Geological Institute, Tr. V. 131, p. 73.

Konhauser, K.O., Jones, B., Reysenbach, A.-L., and Renaut, R.W., 2003, Keys to understanding Earth's earliest life forms: Canadian Journal of Earth Sciences, v. 40, p. 1713-1724.

Konhauser, K.O., Jones, B., Phoenix, V.R., Ferris, G., and Renaut, R. W., 2004, The microbial role in hot spring silicification: Ambio, v.33, p. 552558.

Lowe, D.R., and Braunstein, D., 2003, Microstructure of high temperature $\left(>73^{\circ} \mathrm{C}\right)$ siliceous sinter deposited around hot springs and geysers, Yellowstone National Park: the role of biological and abiological processes in sedimentation: Canadian Journal of Earth Science, v. 40, p. 1611-1642, doi: 10.1139/E03-066.

Lynne, B.Y., Campbell, K.A., Moore, J., and Browne, P.R.L., 2008, Origin and evolution of the Steamboat Springs siliceous sinter deposit, Nevada, U.S.A.: Sedimentary Geology, v. 210, p. 111-131.

Oehler, D.Z. and Cady, S.L., 2014, Biogenicity and syngeneity of organic matter in ancient sedimentary rocks: Recent advances in the search for evidence of past life: Challenges, v. 4, p. 260-283, doi:

$10.3390 /$ challe 5020260 .

Phoenix, V.R., Adams, D.G., Konhauser, K.O., 2000, Cyanobacterial viability during hydrothermal biomineralisation: Chemical Geology, v. 169, p. 329-338.

Preston, L.J., Benedix, G.K., Genge, M.J., and Sephton, M.A., 2008, A multidisciplinary study of silica sinter deposits with applications to silica identification and detection of fossil life on Mars: International Journal of 
Solar System Studies, v. 198, i. 2, p. 331-350, doi:

10.1016/j.icarus.2008.08.006.

Renaut, R.W., Jones, B., and Tiercelin, J.J., 1998, Rapid in situ silicification of microbes at Loburu hot springs, Lake Bogoria, Kenya Rift Valley:

Sedimentology, v. 45: 1083-1103.

Rodgers, K.A., Browne, P.R.L., Buddle, T.F., Cook, K.L., Greatrex, R.A., Hampton, W.A., Herdianita, N.R., Holland, G.R., Lynne, B.Y., Martin, R., Newton, Z., Pastars, D., Sannazarro, K.L., and Teece, C.I.A., 2004, Silica phases in sinters and residues from geothermal fields of New Zealand: Earth-Science Reviews, v. 66, p. 1-61.

Skok, J.R., Mustard, J.F., Ehlmann, B.L., Milliken, R.E., and Murchie, S.L., 2010, Silica deposits in the Nili Patera caldera on the Syrtis Major volcanic complex on Mars: Nature Geoscience, v. 3, p. 838-841, doi: 10.1038/NGEO990.

Walter, M.R., Bauld, J., Brock, T.D., 1972, Siliceous algal and bacterial stromatolites in hot springs and geyser effluents of Yellowstone National Park: Science, v. 178, p. 402-405.

Walter, M.R., 1976, Hot-spring sediments in Yellowstone National Park. In:Walter MR (ed) Stromatolites. Elsevier, Amsterdam, p. 489-498.

Walter, M.R. and Des Marais, D., 1993, Preservation of biological information in thermal spring deposits: developing a strategy for the search for fossil life on Mars: Icarus, v. 101, p. 129-143.

Walter, M.R., Des Marais, D., Farmer, J.D., and Hinman, N.W., 1996, Lithofacies and biofacies of mid-Paleozoic thermal spring deposits in the Drummond Basin, Queensland, Australia: Palaios, v. 11, p. 497-518.

Yellowstone National Park hiking Guide:

http://www.yellowstone.co/hikes/hiking.htm (last accessed 5 June 2015). 
Appendix 1

Queen's Laundry hot spring Transect Data of the broad drainage apron

\section{Transect Orientation}

To date, three perimeter maps have been made at the Queen's laundry hot spring. The first one was obtained by a student (Steve Walsh) as part of a field course taught by Dr. Cady during the summer of 2008. A second one was made by another student (the author) during the summer of 2009. And a third perimeter map was made as part of this thesis project in the summer of 2011. The procedure for acquiring the third transect was modified slightly from the protocols used in prior years (see below?) to make it easier to obtain the resultant perimeter lines and plot the GPS data in the future. For each transect: the dominant microbial community, water flow status (implemented in 2009), distance, and observations were recorded and later transcribed into spreadsheets.

Transect two runs was oriented down the drainage field from the northwest corner of the bathhouse (N: 4934495 and E: 0510297) for forty-five meters at an azimuth of 335 degrees to an endpoint with coordinates of N: 4934532 and E: 051253. The azimuth has a 13-degree correction for the latitude of the hot spring system and this correction was taken into account for all transects. Transect two was positioned across the partially silicified Calothrix biofacies regime on the east side of the broad drainage apron and included marsh grass near the terminal end of the transect.

Transect three began 6.7 meters from the northeast corner of the bathhouse at an azimuth of 356 degrees. The starting point coordinates are N: 4934505 and E: 0510282. From this location the transect began along an azimuth of 245 degrees for 33.3 meters to the west end of the drainage channel. The terminal point of the transect is $\mathrm{N}: 4934483$ and $\mathrm{E}: 0510252$.

The position that transect four was taken from has been changed twice now. In 2009 it was very close to the original transect four and aligned with dead trees on opposite sides of the drainage field. The transect originated from a dead tree that is no longer there. For repeatability the transect was moved, in 2011 , to the northwest corner of the bathhouse, as it is a more stable landmark. 


\title{
2008 Spreadsheets for transects:
}

\section{Table 6. 2008 Transect 2 measurement and characterization}

\author{
2008:YNP-QL Transect 2 \\ (start NW corner of Bath House)
}

Transect info: Start at NW corner of the Bath House, declination $335^{\circ}$ for 45 meters.

\begin{tabular}{|c|c|c|c|c|}
\hline Beginning $(\mathrm{m})$ & Ending $(\mathrm{m})$ & Distance $(\mathrm{m})$ & Water Status & Description \\
\hline $0 \mathrm{~m}$ & $0.6 \mathrm{~m}$ & $0.6 \mathrm{~m}$ & & $\begin{array}{l}\text { Calothrix; brown-green and } \\
\text { salmon pustular mat }\end{array}$ \\
\hline $0.6 \mathrm{~m}$ & $0.8 \mathrm{~m}$ & $0.2 \mathrm{~m}$ & & Phormidium; bubble mat \\
\hline $0.8 \mathrm{~m}$ & $0.95 \mathrm{~m}$ & $0.15 \mathrm{~m}$ & & $\log$ \\
\hline $0.95 \mathrm{~m}$ & $5 \mathrm{~m}$ & $4.05 \mathrm{~m}$ & & $\begin{array}{l}\text { Bubble mat to } 4 \mathrm{~m} \text { and dark } \\
\text { brown leather terrace mat } \\
\text { for following meter }\end{array}$ \\
\hline $5 \mathrm{~m}$ & $6.9 \mathrm{~m}$ & $1.9 \mathrm{~m}$ & & brown Calothrix terracette \\
\hline
\end{tabular}

Table 7. 2008 Transect 3 measurement and characterization

2008:YNP-QL Transect 3

(across upper drainage apron)

Transect info: Start $6.7 \mathrm{~m}$ from NE corner of Bath House at a declination

ran at a delination of $245^{\circ}$ for $29.88 \mathrm{~m}$ toward the west.

\begin{tabular}{|c|c|c|c|}
\hline Beginning(m) & Ending $(\mathrm{m})$ & Distance $(m)$ Water Status & Description \\
\hline 0 & 1 & 1 & $\begin{array}{l}\text { Soft salmon pustular mat on brecciated sinter with } \\
\text { terracette of br-grn mat at } .5 \text { and } .7 \mathrm{~m} \text {. }\end{array}$ \\
\hline 1 & 2 & 1 & brown-green matting \\
\hline 2 & 3 & 1 & thick bubble mat forming biofilms, lg dk-br terrace at $3 \mathrm{~m}$. \\
\hline 3 & 7.9 & 4.9 & dk-br with some small orange pustular Phormidium spots \\
\hline 7.9 & 8.1 & 0.2 & Ig terrace of dk-br with orange included \\
\hline 8.1 & 9.7 & 1.6 & $\begin{array}{l}\text { Streamers (Synechococcuc?) and Phormidium mixed. } \\
\text { Well formed stromatolitic formations as well as, rising to } \\
\text { water level. }\end{array}$ \\
\hline 9.7 & 14.4 & 4.7 & $\begin{array}{l}\text { Fast moving stream with interspersed sinter rises, } \\
\text { perhaps old stromatolitic formations above water line. }\end{array}$ \\
\hline 14.4 & 16.8 & 2.4 & $\begin{array}{l}\text { Streamers and Phormidium mixed, well formed stromat- } \\
\text { olitic formations as well, rising to water level }\end{array}$ \\
\hline 16.8 & 19.8 & 3 & Thick bubble mat biofilms forming small stromatolites \\
\hline 19.8 & 21.6 & 1.8 & $\begin{array}{l}\text { Bordering between bubble mat and Calothrix pustular mat } \\
\text { with terracettes of dk-br Calothrix at 20.5, } 20.3 \text { and } 20 \mathrm{~m} \text {. }\end{array}$ \\
\hline 21.6 & 23.8 & 2.2 & Mix of dk-br and It salmon Calothrix \\
\hline 23.8 & 28 & 4.2 & $\begin{array}{l}\text { Orange bubble mat not in silicified biofilm. Crossing } \\
\text { terrace incline of dk-br Phormidium at } 24.9-26.7 \mathrm{~m} \text {. }\end{array}$ \\
\hline 28 & 33.3 & 5.3 & $\begin{array}{l}\text { Calothrix well formed old terraces of brecciated sinter into } \\
\text { pustular mats, not forming into terraces. }\end{array}$ \\
\hline
\end{tabular}




\section{Table 8. 2008 Transect 4 measurement and characterization}

2008: YNP-QL Transect 4

(across middle drainage apron)

Transect info: Start at a declination of $345^{\circ}$ and $29 \mathrm{~m}$ away from the NE corner of Bath House and ran for $52.5 \mathrm{~m}$ to the west side of the outflow system.

\begin{tabular}{|c|c|c|c|}
\hline Beginning $(\mathrm{m})$ & Ending $(\mathrm{m})$ & Distance $(m)$ Water Status & Description \\
\hline 0 & 0.8 & 0.8 & Salmon pustular mat over brecciated siner \\
\hline 0.8 & 2.45 & 1.65 & Br-grn Phormidium, fluffy and pustular, not terrace \\
\hline 2.45 & 3.55 & 1.1 & Salmon pustular mat with br-grn terraces \\
\hline 3.55 & 5.1 & 1.55 & $\begin{array}{l}\text { Salmon pustular mat with sintered rises above water level } \\
\text { Br-grn terraces throughout }\end{array}$ \\
\hline 5.1 & 7 & 1.9 & Grn-br mat with microterraces \\
\hline 7 & 7.75 & 0.75 & Salmon pustular mat \\
\hline 7.75 & 8.05 & 0.3 & Yellow-green and black mat \\
\hline 8.05 & 9.35 & 1.3 & Grn-br transitioning to dk-br mat \\
\hline 9.35 & 15.7 & 6.35 & Salmon pustular mat with grn-br microterraces \\
\hline 15.7 & 16.1 & 0.4 & Bubble mat with greenish streamers \\
\hline 16.1 & 23 & 6.9 & $\begin{array}{l}\text { Orange bubble mat with terraces. Major stream crossing } \\
\text { at } 18.5 \text { with greenish streamers }\end{array}$ \\
\hline 21 & 22.3 & 1.3 & $\begin{array}{l}\text { Bubble mat forming biofilm. Thin and soft with gas under- } \\
\text { neath }\end{array}$ \\
\hline 22.3 & 22.8 & 0.5 & $\mathrm{Br}$-grn with orange mixed pustular mat \\
\hline 22.8 & 23.3 & 0.5 & Bubble mat, flowing stream; few streamers \\
\hline 23.3 & 29.2 & 5.9 & $\begin{array}{l}\text { Broken up sinter from old biofilm bubble mat with salmon } \\
\text { Calothrix in the broken up spots }\end{array}$ \\
\hline 29.2 & 29.8 & 0.6 & $\begin{array}{l}\text { Bubble mat, thin with streamers on top and forming a } \\
\text { light biofilm }\end{array}$ \\
\hline 29.8 & 31 & 1.2 & $\begin{array}{l}\text { Initial terrace of br-grn transitioning to salmon pustular } \\
\text { mat }\end{array}$ \\
\hline 31 & 41 & 10 & Dry brecciated sinter \\
\hline 41 & 43.1 & 2.1 & Saturated soil, plant life, br-grn, not leathery \\
\hline 43.1 & 52.5 & 9.4 & $\begin{array}{l}\text { Brecciated sinter, light covering of salmon pustular mat } \\
\text { forming small streamers }\end{array}$ \\
\hline
\end{tabular}


2009 Spreadsheets for transects

Table 9. 2009 Transect 2 measurement and characterization

2009:YNP-QL Transect 2

(start NW corner of Bath House)

Transect info: Start at NW corner of the Bath House, declination $335^{\circ}$ for 45 meters.

Instrument used: Trimble G4-6459

GPS: Start N-4934495 End N-4934532

E-0510277 E-051253?

File R071118A File R071118B

\begin{tabular}{|c|c|c|c|c|}
\hline Beginning(m) & Ending(m) & Distance $(\mathrm{m})$ & Water Status & Description \\
\hline $0 \mathrm{~m}$ & $.75 \mathrm{~m}$ & $.75 \mathrm{~m}$ & pool & $\begin{array}{l}\text { orange Phormidium, bottom } \\
\text { of pool olive green }\end{array}$ \\
\hline $.75 \mathrm{~m}$ & $.85 \mathrm{~m}$ & $.10 \mathrm{~m}$ & & stick/log \\
\hline $.85 \mathrm{~m}$ & $4.0 \mathrm{~m}$ & $3.15 \mathrm{~m}$ & glide & $\begin{array}{l}\text { brownish green, orange } \\
\text { bison tracks }\end{array}$ \\
\hline $4.0 \mathrm{~m}$ & $22.25 \mathrm{~m}$ & $18.25 \mathrm{~m}$ & glide & Calothrix \\
\hline $22.25 \mathrm{~m}$ & $27.2 \mathrm{~m}$ & $4.94 \mathrm{~m}$ & moist & tan, moist sinter \\
\hline $27.2 \mathrm{~m}$ & $29.0 \mathrm{~m}$ & $1.8 \mathrm{~m}$ & low glide & $\tan$ Calothrix \\
\hline $29.0 \mathrm{~m}$ & $32.4 \mathrm{~m}$ & $3.4 \mathrm{~m}$ & moist & sinter, hard \\
\hline $32.4 \mathrm{~m}$ & $34.1 \mathrm{~m}$ & $1.7 \mathrm{~m}$ & $\begin{array}{l}\text { surface dry, } \\
\text { below moist }\end{array}$ & less firm sinter \\
\hline $34.1 \mathrm{~m}$ & $35.5 \mathrm{~m}$ & $1.4 \mathrm{~m}$ & moist & $\begin{array}{l}\text { sinter transitioning into } \\
\text { marsh (vegetated Calothrix) }\end{array}$ \\
\hline $35.5 \mathrm{~m}$ & $43.3 \mathrm{~m}$ & $7.8 \mathrm{~m}$ & glide & $\begin{array}{l}\text { pinkish tan Calothrix, marsh } \\
\text { grass, terrace features }\end{array}$ \\
\hline $43.3 \mathrm{~m}$ & $45.0 \mathrm{~m}$ & $1.7 \mathrm{~m}$ & soaked & $\begin{array}{l}\text { soft spongy marsh with } \\
\text { thick grass }\end{array}$ \\
\hline
\end{tabular}


Table 10. 2009 Transect 3 measurement and characterization

\author{
2009:YNP-QL Transect 3 \\ (across upper drainage apron)
}

Transect info: Start $6.7 \mathrm{~m}$ from NE corner of Bath House at a declination of $356^{\circ}$ and ran at a delination of $245^{\circ}$ for $29.88 \mathrm{~m}$ toward the west.

(Aligns with tree at GPS coordinates N-4934472 and E-0510233)

Instrument used: Trimble G4-6459

GPS: Start N-4934505 End N-4934483

$$
\text { E-0510282 E-0510252 }
$$

File R071116A File R071117B

\begin{tabular}{lllll}
\hline Beginning $(\mathrm{m})$ & Ending $(\mathrm{m})$ & Distance $(\mathrm{m})$ & Water Status & Description \\
\hline $0 \mathrm{~m}$ & $5.05 \mathrm{~m}$ & $5.05 \mathrm{~m}$ & glide & salmon Calothrix \\
\hline $5.05 \mathrm{~m}$ & $6.94 \mathrm{~m}$ & $1.89 \mathrm{~m}$ & glide & $\begin{array}{l}\text { Calothrix olive-green } \\
\text { microterraces }\end{array}$ \\
\hline $6.94 \mathrm{~m}$ & $8.48 \mathrm{~m}$ & $1.54 \mathrm{~m}$ & pool & $\begin{array}{l}\text { Calothrix/Phormidium (Cal. } \\
\text { on terr. Phorm. in pools }\end{array}$ \\
\hline $8.48 \mathrm{~m}$ & $9.49 \mathrm{~m}$ & $1.01 \mathrm{~m}$ & pool & $\begin{array}{l}\text { bubble } \text { mat; crumpled by } \\
\text { large mammals }\end{array}$ \\
\hline $9.49 \mathrm{~m}$ & $11.54 \mathrm{~m}$ & $2.05 \mathrm{~m}$ & riffle & $\begin{array}{l}\text { bubble mat and streamers in } \\
\text { channel }\end{array}$ \\
\hline $11.54 \mathrm{~m}$ & $12.36 \mathrm{~m}$ & $.82 \mathrm{~m}$ & riffle & green streamers in channel \\
\hline $12.36 \mathrm{~m}$ & $15.27 \mathrm{~m}$ & $2.91 \mathrm{~m}$ & riffle & $\begin{array}{l}\text { end green streamers, begin } \\
\text { orange streamers }\end{array}$ \\
\hline $15.27 \mathrm{~m}$ & $18.04 \mathrm{~m}$ & $2.77 \mathrm{~m}$ & glide & $\begin{array}{l}\text { orange streamers; crumpled } \\
\text { bubble mat }\end{array}$ \\
\hline $18.04 \mathrm{~m}$ & $18.88 \mathrm{~m}$ & $.84 \mathrm{~m}$ & pool & orange Phormidium \\
\hline $18.88 \mathrm{~m}$ & $19.97 \mathrm{~m}$ & $1.09 \mathrm{~m}$ & glide & dark Calothrix terracettes \\
\hline $19.97 \mathrm{~m}$ & $22.27 \mathrm{~m}$ & $2.3 \mathrm{~m}$ & glide & salmon Calothrix \\
\hline $22.27 \mathrm{~m}$ & $22.49 \mathrm{~m}$ & $.22 \mathrm{~m}$ & glide & silicified bubble mat \\
\hline $22.49 \mathrm{~m}$ & $23.18 \mathrm{~m}$ & $.69 \mathrm{~m}$ & glide & end silicified bubble mat \\
\hline $23.18 \mathrm{~m}$ & $23.92 \mathrm{~m}$ & $.74 \mathrm{~m}$ & pool & crumpled bubble mat \\
\hline $23.92 \mathrm{~m}$ & $25.88 \mathrm{~m}$ & $1.96 \mathrm{~m}$ & riffle & orange streamers \\
\hline $25.88 \mathrm{~m}$ & $28.98 \mathrm{~m}$ & $3.1 \mathrm{~m}$ & glide & orange Phormidium \\
\hline $28.98 \mathrm{~m}$ & $29.44 \mathrm{~m}$ & $.46 \mathrm{~m}$ & glide & olive green Calothrix \\
\hline $29.44 \mathrm{~m}$ & $29.88 \mathrm{~m}$ & $.44 \mathrm{~m}$ & glide & Calothrix \\
\hline & & & &
\end{tabular}


Table 11. 2009 Transect 4 measurement and characterization

2009: YNP-QL Transect 4

(across middle drainage apron)

Transect info: Start at a declination of $345^{\circ}$ and $29 \mathrm{~m}$ away from the NE corner of Bath House and ran for $61.9 \mathrm{~m}$ to the west end of the outflow system.

(Aligns with Tree 0 to Tree1: Tree $0 \mathrm{~N}-4934523$

$$
\text { E-0510273 }
$$

Tree1 N-4934477

E-0510235

Instrument used: Trimble G4-6459

GPS: Start N - $4934523 \quad$ End: N - 4934477

E - $0510273 \quad$ E -0510235

\begin{tabular}{|c|c|c|c|c|}
\hline Beginning(m) & Ending $(\mathrm{m})$ & Distance $(\mathrm{m})$ & Water Status & Description \\
\hline $61.9 \mathrm{~m}$ & $58.7 \mathrm{~m}$ & $3.2 \mathrm{~m}$ & $\mathrm{~N} / \mathrm{A}$ & brecciated sinter \\
\hline $58.7 \mathrm{~m}$ & $52.5 \mathrm{~m}$ & $6.2 \mathrm{~m}$ & & $\begin{array}{l}\text { edge of wet zone, Calothrix } \\
\text { biofacies }\end{array}$ \\
\hline $52.5 \mathrm{~m}$ & $51.0 \mathrm{~m}$ & $1.5 \mathrm{~m}$ & & dry island \\
\hline $51.0 \mathrm{~m}$ & $45.3 \mathrm{~m}$ & $5.7 \mathrm{~m}$ & riffle & $\begin{array}{l}\text { Calothrix biofacies; tan and } \\
\text { salmon mixed facies }\end{array}$ \\
\hline $45.3 \mathrm{~m}$ & $45.1 \mathrm{~m}$ & $0.2 \mathrm{~m}$ & $\begin{array}{l}\text { shallow sheet } \\
\text { flow }\end{array}$ & $\begin{array}{l}\text { Calothrix biofacies; tan and } \\
\text { salmon mixed facies }\end{array}$ \\
\hline $45.1 \mathrm{~m}$ & $44.3 \mathrm{~m}$ & $0.8 \mathrm{~m}$ & & orange streamer \\
\hline $44.3 \mathrm{~m}$ & $44.1 \mathrm{~m}$ & $0.2 \mathrm{~m}$ & & orange bubble mat \\
\hline $44.1 \mathrm{~m}$ & $42.1 \mathrm{~m}$ & $2.0 \mathrm{~m}$ & $\begin{array}{l}\text { pool/riffle } \\
\text { main water } \\
\text { flow }\end{array}$ & $\begin{array}{l}\text { orange and green streamers } \\
\text { terraces mixed w/brown }\end{array}$ \\
\hline $42.1 \mathrm{~m}$ & $37.8 \mathrm{~m}$ & $4.3 \mathrm{~m}$ & & orange/brown tufts \\
\hline $37.8 \mathrm{~m}$ & $35.4 \mathrm{~m}$ & $2.4 \mathrm{~m}$ & $\begin{array}{l}\text { sheet, fast } \\
\text { flow }\end{array}$ & orange bubble mat \\
\hline $35.4 \mathrm{~m}$ & $31.7 \mathrm{~m}$ & $3.7 \mathrm{~m}$ & & $\begin{array}{l}\text { mixed green pustules; } \\
\text { orange bubble mat }\end{array}$ \\
\hline $31.7 \mathrm{~m}$ & $30.6 \mathrm{~m}$ & $1.1 \mathrm{~m}$ & & tan/salmon Calothrix \\
\hline $30.6 \mathrm{~m}$ & $30.3 \mathrm{~m}$ & $0.3 \mathrm{~m}$ & & Calothrix pustules \\
\hline $30.3 \mathrm{~m}$ & $29.4 \mathrm{~m}$ & $0.9 \mathrm{~m}$ & water edge & \\
\hline $29.4 \mathrm{~m}$ & $26.4 \mathrm{~m}$ & $3.0 \mathrm{~m}$ & dry island & \\
\hline $26.4 \mathrm{~m}$ & $23.5 \mathrm{~m}$ & $2.9 \mathrm{~m}$ & & Calothrix \\
\hline $23.5 \mathrm{~m}$ & $23.3 \mathrm{~m}$ & $0.2 \mathrm{~m}$ & & tan/salmon Calothrix \\
\hline $23.3 \mathrm{~m}$ & $13.2 \mathrm{~m}$ & $10.1 \mathrm{~m}$ & riffle & orange/brown Calothrix \\
\hline $13.2 \mathrm{~m}$ & $11.8 \mathrm{~m}$ & $1.4 \mathrm{~m}$ & sheet flow & brown/orange \\
\hline $11.8 \mathrm{~m}$ & $10.5 \mathrm{~m}$ & $1.3 \mathrm{~m}$ & edge of water & orange/brown \\
\hline $10.5 \mathrm{~m}$ & $0 m$ & $10.5 \mathrm{~m}$ & & dry sinter \\
\hline
\end{tabular}




\section{1 spreadsheets for transects}

\section{Table 12. 2011 Transect 2 measurement and characterization}

2011:YNP-QL Transect 2

(start NW corner of Bath House)

Transect info: Start at NW corner of the Bath House, declination $335^{\circ}$ for 45 meters.

Calothrix transect

Instrument used: Trimble Juno ST

\begin{tabular}{|c|c|c|c|c|}
\hline Beginning $(m)$ & Ending $(m)$ & Distance $(\mathrm{m})$ & Water Status & Description \\
\hline 0 & 0.8 & 0.8 & pool & wet breccia and debris behind log \\
\hline 0.8 & 0.9 & 0.1 & & log in drainage apron \\
\hline 0.9 & 1.4 & 0.5 & glide & moist breccia \\
\hline 1.4 & 1.7 & 0.3 & glide & olive brown pustular mat \\
\hline 1.7 & 1.85 & 0.15 & glide & brown pustular mat \\
\hline 1.85 & 1.88 & 0.03 & glide & microterracette \\
\hline 1.88 & 2.05 & 0.17 & & moist breccia \\
\hline 2.05 & 3.05 & 1 & glide & brown pustular mat \\
\hline 3.05 & 3.06 & 0.01 & glide & microterracette \\
\hline 3.06 & 4.6 & 1.54 & glide & tan and salmon juvenile pustular mat \\
\hline 4.6 & 5.1 & 0.5 & glide & microterracette series at $4.6,4.8,5.0$ and $5.1 \mathrm{~m}$ \\
\hline 5.1 & 6.4 & 0.7 & glide & $\tan$ and It $\tan$ juvenile pustular mat, little bit of debris \\
\hline 6.4 & 7.1 & 0.7 & glide & microterracette series at $6.4,6.6$, and $7.1 \mathrm{~m}$ \\
\hline 7.1 & 8 & 0.9 & glide & juvenile pustular mat \\
\hline 8 & 8.07 & 0.07 & glide & microterracette \\
\hline 8.07 & 17.4 & 9.33 & glide & juvenile Calothrix features-pustular mat and microterraces \\
\hline 17.4 & 22.8 & 5.4 & glide & $\begin{array}{l}\text { sinter-some brecciated with patchy brown rejuvenated } \\
\text { communities }\end{array}$ \\
\hline 22.8 & 26.6 & 3.8 & none & $\begin{array}{l}\text { sinter and brecciated sinter, no visible water flowing on } \\
\text { surface }\end{array}$ \\
\hline 26.6 & 35.1 & 8.5 & glide & $\begin{array}{l}\text { sinter-some brecciated with patchy brown rejuvenated } \\
\text { communities }\end{array}$ \\
\hline $\begin{array}{r}35.1 \\
45\end{array}$ & 44 & 8.9 & none & $\begin{array}{l}\text { dried sinter, no water flowing } \\
\text { the march area begins }\end{array}$ \\
\hline
\end{tabular}




\section{Table 13. 2011 Transect 3 measurement and characterization}

2011:YNP-QL Transect 3

(across upper drainage apron)

Transect info: Start $m$ from NE corner of Bath House at a declination of $356^{\circ}$ and

ran at a delination of $245^{\circ}$ for $40.6 \mathrm{~m}$ toward the west.

(Aligns with tree at GPS coordinates $\mathrm{N}$ - and $\mathrm{E}-$ )

Instrument used: Trimble Juno ST

GPS: Start N- End N-

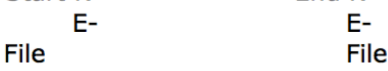

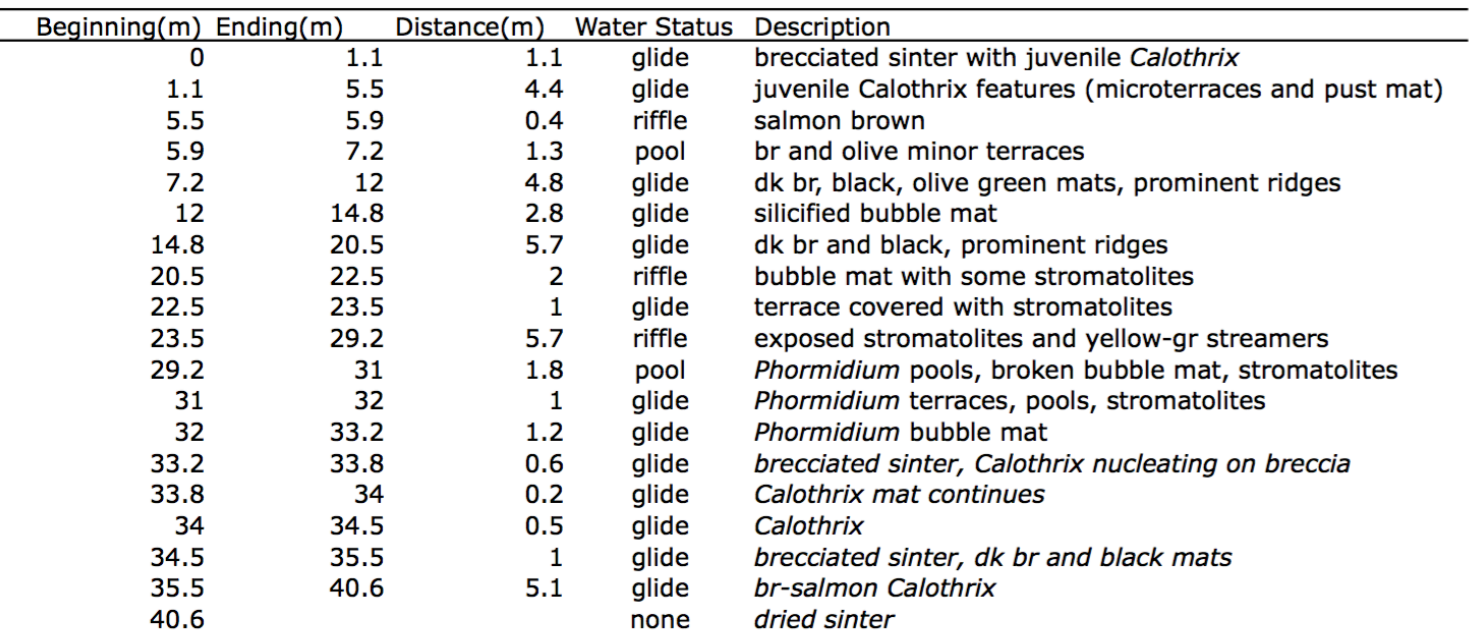




\title{
Table 14. 2011 Transect 4 measurement and characterization
}

\author{
2011:YNP-QL Transect 4 \\ (start NW corner of Bath House)
}

Transect info: Start at NW corner of the Bath House, declination $335^{\circ}$ for 33 meters.

Second transect across the drainage apron - adjusted from the previous two years.

Instrument used: Trimble Juno ST

\begin{tabular}{|c|c|c|c|c|c|c|}
\hline Line Name & Beginning $(m)$ & Ending $(\mathrm{m})$ & Distance $(\mathrm{m})$ & Address & Water Status & Description \\
\hline ts42011 & 0 & 3 & 3 & 3.0 ts42011 & pool & brecciated debris \\
\hline ts 42011 & 3 & 5 & 2 & 5.0 ts 42011 & pool & $\begin{array}{l}\text { orange to dk orange in pools, } \\
\text { exposed Phormidium }\end{array}$ \\
\hline ts 42011 & 5 & 14.5 & 9.5 & 14.5 ts 42011 & riffle and pool & $\begin{array}{l}\text { streamers and developed } \\
\text { terraces }\end{array}$ \\
\hline ts42011 & 14.5 & 15.6 & 1.1 & 15.6 ts 42011 & pool & $\begin{array}{l}\text { orange to dk orange } \\
\text { Phormidium, some debris }\end{array}$ \\
\hline ts42011 & 15.6 & 15.7 & 0.1 & 15.7 ts 42011 & riffle & orange-green streamers \\
\hline ts 42011 & 15.7 & 16.7 & 1 & 16.7 ts 42011 & pool & $\begin{array}{l}\text { exposed stromatolites, } \\
\text { orange brecciated } \\
\text { community, some debris }\end{array}$ \\
\hline ts 42011 & 16.7 & 17 & 0.3 & 17.0 ts 42011 & pool & $\begin{array}{l}\text { short orange-green } \\
\text { streamers }\end{array}$ \\
\hline ts42011 & 17 & 18.1 & 1.1 & 18.1 ts 42011 & riffle & orange-green streamers \\
\hline ts 42011 & 18.1 & 19.4 & 1.3 & 19.4 ts 42011 & pool & $\begin{array}{l}\text { exposed stromatolites, pools } \\
\text { behind them }\end{array}$ \\
\hline ts42011 & 19.4 & 19.9 & 0.5 & 19.9 ts 42011 & pool & orange bubble mat \\
\hline ts42011 & 19.9 & 22.3 & 2.4 & 22.3 ts 42011 & glide & $\begin{array}{l}\text { orange bubble mat, riffle at } \\
21.0-21.4 \mathrm{~m}\end{array}$ \\
\hline ts42011 & 22.3 & 22.5 & 0.2 & 22.5 ts 42011 & glide & olive brown mat \\
\hline ts42011 & 22.5 & 23.3 & 0.8 & 23.3 ts 42011 & glide & $\begin{array}{l}\text { orange on what appears to } \\
\text { debris washed into animal } \\
\text { tracks on broken bubble mat }\end{array}$ \\
\hline ts42011 & 23.3 & 24.7 & 1.4 & 24.7 ts 42011 & riffle & $\begin{array}{l}\text { olive mat in flow of water, } \\
\text { small topographic lows create } \\
\text { drainage opportunities }\end{array}$ \\
\hline ts42011 & 24.7 & 25.8 & 1.1 & 25.8 ts 42011 & glide & orangish, salmon pustular ma \\
\hline ts42011 & 25.8 & 26 & 0.2 & 26.0 ts 42011 & pool & salmon flocculant material \\
\hline ts 42011 & 26 & 26.5 & 0.5 & 26.5 ts 42011 & glide & microterracette \\
\hline ts42011 & 26.5 & 27 & 0.5 & 27.0 ts 42011 & glide & br pustular mat, some debris \\
\hline ts42011 & 27 & 27.2 & 0.2 & 27.2 ts 42011 & glide & microterracette \\
\hline ts 42011 & 27.2 & 29.2 & 2 & 29.2 ts 42011 & glide & $\begin{array}{l}\text { salmon, tan pustular mat; } \\
\text { poss start of juvenile } \\
\text { microterraces }\end{array}$ \\
\hline ts42011 & 29.2 & 33 & 3.8 & 33.0 ts 42011 & glide & salmon masses with $\mathrm{dk}$ browr \\
\hline
\end{tabular}




\section{Appendix 2}

Images of samples collected in the field and sample preparation and the resultant thin sections

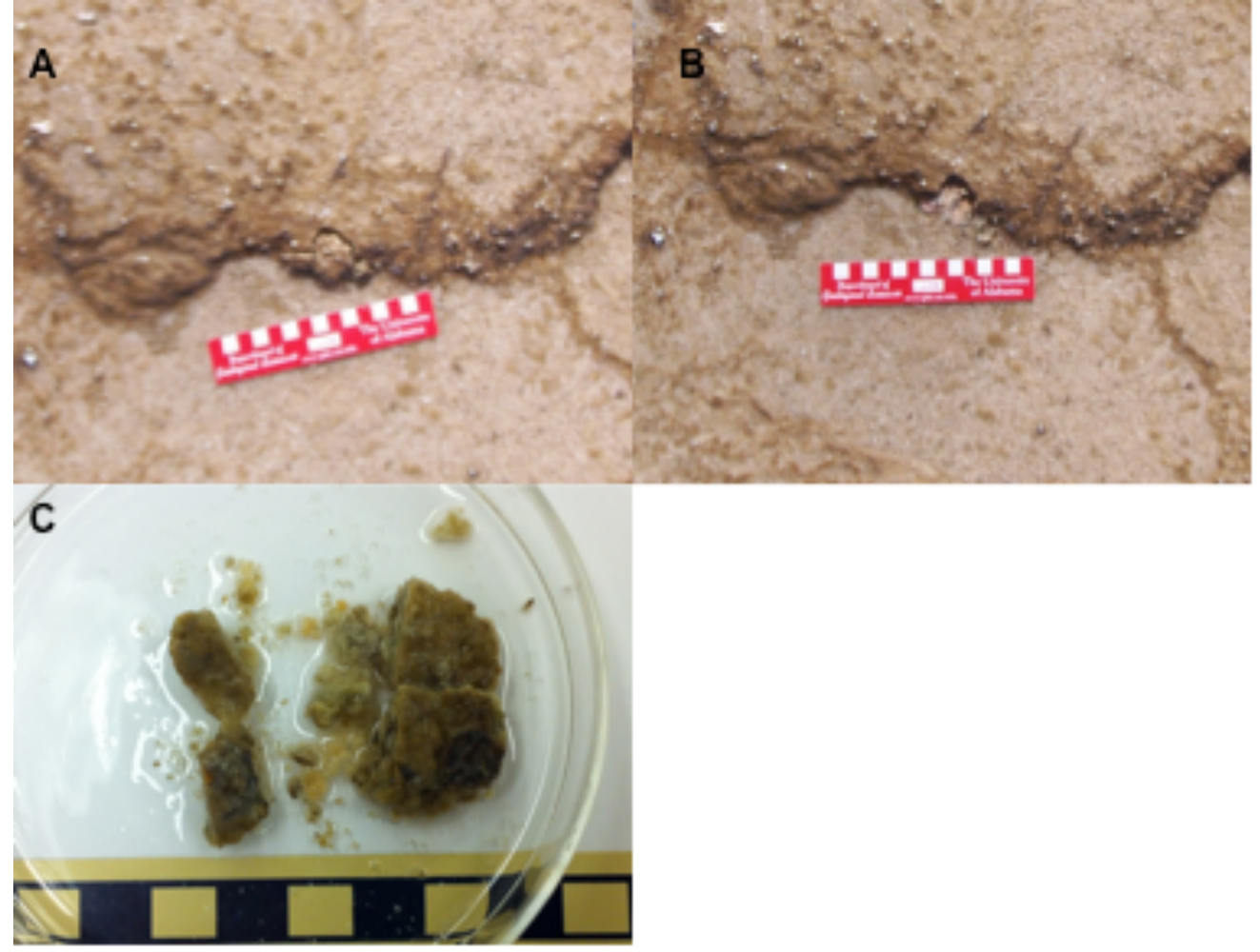

Fig 32. (A) Eastside partially silicified biofacies terrace bulk sample 110921.6 prior to collection, (B) after collection, and (C) after clean edge prepared for thin sectioning in the laboratory. 


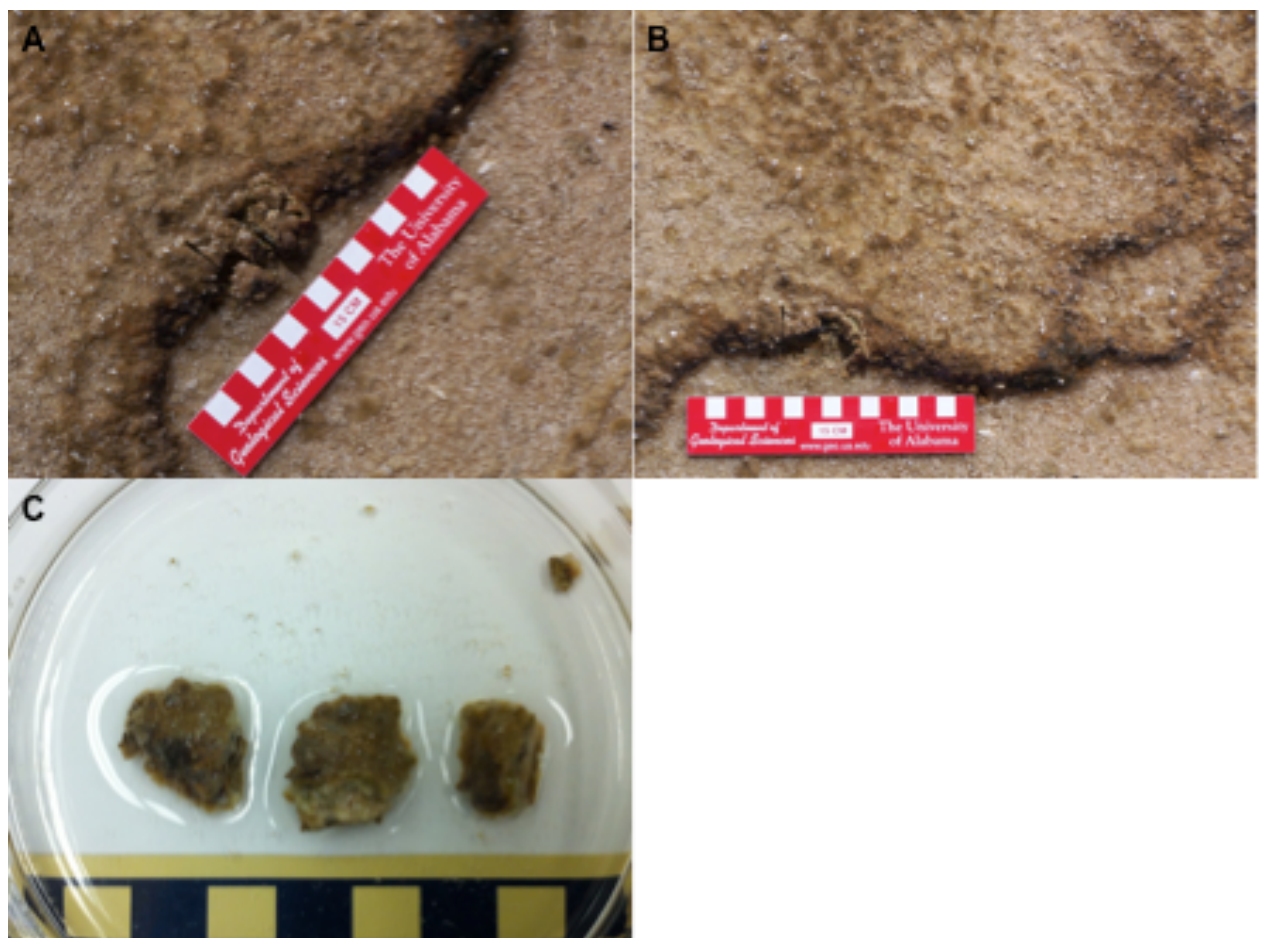

Fig 33. (A) Eastside partially silicified biofacies terrace bulk sample 110921.5 prior to collection, (B) after collection, and (C) in the laboratory.
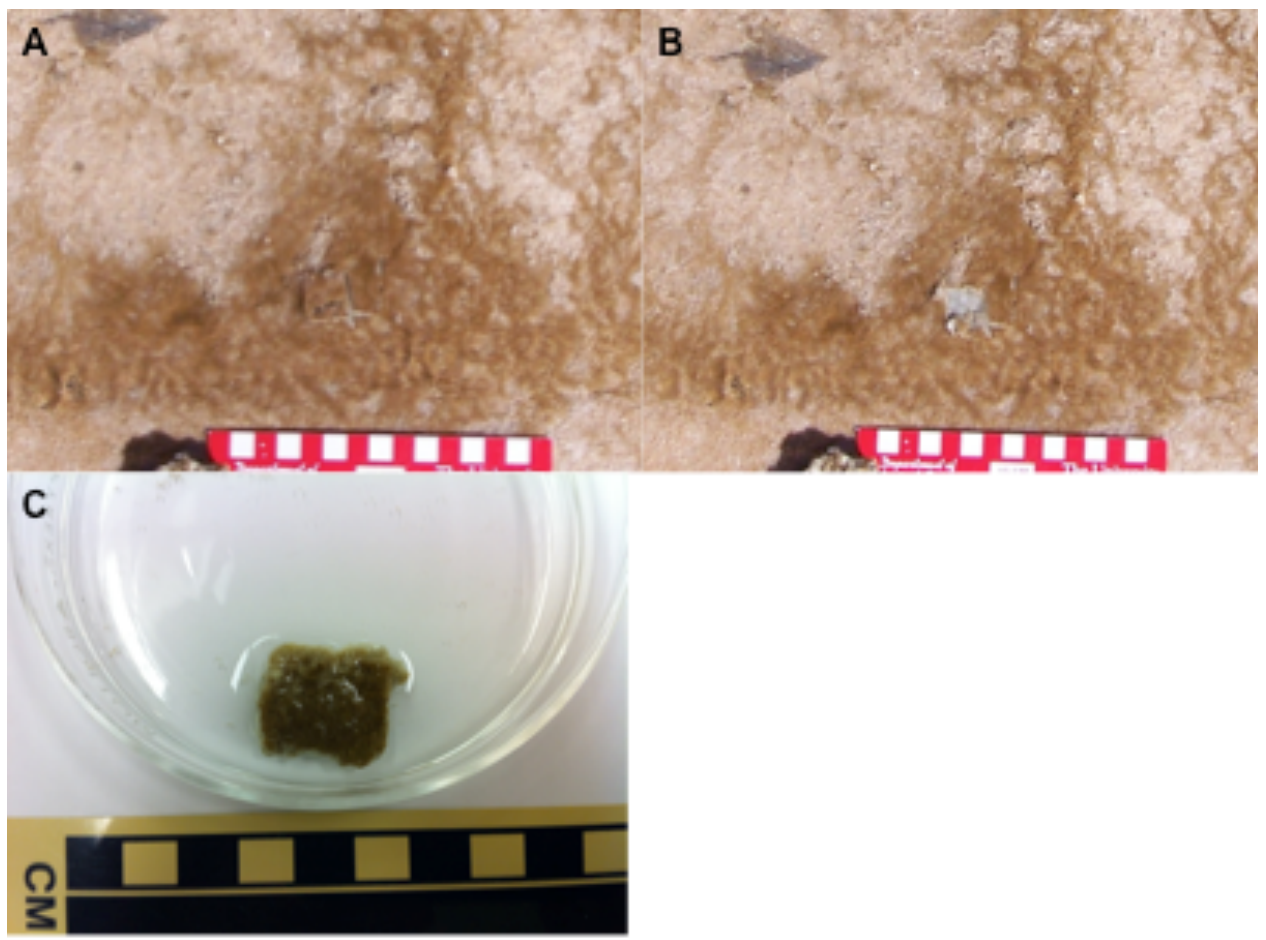

Fig 34. (A) Westside partially silicified biofacies terrace bulk sample 110921.3 prior to collection, (B) after collection, and (C) in the laboratory. 


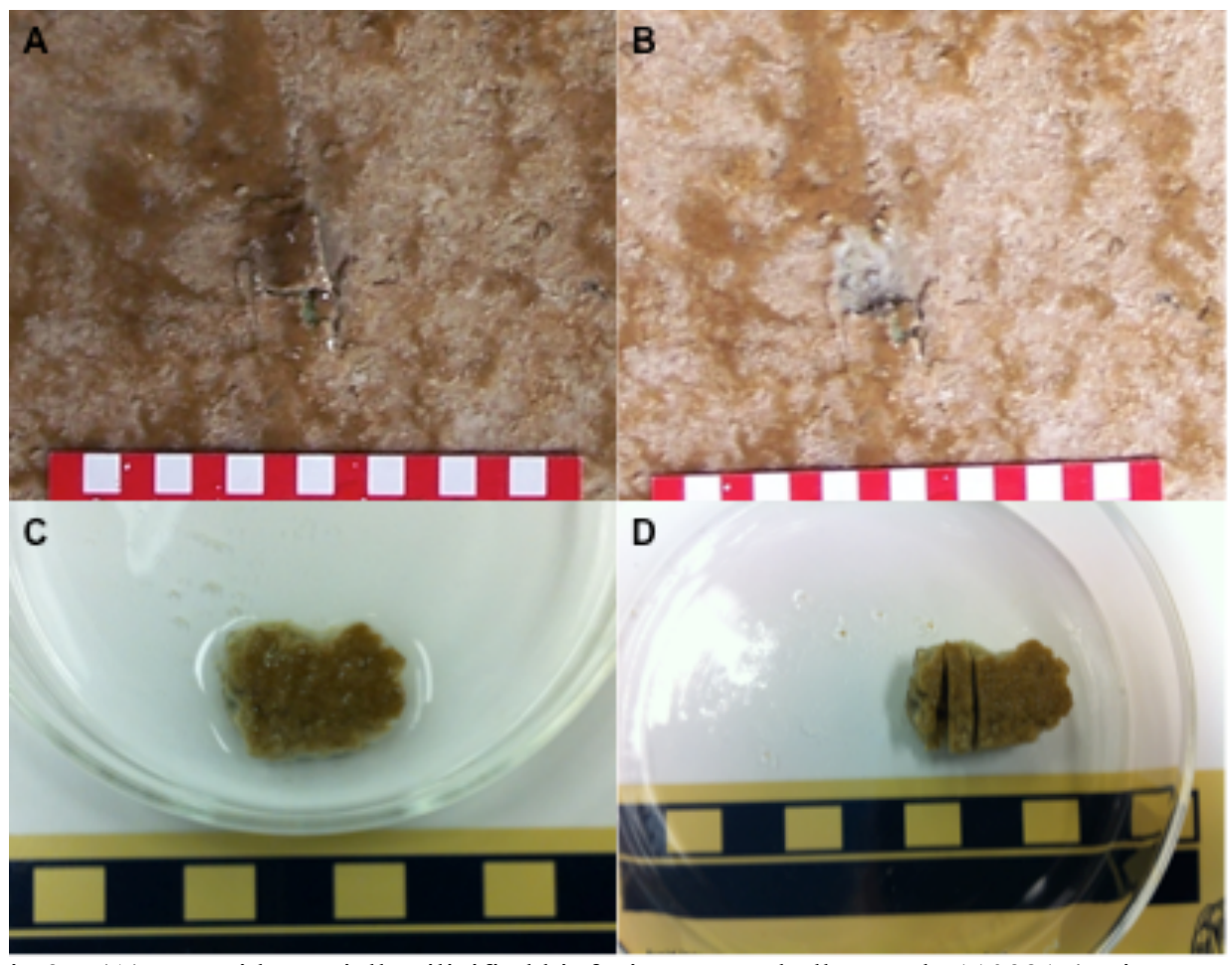

Fig 35. (A) Westside partially silicified biofacies terrace bulk sample 110921.4 prior to collection, (B) after collection, (C) in the laboratory, and (D) after slicing for thin section preparation.

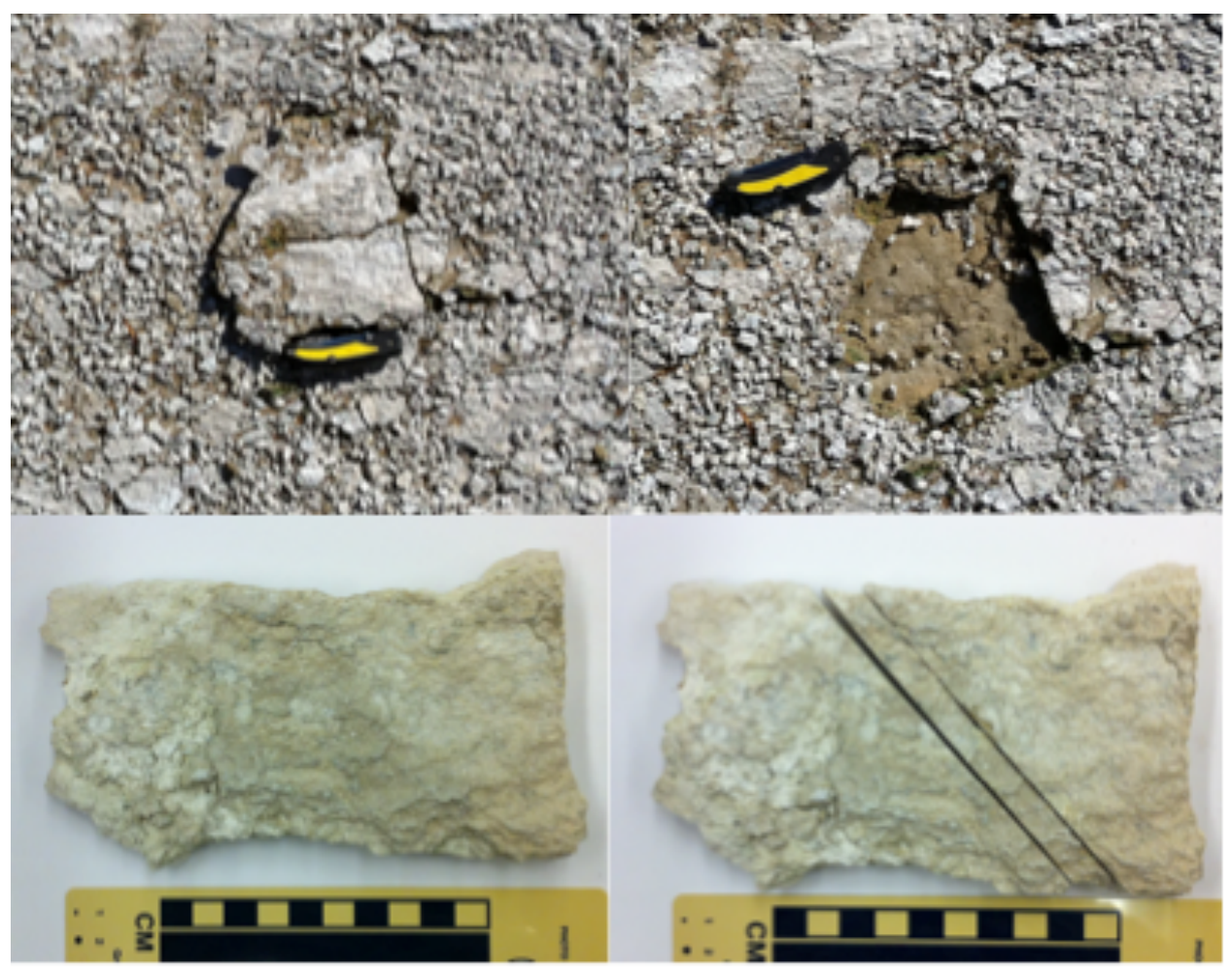


Fig 36. (A) Aerially exposed biofacies terrace bulk sample 111001.10 prior to collection, (B) after collection, (C) in the laboratory, and (D) after slicing for thin section preparation.

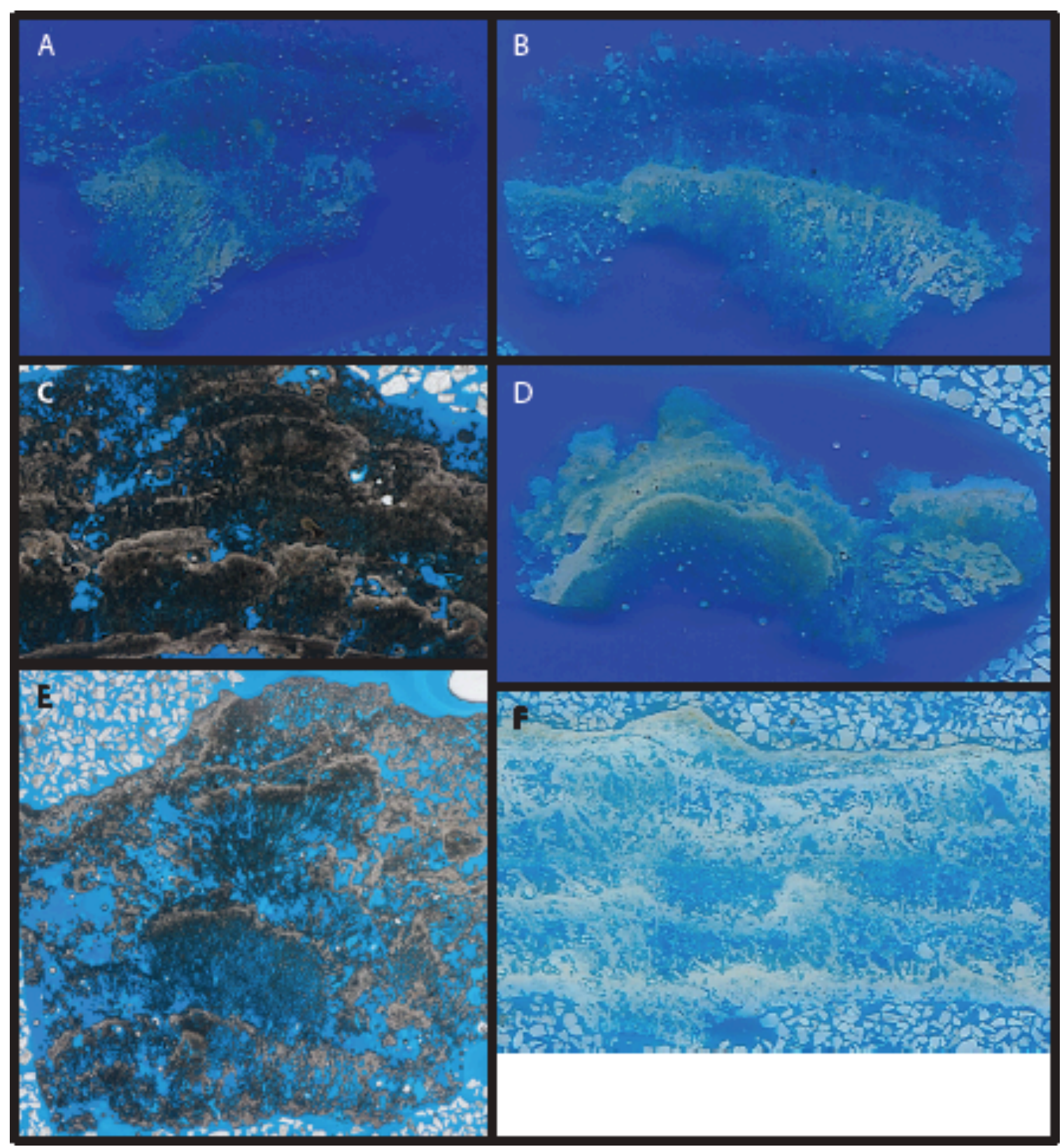

Fig. 37. Thin sections prepared from partially silicified and aerially exposed Calothrix biofacies sinters that in the field displayed varying degrees of surface curvi-linear features at Queen's Laundry hot spring in Yellowstone National Park. (A) Partially silicified biofacies sample, 110921.3, from the west side of the active drainage apron. (B) Partially silicified biofacies sample, 110921.4, from the west side of the active drainage apron. (C) Partially silicified biofacies sample, 110921.6, from the east side of the broad drainage apron and a well-developed terrace. (D) Partially silicified biofacies sample, 110921.5, from the east side of the active drainage apron. (E) Aerially exposed sample 110919.24B from the west side beyond the active drainage apron. (F) Aerially exposed sample, 111001.10 , from the west side beyond the active drainage apron. 
Appendix 3

Characterization spreadsheets of terraces 


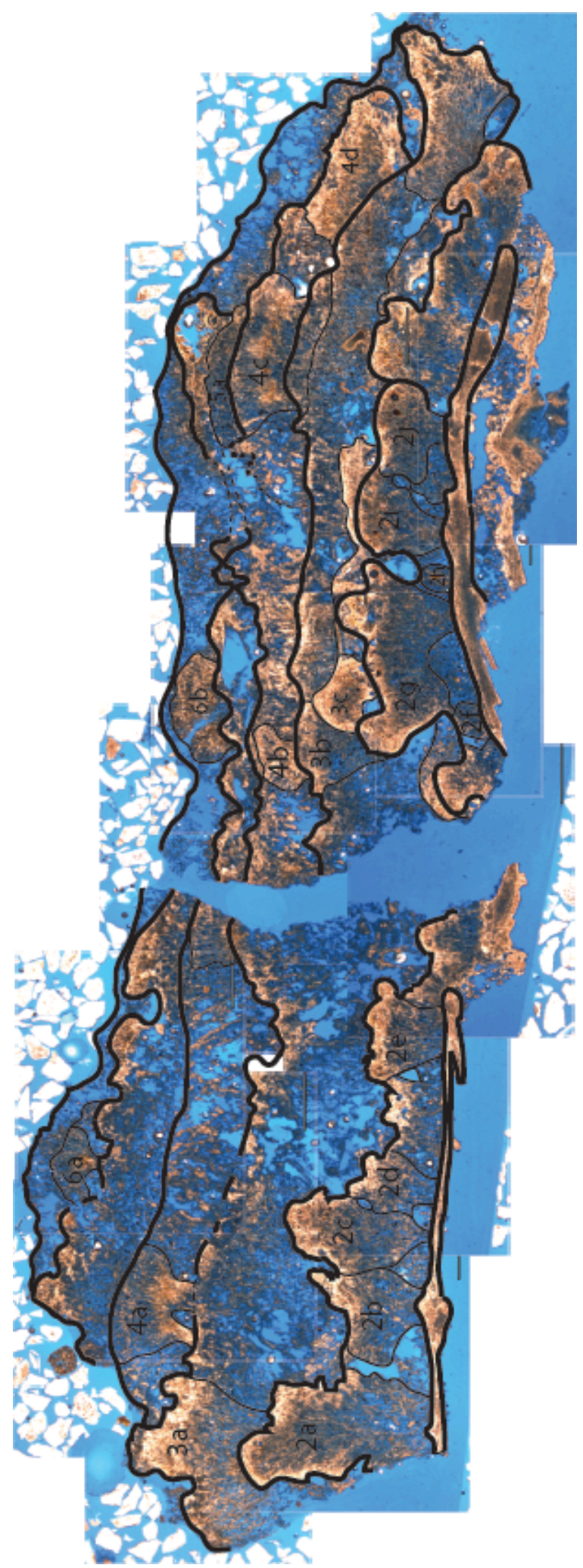

Fig. 38. Annotated thin section photomosaic of partially silicified terrace sample 110921.6. Table 15. Morphometrics of microbial structures within the partially silicified Calothrix dominated terrace biofacies sample 110921.6. 


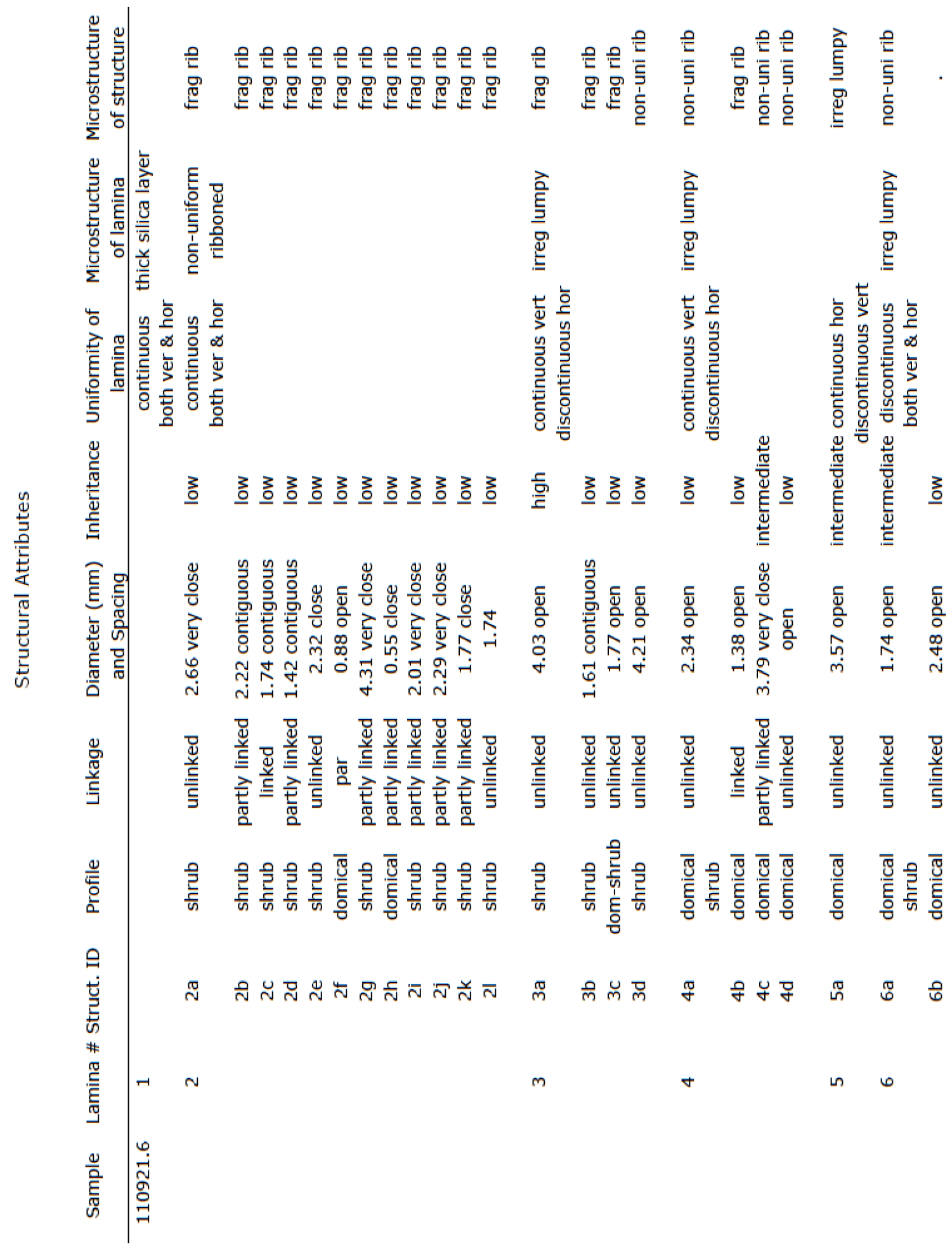

Table 16. Attributes of microbial structures in the partially silicified Calothrix dominated terrace biofacies sample 110921.6. 


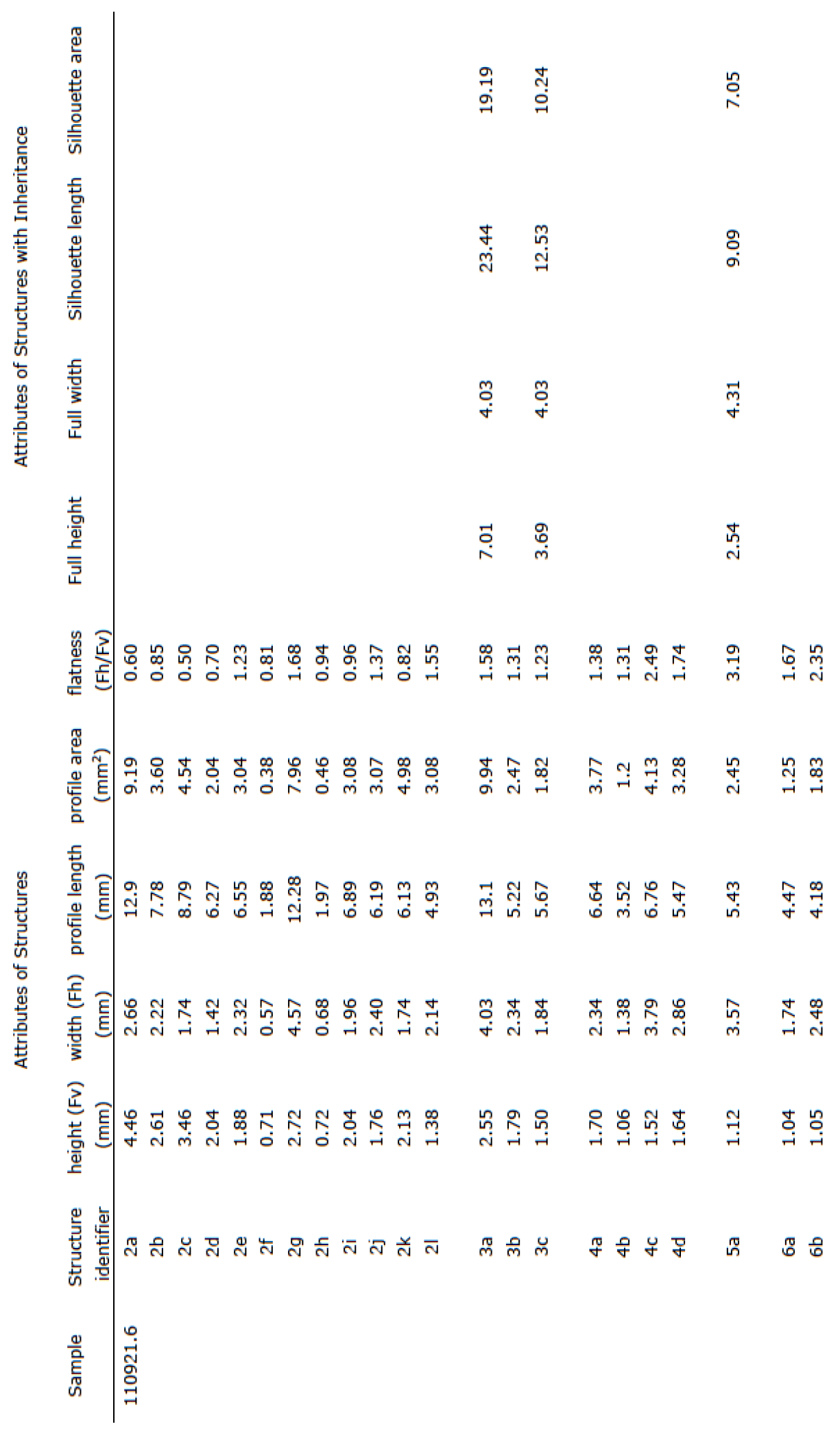




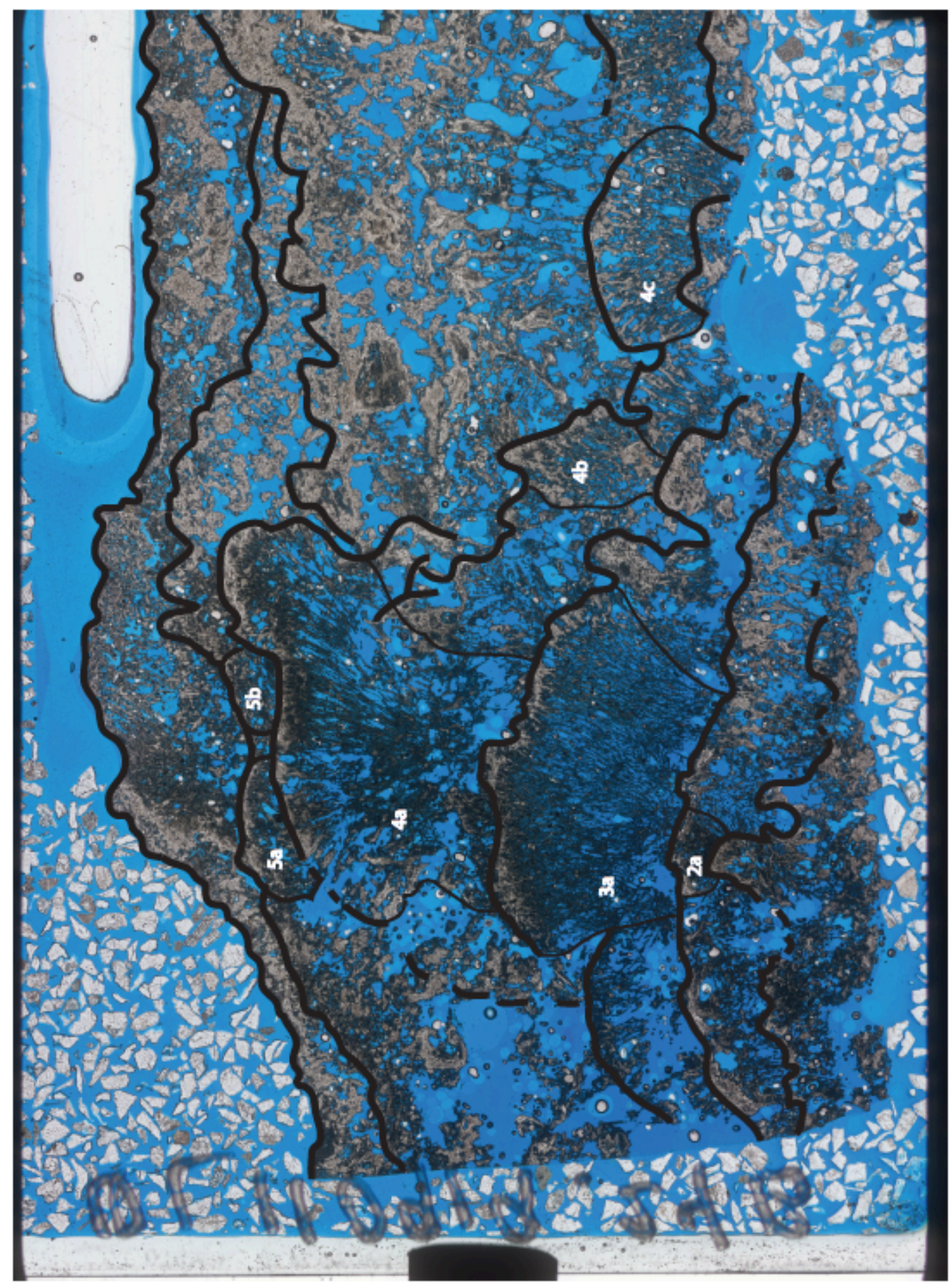

Fig. 39. Image of aerially exposed terrace thin section of sample 110921.24B. 
Table 17. Morphometrics of microbial structures within the aerially exposed Calothrix dominated terrace biofacies sample 110919.24B. 


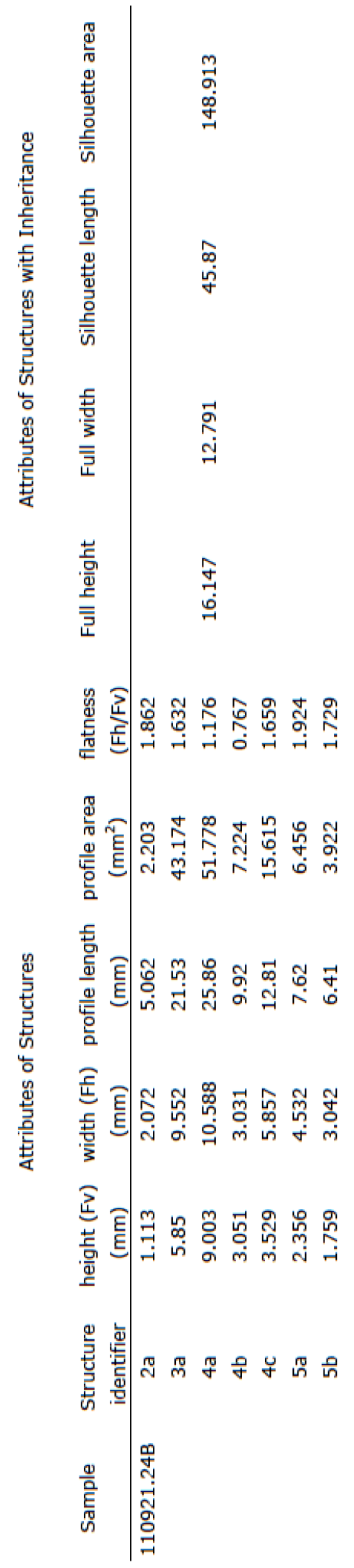

Table 18. Attributes of microbial structures in the aerially exposed Calothrix dominated terrace biofacies sample 110919.24B. 


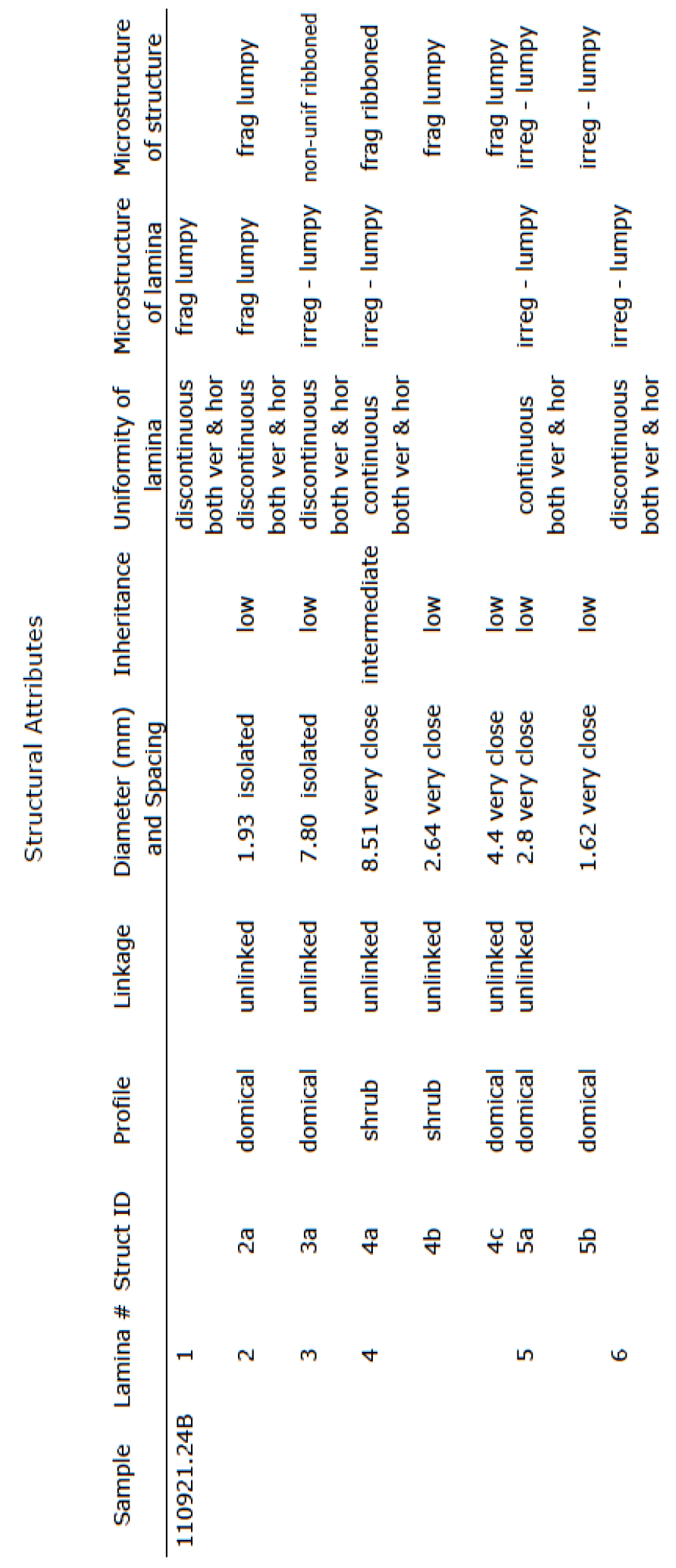


XRD patterns from partially silicified and aerially exposed samples

The diffraction patterns of all of the samples analyzed by XRD, which included two partially silicified Calothrix biofacies samples and three aerially exposed Calothrix biofacies samples, consisted of a broad "opal-A" silica peak $\left(\sim 22.2^{\circ} 2 \theta\right)$ (Fig.s 32-36). Opaline silica is a typical silica phase within the modern hydrothermal setting.

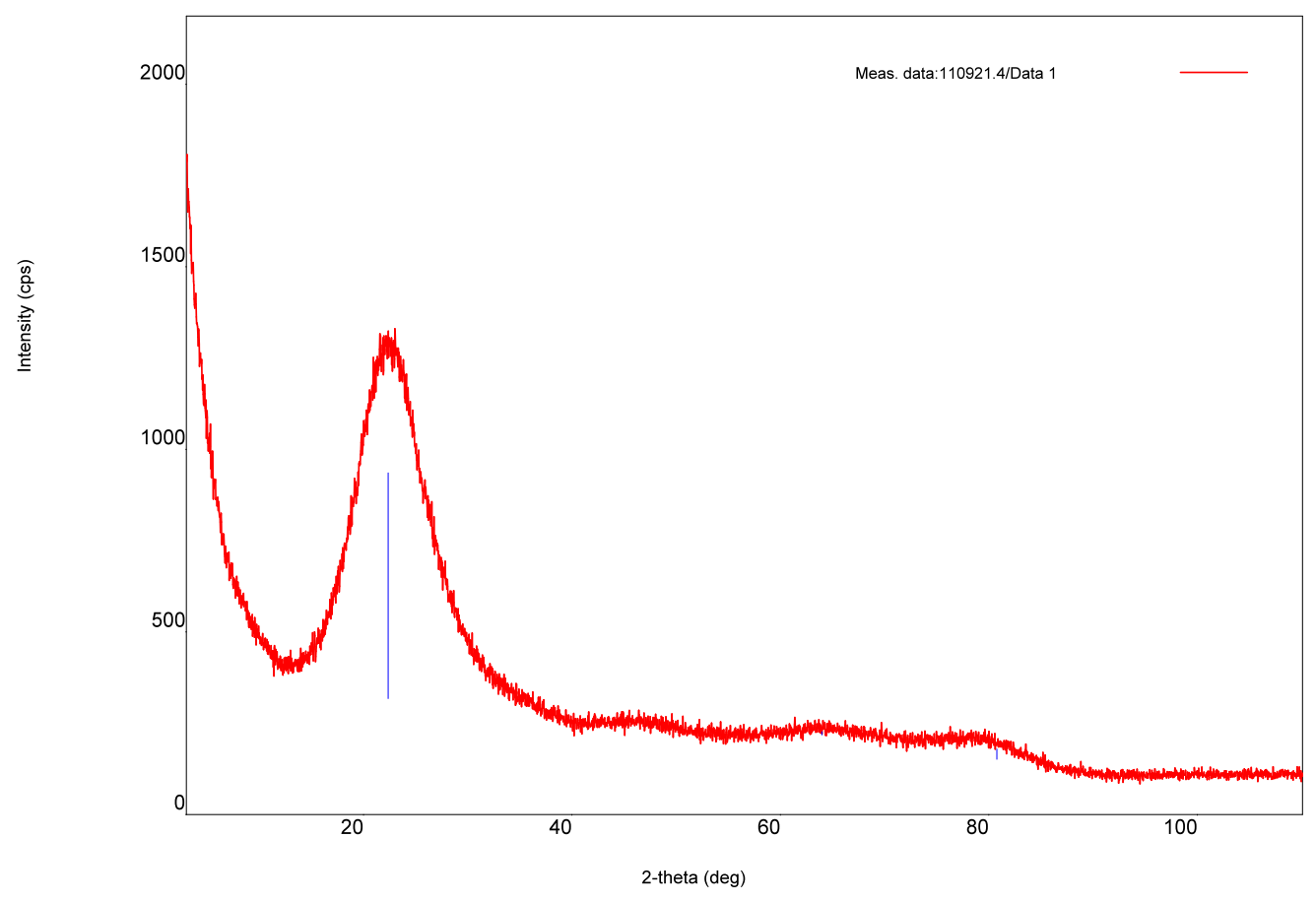

Fig. 40. XRD pattern of sample 110921.4. 


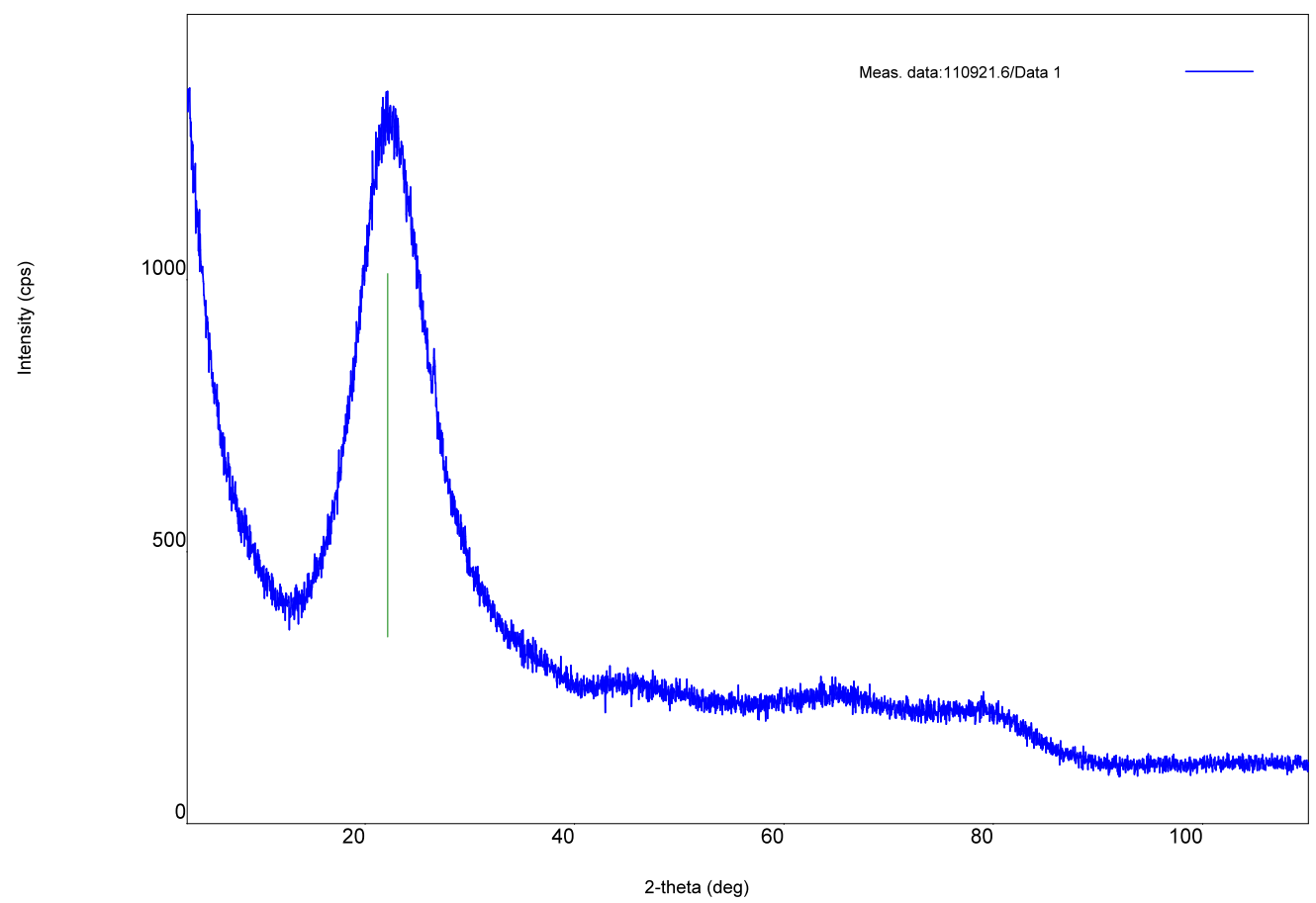

Fig. 41. XRD pattern of sample 110921.6.

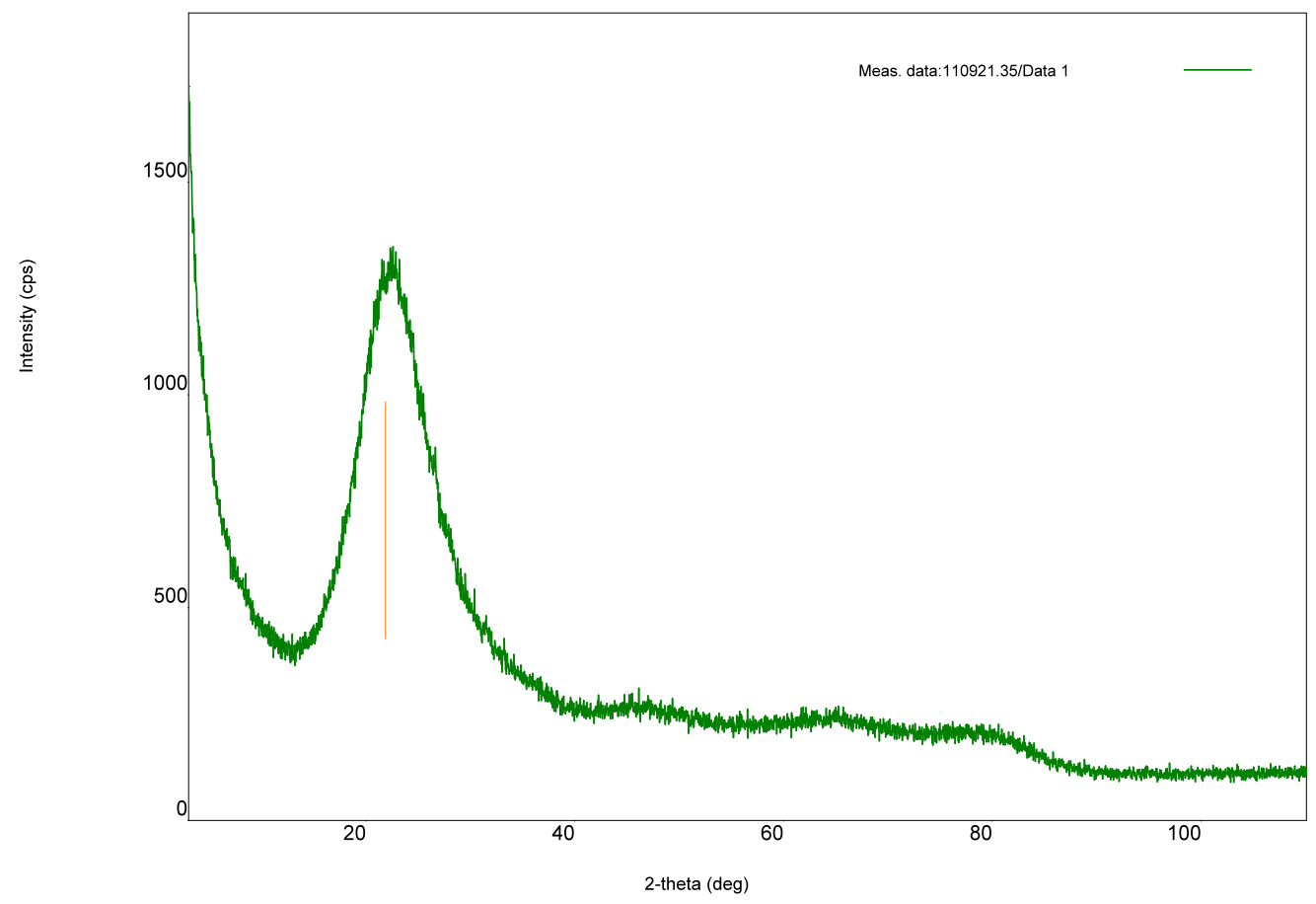

Fig. 42. XRD pattern of sample 110921.35. 


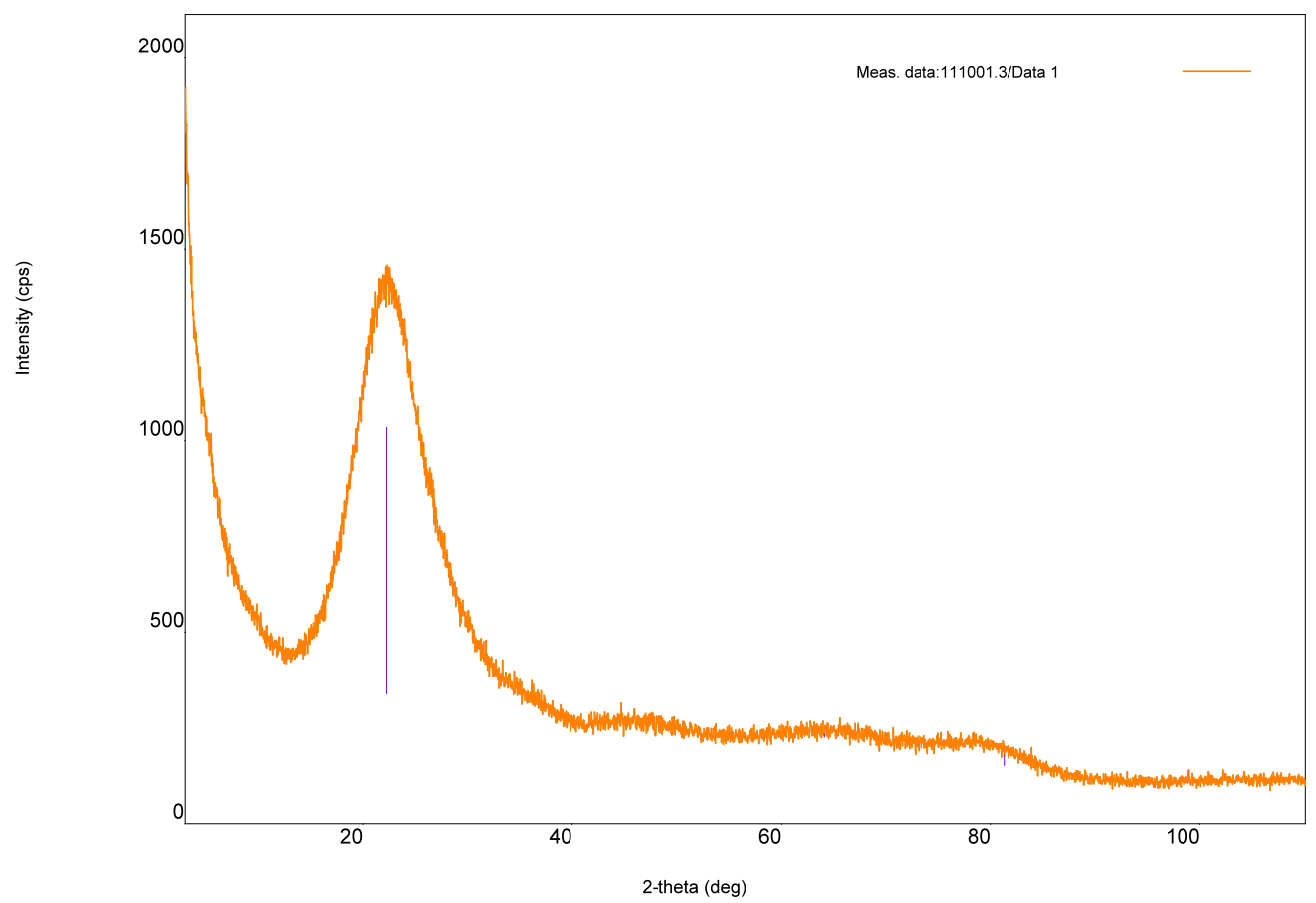

Fig. 43. XRD pattern of sample 111001.3.

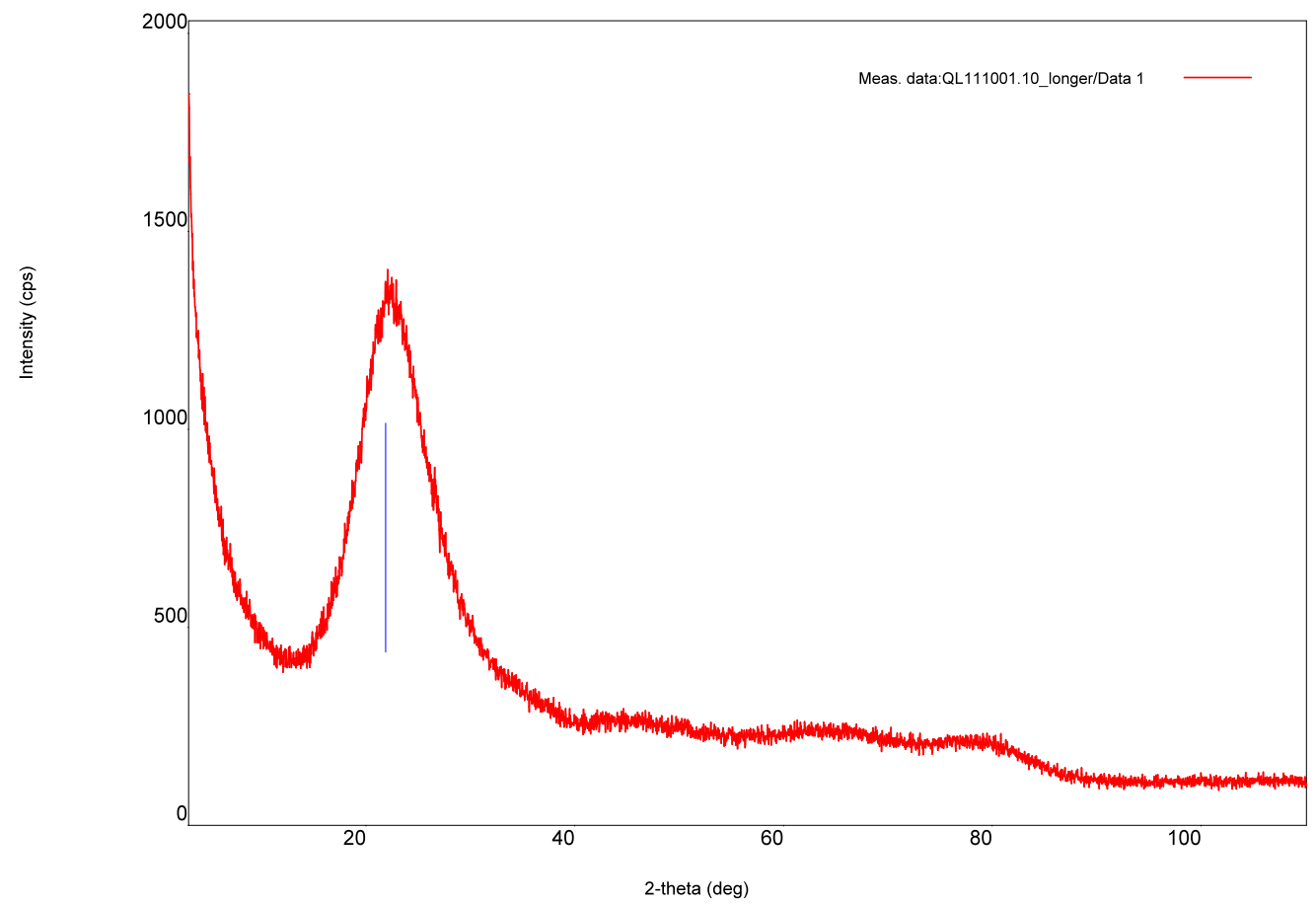

Fig. 44. XRD pattern of sample 111001.10. 
To determine whether mechanical grinding in the micronizing mill altered the degree of order/disorder of the sinter samples, the XRD patterns of the hand-ground sample (upper XRD pattern, Fig. 31) and milled sample (lower XRD pattern, Fig. 31) were compared. The preparation of two additional XRD samples that were isolated from a thick, massive silica layer in lithofacies sample 111001.3 for comparison of the two grinding methods. The aerially exposed biofabric was removed from above and below the silica deposit by hand scraping and cutting with a razor blade.

The isolated silica deposit was split into two subsamples: one was hand ground and the other was mechanically ground with the micronizing mill. One of the samples was ground in the micronizing mill (2 minutes) whereas the other was hand ground with a mortar and pestle until the sample was reduced to meet $\sim 20 \mu \mathrm{m}$ grain size. The grain size for both sample preparations was verified via optical light microscopy.

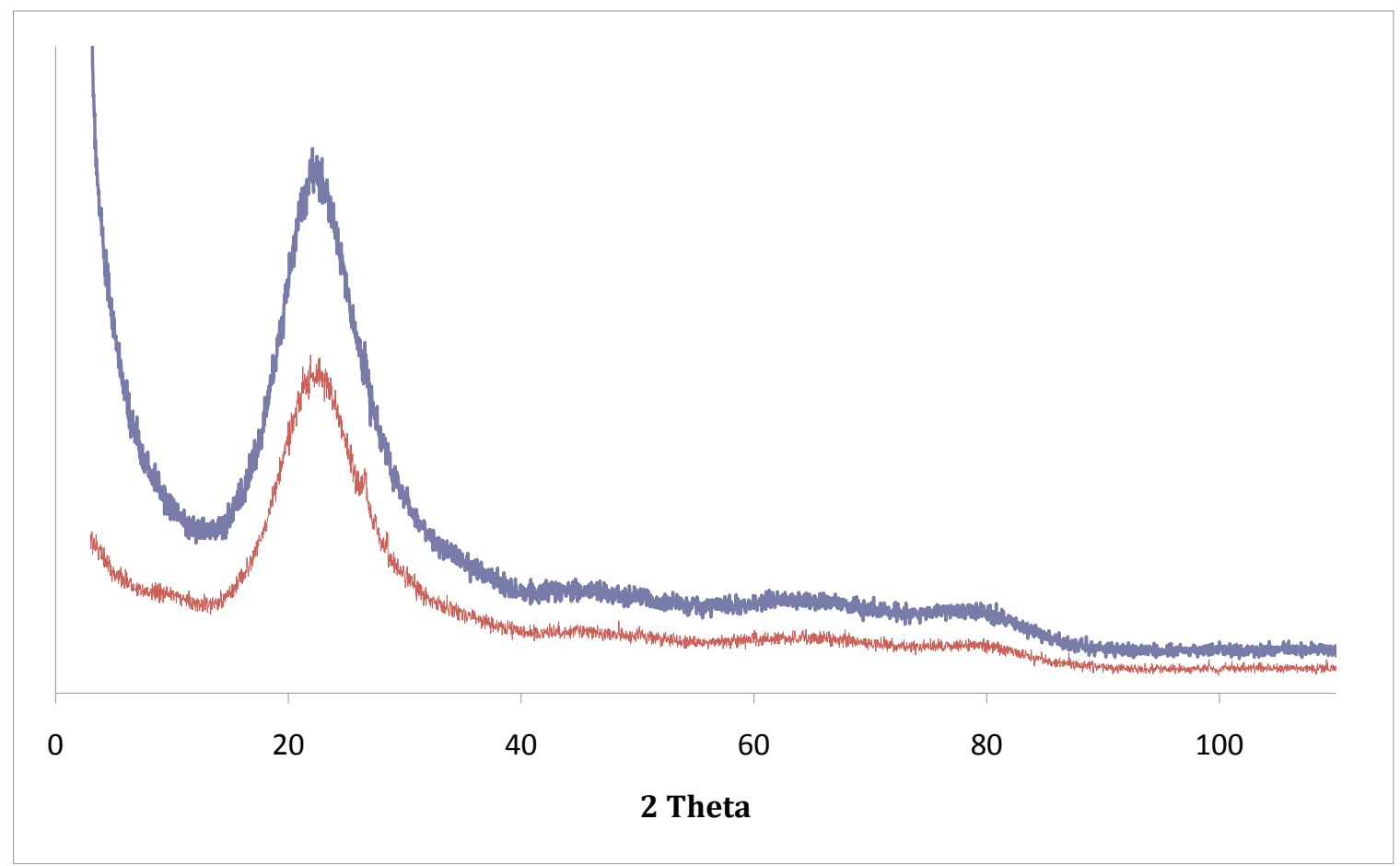

Fig. 45. Plot of the XRD patterns of two samples (upper, dry milled, lower, hand ground) obtained from the same aerially exposed Calothrix biofacies illustrate that the use of a micronizing mill and dry milling the samples did not alter the degree of order/disorder of the material during sample processing. 